\title{
Individual Radiation Protection Monitoring in the Marshall Islands: Enewetak Island Resettlement Support (May-December 2001)
}

T. Hamilton, D. Hickman, C. Conrado, T. Brown, J. Brunk, A. Marchetti, C. Cox, R. Martinelli, S. Kehl, K. Johannes, D. Henry, R. T. Bell, G. Petersen

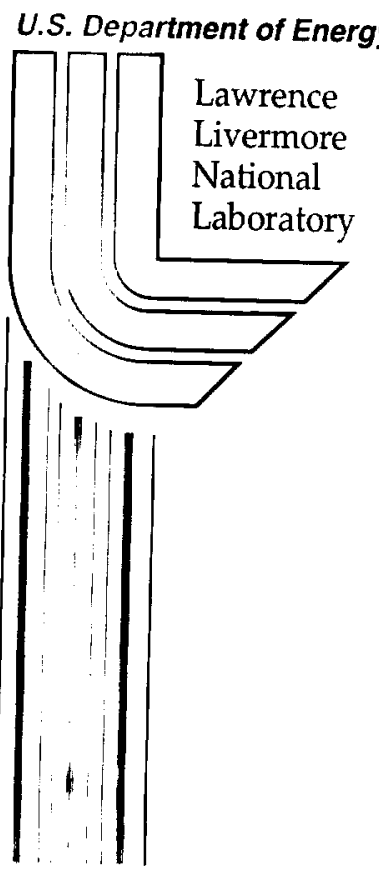

June 1, 2002 


\section{DISCLAIMER}

This document was prepared as an account of work sponsored by an agency of the United States Government. Neither the United States Government nor the University of California nor any of their employees, makes any warranty, express or implied, or assumes any legal liability or responsibility for the accuracy, completeness, or usefulness of any information, apparatus, product, or process disclosed, or represents that its use would not infringe privately owned rights. Reference herein to any specific commercinl product, process, or service by trade name, trademark, manufacturer, or otherwise, does not necessarily constitute or imply its endorsement, recommendation, or favoring by the United States Government or the University of California. The views and opinions of authors expressed herein do not necessarily state or reflect those of the United States Government or the University of California, and shall not be used for advertising or product endorsement purposes.

This work was performed under the auspices of the U. S. Department of Energy by the University of Californ : : I.awrence Livermore National Laboratory under Contract No. W-7405-Eng-48.

This report has been reproduced directly from the best available copy.

Available electronically at http://www.doe.gov/bridge

Available for a processing fee to U.S. Department of Energy and its contractors in paper from

U.S. Department of Energy

Office of Scientific and Technical Information

P.O. Box 62

Oak Ridge, TN 37831-0062

Telephone: (865) 576-8401

Facsimile: (865) 576-5728

E-mail: reports@adonis.osti.gov

Available for the sale to the public from

U.S. Department of Commerce

National Technical Information Service

5285 Port Royal Road

Springfield, VA 22161

Telephone: (800) 553-6847

Facsimile: (703) 605-6900

E-mail: orders@ntis.fedworld.gov

Online ordering: http://www.ntis.gov/ordering.htm

OR

Lawrence Livermore National Laboratory

Technical Information Department's Digital Library

http://www.llnl.gov/tid/Library.html 


\section{Individual Radiation Protection Monitoring in the Marshall Islands: Enewetak Island Resettlement Support (May-December 2001).}

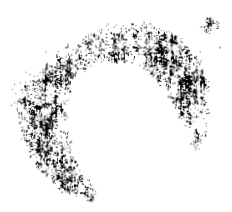

Terry Hamilton, David Hickman, Cynthia Conrado, Tom Brown, James Brunk, Alfredo Marchetti, Carolyn Cox, Roger Martinelli, Steven

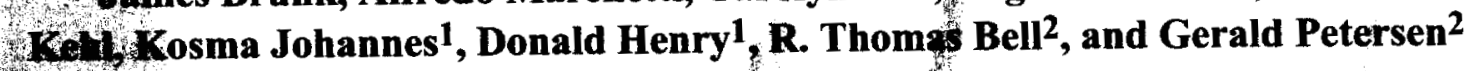

The following document has been prepared as a hardcopy supplement to the U.S. Department of Energy web site, http://tis.eh.doe.gow/health/rwd/. This report has been prepared in partial fulfiliment of LLNL progra level goals and actions sppporting Enewetak Atoll resettlement as formally outlined $u$ (MOU) between the U.S. Department of Energy, th the Enewetak/Ujelang Local Atoll Government.

Work performed under the auspices of the U.S. Department of Ene California Lawrence Livermore National Laboratory under Contrac W-7405-Eng-48.

1Enewetak Radiological Laboratory, Enewetak/Ujelang Support Program, P.O. Box 3249, Majuro, MH 96960

2Office of Health Studies, U.S. Department of Energy, Germantown Road, Germantown, MD 20874

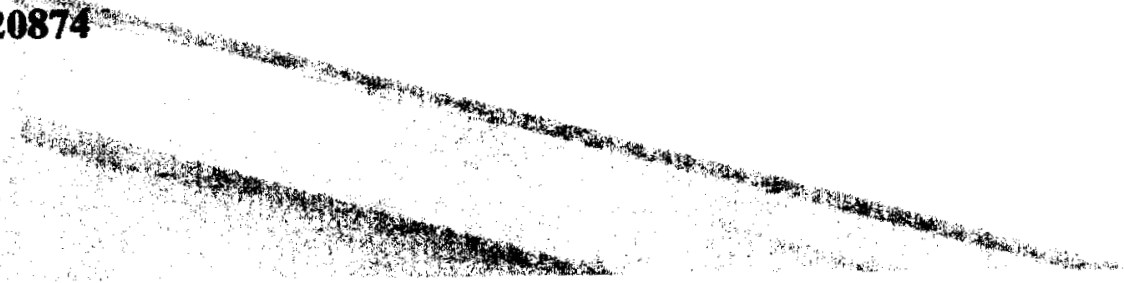




\section{Table of Contents}

Introduction

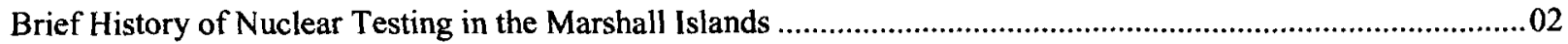

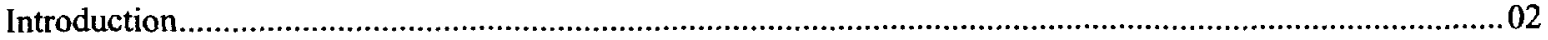

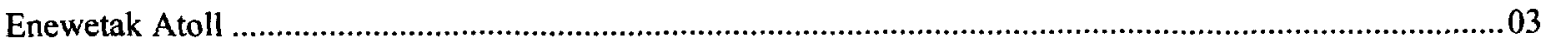

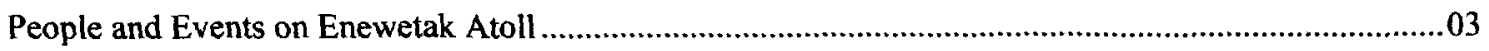

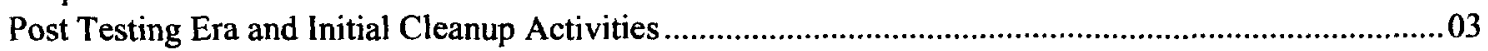

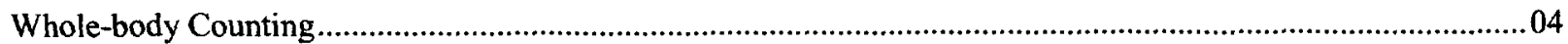

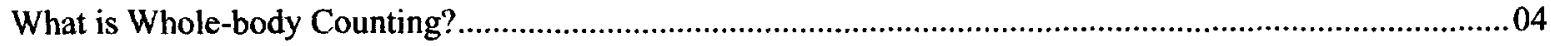

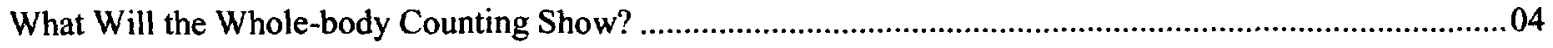

Estimating doses from Cesium-137 using Whole-body Counting .........................................................04

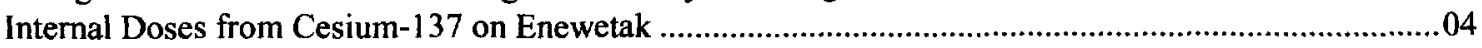

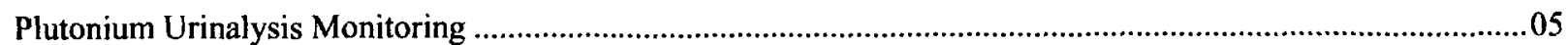

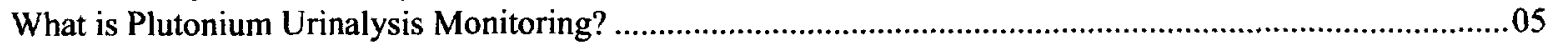

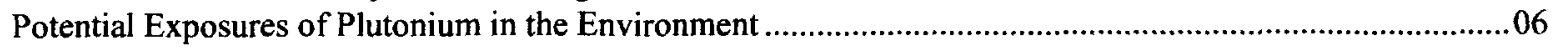

What is the Purpose of Plutonium Urinalysis in the Marshall Islands? .................................................07

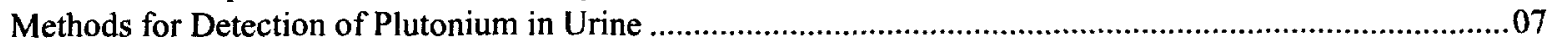

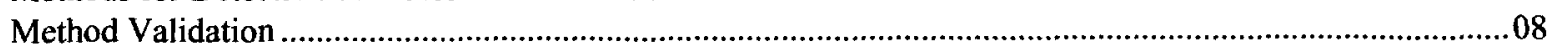

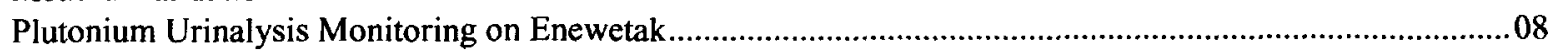

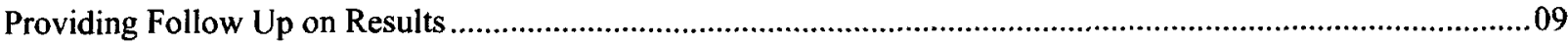

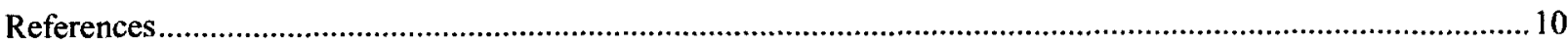

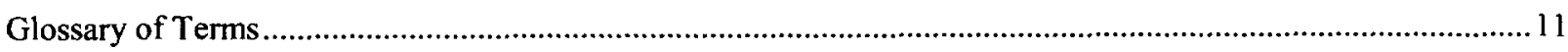

Appendix A: Individual Measurement Data ......................................................................................

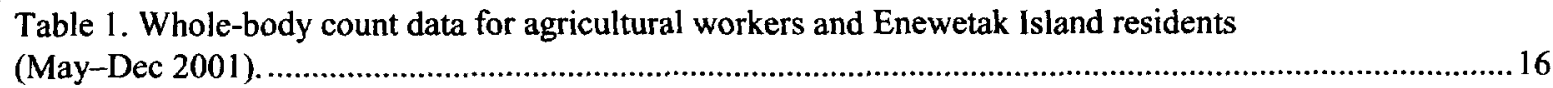

Table 2. Plutonium urinalysis data for agricultural workers and Enewetak Island residents

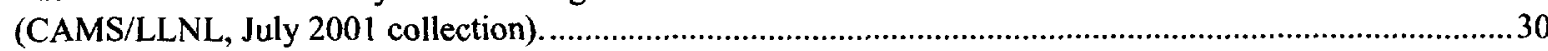

\section{List of Figures}

Figure 1. Picture of the newly constructed Enewetak Radiological Laboratory.

Figure 2. Map of the Republic of the Marshall Islands showing fallout pattern from the Bravo test conducted on 1 March 1954.

Figure 3 . The whole-body counter with a volunteer seated in the chair.

Figure 4. An Assessment of Cesium-137 exposure in the resident population on Enewetak Island (May-December 2001) by whole-body counting. 
Figure 5. Results of a NIST interlaboratory exercise on low-level Plutonium-239 determination in synthetic urine (micro Becquerel, $\mu \mathrm{Bq}$ ).

Figure 6. An assessment of the projected 70-year lifetime dose from plutonium deposition in residents on Enewetak Island (July 2001 collection). 


\section{INTRODUCTION}

The United States (U.S.) Department of Energy (DOE) has recently implemented a series of strategic initiatives to address long-term radiological surveillance needs at former U.S. test sites in the Marshall Islands. The plan is to engage local atoll communities in developing shared responsibilities for implementing radiation protection programs for resettled and resettling populations. Using pooled resources of the U.S. Department of Energy and local atoll governments, individual radiation protection programs have been developed in whole-body counting and plutonium urinalysis to assess potential intakes of radionuclides from residual fallout contamination. The whole-body counting systems are operated and maintained by Marshallese technicians (Figure 1). Samples of urine are collected from resettlement workers and island residents under controlled conditions and analyzed for plutonium isotopes at the Lawrence Livermore National Laboratory using advanced accelerator based measurement technologies. This web site provides an overview of the methodologies, a full disclosure of the measurement data, and a yearly assessment of estimated radiation doses to resettlement workers and island residents.

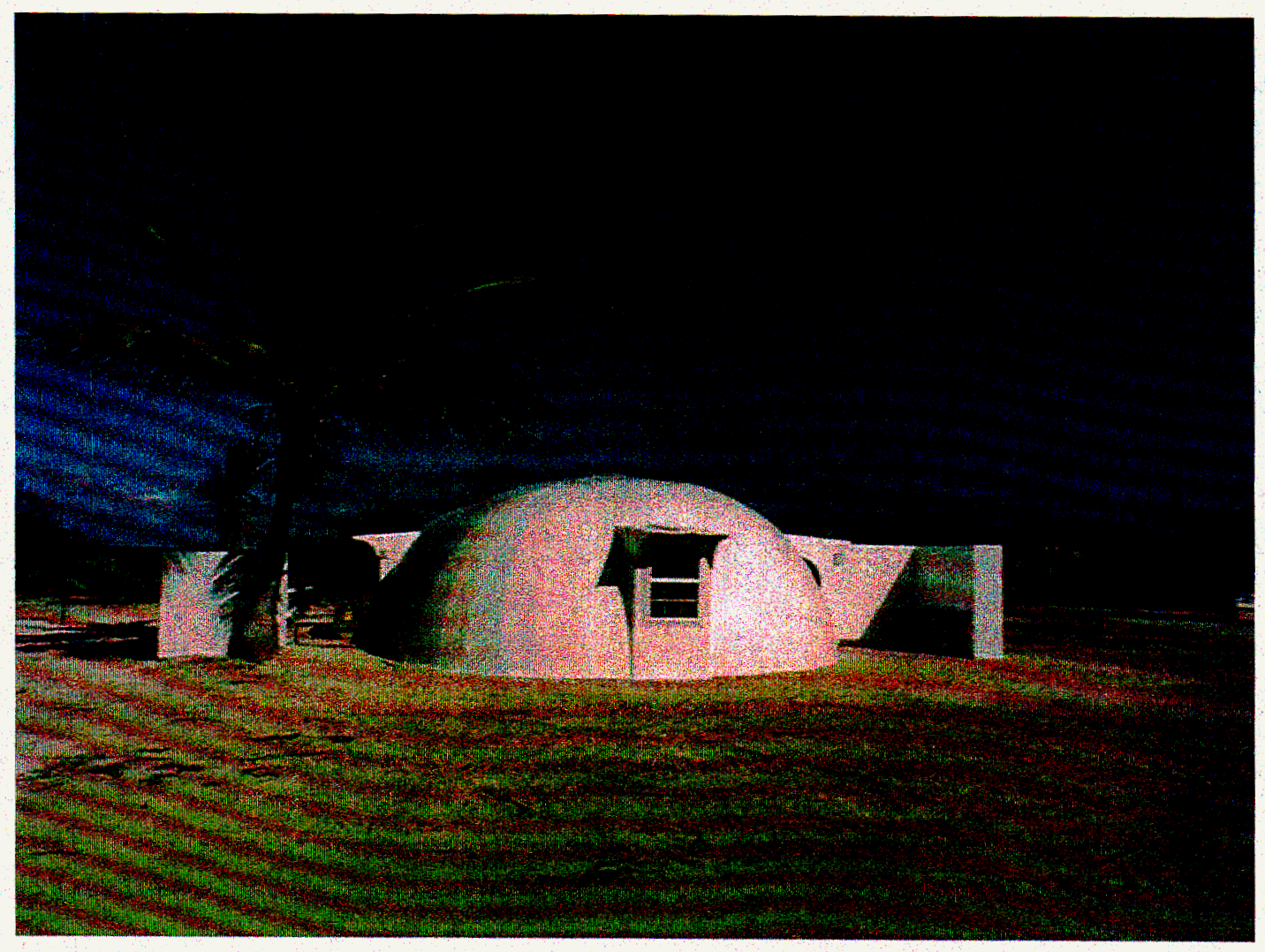

Figure I. Picture of the newly constructed Enewetak Radiological Laboratory. View related publication, UCRL-JC-147325 (Bell et al., 2002). 


\section{BRIEF HISTORY OF NUCLEAR TESTING IN THE MARSHALL ISLANDS}

\section{Introduction}

Immediately after WWII, the United States created a Joint Task Force to develop a nuclear weapons testing program. Planners examined a number of possible locations in the Atlantic, the Caribbean, and the Pacific but decided that coral atolls in the northern Marshall Islands offered the best advantages of stable weather conditions, fewest inhabitants to relocate, and isolation with hundreds of miles of open ocean to the west where trade winds were likely to disperse radioactive fallout. During the period between 1945 and 1958 , there were a total of
67 nuclear tests conducted on Bikini and Enewetak Atoll in the Marshall Islands.

The most significant contaminating event was the Castle Bravo test conducted on 1 March 1954. Bravo was an experimental thermonuclear device with an estimated explosive yield of $15 \mathrm{MT}$ that led to widespread fallout contamination over the inhabited islands of Rongelap and Utirik Atolls as well as other areas to the east of Bikini (Figure 2). Today, the Department of Energy, through the Office of Health Studies, continues to provide environmental monitoring, healthcare, and medical services on affected atolls.

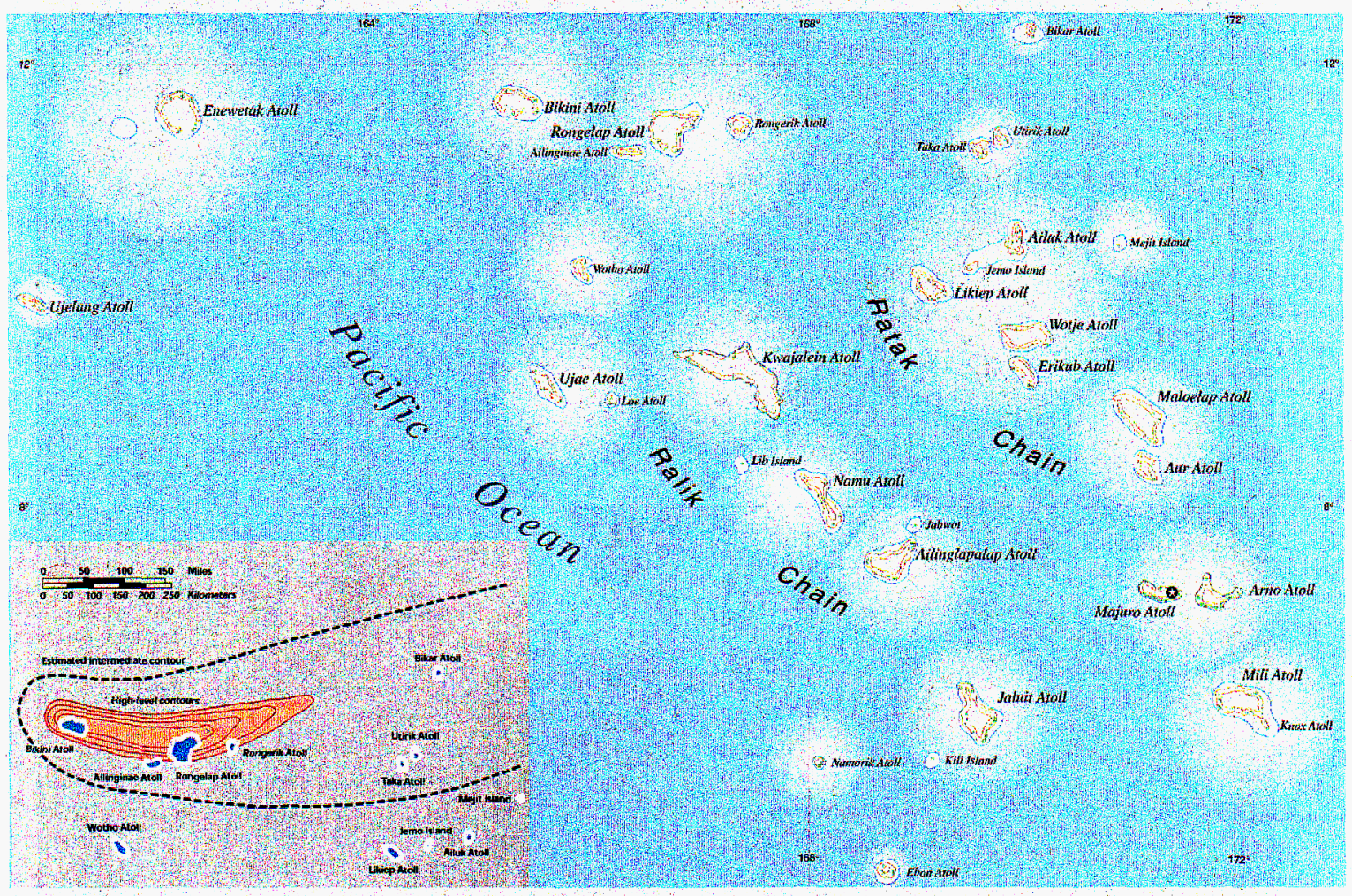

Figure 2. Map of the Republic of Marshall Islands showing the fallout pattern from the Bravo test conducted on 1 March 1954. 


\section{Enewetak Atoll}

\section{People and Events on Enewetak Atoll}

After an initial series of nuclear tests on Bikini Atoll in 1946, local inhabitants of Enewetak were relocated to a new home on Ujelang Atoll in December 1947 in preparation for the scheduled first series of nuclear tests on Enewetak.

Operation Sandstone commenced in April 1948 and included 3 tests atop 200-foot high steel towers located separately on the islands of Enjebi, Aomen, and Runit. An additional 4 near surface tests were conducted on steel towers as part of Operation Greenhouse during 1951. Operation Ivy, in 1952, set the stage for the first test of a large thermonuclear device. The Mike thermonuclear blast of 31 October 1952 had an explosive yield of 10.4 MT and vaporized the island of Elugelab, leaving behind a one-half mile deep crater. Early analysis of Mike fallout debris showed the presence of two new isotopes of plutonium, ${ }^{244} \mathrm{Pu}$ and ${ }^{246} \mathrm{Pu}$, and lead to the discovery of the new heavy elements, Einsteinum and Fermium (Seaborg and Loveland, 1990). Operation Castle involved a single test on Enewetak in 1954 and five high-yield tests on Bikini. A total of 11 nuclear tests were conducted on Enewetak in 1956 as part of Operation Redwing, including an air burst from a balloon located over water. The United States anticipated the acceptance of a call for suspension of atmospheric nuclear testing and assembled a large number of devices for testing before the moratorium started. From April through August 1958, 22 nearsurface nuclear denotations were carried out on Enewetak either on platforms, barges, or underwater (10 tests at Bikini, 2 tests near Johnson Atoll, and a high altitude test about 60 miles west of Bikini). Most of the nuclear tests on Enewetak Atoll were conducted in the northern reaches of the atoll and produced highly localized fallout contamination because large quantities of soil, water and lagoon sediment were incorporated into the ensuing fireball and fallout cloud. As a consequence, the northern islands on Enewetak received significant amounts of local fallout deposition containing a range of fission products, activation products, and unfissioned nuclear fuel. By the time the test moratorium came into effect on 31 October 1958, the United States had conducted 42 tests on Enewetak Atoll.

\section{Post Testing Era and Initial Cleanup Activities}

Enewetak Atoll continued to be used for defense programs until the start of a cleanup and rehabilitation program in 1977 . Over 4,000 U.S. servicemen assisted in the cleanup operations with 6 lives lost in accidents in what became known as the Enewetak Radiological Support Project (U.S. DOE, 1982). Over 100,000 cubic yards of soil from the surface of six islands were removed and deposited in Cactus crater on Runit Island. The Nevada Operations Office of the Department of Energy was responsible for certification of radiological conditions of each island upon completion of the project. The Operations Office also developed several large databases to document radiological conditions before and after the cleanup operations and to provide data to update available dose estimates. The Enewetak cleanup was largely focused on the removal and containment of plutonium along with other heavy radioactive elements. Even during this early period of cleanup and rehabilitation, the adequacy of cleanup of the northern islands on Enewetak was brought into question because predictive assessments showed that ingestion of cesium-137 and other fission products from consumption of locally grown foods was the most significant exposure pathway.

The people of Enewetak remained on Ujelang Atoll until resettlement of Enewetak Island began in 1980. Between 1980-1997, the resettled population was periodically monitored for internally deposited radionuclides by scientists from the Brookhaven National Laboratory using whole-body counting and plutonium urinalysis techniques (Sun et al., 1997a, 1997b).

More recently, the Department of Energy agreed to design and construct a radiological laboratory on Enewetak Island and help develop the necessary local resources to maintain and operate the facility. This cooperative effort was formalized in August 2000 between the U.S. Department of Energy, the Republic of the Marshall Islands, and the Enewetak/Ujelang Local Atoll Government (MOU, 2000).

The laboratory facility was completed in May 2001. The laboratory incorporates both a permanent whole-body counting system to assess internal exposures to cesium-137 and clean living space for people providing 24-hour urine samples. Scientists from the Health and Ecological Assessment Division of the Lawrence Livermore National Laboratory now direct the whole-body counting and plutonium urinalysis radiation protection monitoring programs in the Marshall Islands, 


\section{WHOLE-BODY COUNTING}

\section{What Is Whole-Body Counting?}

The whole-body counting systems installed in the Marshall Islands contain large volume sodium iodide radiation detectors that measure gamma rays coming from radionuclides deposited in the body. The system is modeled after the "Masse-Bolton Chair" design (Figure 3). It can be used to detect high-energy gamma-emitting radionuclides such as cesium-137, cobalt- 60 and potassium-40, in most of the body and all of the internal organs. Using internationally accepted methods, the total amount of a radionuclide measured by whole-body counting is converted into a dose estimate using specially designed computer software (Canberra, 1998a, 1998b.).

The whole-body counting systems in the Marshall Islands are calibrated using a human surrogate calibration source, called a Bottle Manakin Absorption (BOMAB) phantom, filled with a known amount of a mixed gamma-emiting standard traceable to the U.S. National Institute of Standards and Technology. Background and other quality control check counts are performed on a daily basis to ensure that the system conforms to applicable quality requirements.

Local Marshallese technicians are responsible for all daily operations in the whole-body counting facilities. Each technician receives an initial six weeks of intensive training and periodic retraining at the Lawrence Livermore National Laboratory and is employed to run the facility for up to 40 hours per week. Scientists from the Lawrence Livermore National Laboratory provide on-going technical assistance, advanced training, and perform a more detailed data quality assurance appraisal before the data is released or posted to this web site.

\section{What Will the Whole-body Counting Show?}

The main pathway for exposure to residual fallout contamination in the northern Marshall Islands is through ingestion of cesium-137 contained in locally grown foods, such as coconut, Pandanus fruit, and breadfruit. The whole-body counting program in the Marshall Islands will offer island residents an unprecedented level of protection until it is clearly demonstrated that radiation surveillance measures can be relaxed. The value of this type of radiation protection monitoring program lies in the fact that the whole-body count data provides a direct measure of the full range of radionuclide intakes in the local populations. Information about individual intakes and potential 'high-end' health risks can be assessed from the measurement data rather than relying on assumptions based on a range of assumed intake scenarios. In combination with environmental monitoring data, residents who receive a whole-body count showing the presence of cesium-137 can make an informed decision about their eating habits and/or lifestyle based on what is considered a 'safe' or acceptable health risk. The Marshall Islands Government has adopted a very stringent cleanup dose standard of 15 mrem per year $(0.15$ millisievert per year) as an acceptable level of exposure. As communities return to their native islands, wholebody counting will provide a level of reassurance that radiation related health risks remain at or below these established standards.

\section{Estimating Doses from Cesium-137 Using Whole-body Counting}

People living in the Marshall Islands may be exposed to cesium-137 taken up from the soils into locally grown foods. Whole-body counting provides a direct measure of the amount of cesium-137 inside the body of people. The biokinectic behavior of cesium-137 in the human body is well known and allows information from the whole-body counter to be converted to a radiation dose. The radiation dose is the quantity used by health physicists to estimate radiation induced health risks. Dose estimates provided on this web site are expressed as an annual or projected lifetime 70-year dose, assuming a chronic exposure to cesium-137 and/or plutonium239

\section{Internal Doses from Cesium-137 on Enewetak}

The whole-body counting data are shown in Table 1 of Appendix A. 


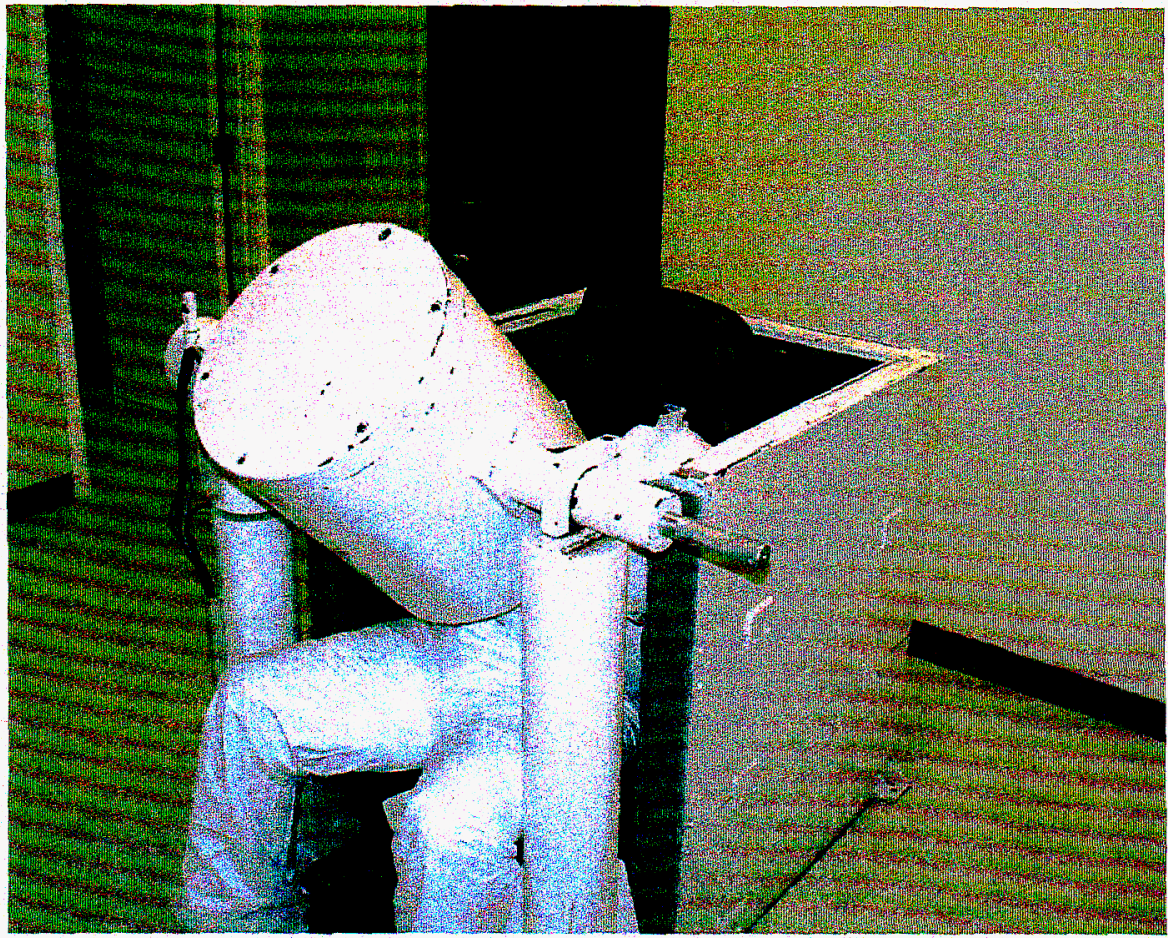

Figure 3. The whole-body counter with a volunteer seated in the chair.

The annual internal effective dose estimates from cesium- 137 in the resident population on Enewetak Atoll during 2001 are presented in graphical form on the frequency distribution bar chart (Figure 4).

The vast majority of people living on Enewetak Island received an annual internal dose from cesium-137 of less than $1 \mathrm{mrem}$. The average individual doses to adults ( 358 individuals), teenagers (41 individuals) and children ( 6 individuals) were $0.4 \pm 0.4,0.2 \pm 0.2$, and $<0.1$ mrem per year, respectively. The average dose for adult males of 0.4 mrem per year was slightly higher than that observed in adult females (around 0.3 mrem per year). Annual dose estimates compare with a natural background dose of 140 mrem per year in the Marshall Islands and $300 \mathrm{mrem}$ per year in the United States. The annual doses observed on Enewetak Island are well below the recommended dose limit for members of the public in the United States of 100 mrem per year. Under present living conditions, the observed doses indicate island residents are receiving adequate radiation protection from residual fallout contamination.

\section{PLUTONIUM URINALYSIS MONITORING}

\section{What Is Plutonium Urinalysis Monitoring?}

Plutonium urinalysis is a very sensitive measurement technique used to determine the amount of plutonium in human urine as a means of estimating human exposure to plutonium. Plutonium urinalysis tests are performed by collecting urine from individuals over a 24 -hour period. The test turns a urine sample into a powder, which scientists then analyze by counting the number of plutonium atoms in the sample, using mass spectrometry. Everybody has a small amount of plutonium in their bodies from 


\section{Annual Internal Dose to Enewetak Residents from Dietary Exposure to Cesium-137 (May - December 2001)}

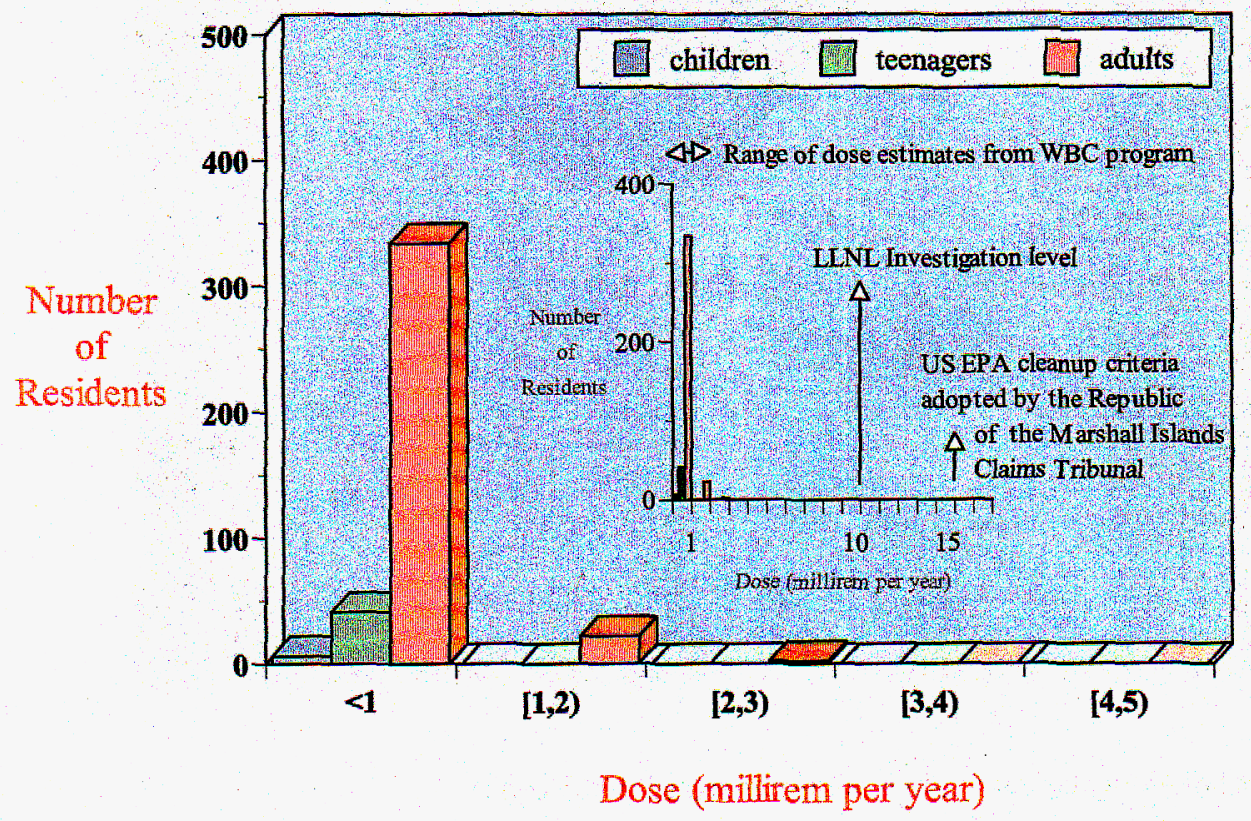

Figure 4. An assessment of Cesium-137 exposure in the resident population on Enewetak Island (May-December 2001) by whole-body counting.

exposure to worldwide fallout contamination. The amount of plutonium detected in the Marshall Islands can be compared with baseline excretion rates to assess likely intakes associated with resettlement.

The Marshall Islands urinalysis program uses a state-of-the-art measurement technology available at the Center for Accelerator Mass Spectrometry (CAMS) at the Lawrence Livermore National Laboratory. Accelerator mass spectrometry is about 100 times more sensitive than monitoring techniques commonly employed in occupational monitoring programs used throughout the United States.

\section{Potential Exposures to Plutonium in the Environment}

Plutonium is an important radioactive element produced in nuclear explosions. Plutonium emits alpha particles (or alpha-rays). Alpha particles are heavy, slow moving, charged particles that travel only one or two inches in air, and can be stopped by a piece of paper or the dead, outside layers of our skin. Therefore, any possible health effects from plutonium come from internal exposure.

Persistent and measurable quantities of residual fallout plutonium contamination have been observed in soils from test sites in the northern Marshall Islands. However, plutonium is not readily transferred from soils to plants (for example, the concentration of plutonium in vegetation is about 100,000 times less than in associated soil) nor is there significant gastrointestinal adsorption of plutonium through the gut of animals and/or marine organisms.

The main potential exposure pathway for plutonium is from inhalation of contaminated dust particles in the air that people breath. Inhaled or ingested plutonium may eventually end up in various tissues - especially the lungs, liver and boneresulting in continuous exposure of these tissues to alpha particle radiation. Plutonium remains in the body for a long time, but the systemic uptake and associated dose contribution from plutonium in people living on Enewetak and Rongelap Islands are 
still expected to be low (Harrison et al., 1989; ICRP, $1986,1990,1993,1994)$.

Potential radionuclide inhalation exposure rates due to resuspension of contaminated soil can be estimated from the product of the soil concentration, resuspension enhancement factors, and inhalation dose factors for the various radionuclides. These estimates show that the projected dose contribution from residual plutonium on Enewetak and Rongelap Islands will be less that $5 \%$ of the total man-made dose over a lifetime. Dose estimates from environmental data are also consistent with results from previous urinalysis studies conducted in the Marshall Islands by the Brookhaven National Laboratory.

\section{What Is the Purpose of Plutonium Urinalysis in the Marshall Islands?}

Plutonium urinalysis is a measurement technique that ultimately provides information to individuals on the amount of plutonium they have in their bodies. Although plutonium is expected to be a minor contributor to the total man-made dose, it is a concern to people living in the northern Marshall Islands who are potentially exposed to elevated concentrations of plutonium in the environment. Consequently, the U.S. Department of Energy agreed to monitor resettlement workers and perform a limited number of urinalysis tests on island residents, using advanced measurement technologies available at the Lawrence Livermore National Laboratory.

The Marshall Islands plutonium urinalysis monitoring program was designed to address the following issues:

1) To provide more reliable and accurate data to assess baseline and significant incremental intakes of plutonium in the resettled and resettling populations using advanced accelerator based mass spectrometric measurement technologies.

2) To monitor the levels of plutonium exposure in critical populations groups, such as workers engaged in soil remediation or agriculture.

3) To demonstrate and document that occupational and/or public exposures to plutonium are below levels that will impact human health.

4) To participate in analytical proficiency testing programs to ensure that the accuracy and reliability of the measurements meet all applicable quality requirements.
5) To document and test the reliability of using environmental data to assess plutonium exposures to people living on coral atolls.

\section{Methods for Detection of Plutonium in Urine}

The decision to support a Marshall Islands plutonium urinalysis monitoring program at the Lawrence Livermore National Laboratory was originally made in 1998. Urine samples were initially sent to the University of Utah for analysis of plutonium, using fission track analysis. Fission is a process where heavy nuclei, such as plutonium and uranium, break up into two large fragments. Fission may occur spontaneously or be induced by collisions with neutrons.

During fission track analysis, samples are exposed to a source of neutrons in a reactor, in contact with a quartz or plastic slide. Any resulting fission fragments leave behind tracks on the slide that can be counted under an optical microscope to determine the amount of plutonium present. Historically, fission track analysis has been plagued with a number of deficiencies including the use of less than reliable and tedious preparative methods, low chemical yields, contamination issues, and inaccurate quantification. The University of Utah and the Brookhaven National Laboratory improved on the fission track process methodology and adopted a more rigorous approach to data reduction and quality assurance.

More recently, scientists from the Lawrence Livermore National Laboratory have developed an ultra low-level detection technique for determination of plutonium isotopes in urine using accelerator mass spectrometry. Accelerator mass spectrometry has a detection sensitivity around 1 to $3 \mu \mathrm{Bq}$ of plutonium and avoids many of the disadvantages of using either conventional atom counting techniques, such as alpha spectrometry and/or other competing new technologies.

There are two main isotopes of plutonium in the environment-plutonium-239 and plutonium-240. The isotopic composition of plutonium (i.e., the relative amounts of plutonium-239 and plutonium240) vary significantly, depending on the origin of the plutonium. For example, the plutonium-240 content of local fallout produced in high yield nuclear tests in the Marshall Islands is significantly higher $\left({ }^{240} \mathrm{Pu} /{ }^{239} \mathrm{Pu} \sim 0.25-0.35\right)$ than that contained in global fallout $\left({ }^{240} \mathrm{Pu} /{ }^{239} \mathrm{Pu} 0.18\right)$ or in unfissioned nuclear 
fuel $\left({ }^{240} \mathrm{Pu} /{ }^{239} \mathrm{Pu} \sim 0.05\right)$. Consequently, it may be possible to use urinalysis and plutonium isotope measurements as an investigative tool to assess exposures to Bravo or other specific test events.

The higher level of plutonium-240 in nuclear fallout also needs to be considered in dose estimates. It should also be noted that alpha spectrometry is a much less sensitive measurement technique and, along with fission track analysis, cannot distinguish between plutonium-239 and plutonium-240.

\section{Method Validation}

Method validation is the process used to monitor and document the quality of measurement data. The Lawrence Livermore National Laboratory has recently demonstrated the viability of using accelerator mass spectrometry for ultra-trace plutonium isotope detection and measurement. Method validation has included the successful participation of LLNL in an interlaboratory exercise organized by the U.S. National Institute of Standards and Technology (NIST). The results of this exercise clearly show that accelerator mass spectrometric technologies are well suited for detection of $\mu \mathrm{Bq}$ concentrations of plutonium-239 and plutonium-240 in urine (Figure 5).

View full report, UCRL-ID-147972

(Marchetti et al, 2001).

\section{Plutonium Urinalysis Monitoring on Enewetak}

The urinalysis data are shown in Table 2 of Appendix A.

Accelerator Mass Spectrometry enables monitoring of plutonium excretion down to 1 to 3 $\mu \mathrm{Bq}$ per 24 hours. The improved sensitivity and reliability of this measurement technique was required in order to more ably assess potential lowlevel chronic or incremental exposures to plutonium in excess of baseline excretion resulting from previous exposures to general worldwide environmental contamination. However, the urinary excretion of plutonium by Enewetak residents and agricultural workers during the July-August 2001 collection was still far below a level where the measurements could be performed with an acceptable level of uncertainty. Moreover, the majority of the results fall below the critical level of the measurements. This would normally negate the need to report a dose value at all; rather, we would assume the dose from plutonium was zero. For completeness, we have included dose estimates in our reporting.

The projected 70-year lifetime doses are presented in graphical form on a frequency distribution bar chart (Figure 6). The projected 70-year lifetime dose from internally deposited plutonium in the Enewetak resident population is less than 10 mrem (or $0.1 \mathrm{mSv}$ ), well below applicable cleanup standards (Figure 6).

\section{Results of Intercomparison Study Organized by the U.S. National Institute of Standards and Technology}

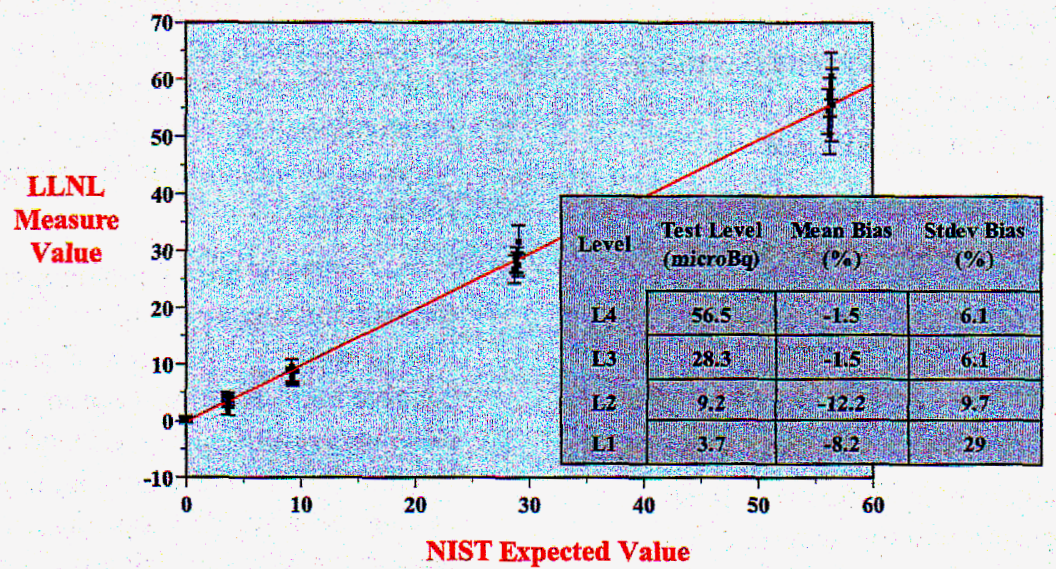

Figure 5. Results of a NIST interlaboratory exercise on low-level plutonium-239 determination in synthetic urine (microBecquerel, $\mu \mathrm{Bq}$ ) 


\section{Projected 70-year Lifetime Dose to Enewetak Island Residents from Internally Deposited Plutonium (based on July 2001 urinalysis collection)}

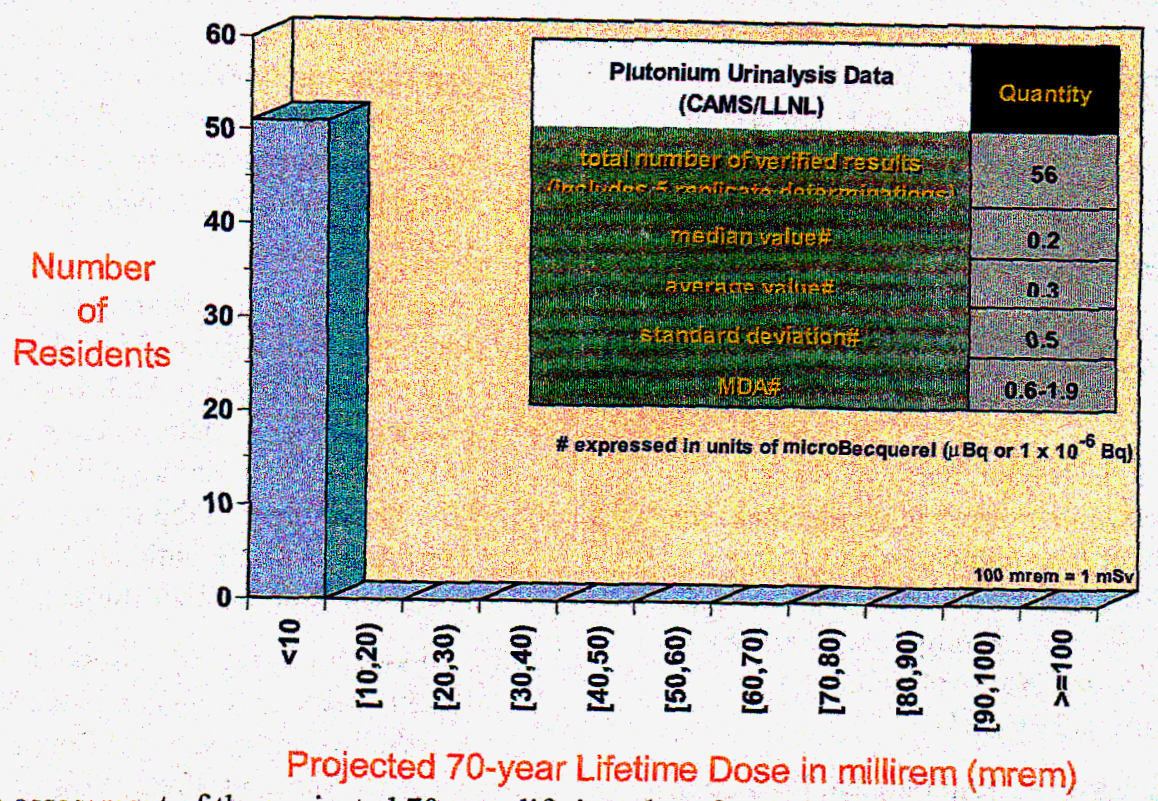

Figure 6. An assessment of the projected 70-year lifetime dose from plutonium deposition in residents on Enewetak Island (July 2001 collection)

Urinary excretion of plutonium by Enewetak Atoll agricultural workers and island residents will consist of a baseline, long-term excretion from residual systemic burdens acquired from all previous exposures and a potential prompt-excretion component from any intake associated with resettlement. Dose estimates shown here assume that the intake of plutonium is equivalent to the daily excretion rate, i.e., that the total body burden of plutonium will remain at the present level. This is a very conservative (i.e., dose maximizing) assumption. There is no evidence of significant incremental intakes of plutonium because urinary excretion of plutonium by Enewetak residents is within the range of what might be expected from residual systematic burdens acquired from previous exposures to worldwide fallout contamination. Previous estimates of the background urinary excretion of plutonium in adults from the northern Marshall Islands range from 1-2 $\mu \mathrm{Bq}$ per 24 -hour urine sample (NRC, 1994).

\section{PROVIDING FOLLOW UP ON RESULTS}

All program volunteers receive a preliminary copy of their dose report immediately after they receive a whole-body count. Scientists from the Lawrence Livermore National Laboratory verify the measurements, and if required, a revised dose report is generated and returned to the individuals concerned. Annual doses of $10 \mathrm{mrem}$ or above evoke a predetermined action or investigation. These actions may include follow-up measurements, a dietary evaluation, and/or a work history review. Below this level, we assume that default assumptions for assigning doses are valid and need not be considered for investigation of intake. This action level is one-tenth of the investigation level used throughout the Department of Energy and is well below the 15 mrem cleanup standard adopted by the Marshall Islands. In addition, at the end of each calendar year, all program volunteers receive a final written report containing all available verified individual whole-body counts and plutonium urinalysis measurement data along with their estimated annual or committed lifetime doses. 


\section{REFERENCES}

Bell, R. T., D. Hickman, L. Yamaguchi, W Jackson, and T. Hamilton (2002), $A$ Whole-body Counting Facility in a Remote Enewetak Island Setting, Lawrence Livermore National Laboratory, Livermore, CA, UCRL-JC-147325 (Submitted to Health Physics).

Canberra Industries (1998a), Abacos-2000, Canberra Industries, Meriden, CT.

Canberra Industries (1998b), Genie-200 Spectroscopy System, Canberra Industries, Meriden, CT.

Harrison, J. D., G. P. L. Naylor, and J. W. Stather (1989), Gastrointestiral Absorption of Plutonium and Americium in Rats and Guineapigs after Ingestion of Dusts from the Former Nuclear Weapons Test Site at Marolinga: Implications for Human Exposure, National Radiation Protection Board, NRPB-M196.

International Commission on Radiological Protection (ICRP) (1986), The Metabolism of Plutonium and Related Compounds, Oxford: Pergamon Press, Publication 48.

International Commission on Radiological Protection (ICRP) (1990), Age-Dependent Doses to Members of the Public from Intake of Radionuclides: Part 1, New York: Pregamon Press, Publication 56.

International Commission on Radiological Protection (ICRP) (1993), Age-Dependent Dose to Members of the Public from Intake of Radionuclides: Part 2 Ingestion Dose Coefficients, New York: Pregamon Press, Publication 67.

International Commission on Radiological Protection (ICRP) (1994), Human Respiratory Tract Model for Radiological Protection, New York: Pergamon Press, Publication 66.
Marchetti, A.A., T.A. Brown, J.E. McAninch, J. Brunk, C.C. Cox, R.E. Martinelli, J.P. Knezovich, and T.F. Hamilton (2002), Measurement of Plutonitum Isotopes in Urine at Microbecquerel Levels: AMS Results of a NIST Interlaboratory Exercise, Lawrence Livermore National Laboratory, Livermore, CA, UCRL-ID147972.

Memorandum of Understanding (MOU) (1999) by and between the Republic of the Marshall Islands, the Rongelap Atoll Local Government Council, the U.S. Department of Energy, Office of Environmental Safety and Health, and the U.S. Department of the Interior, Office of Territorial and International Affairs for the Rongelap Resettlement Project.

NRC (1994), Radiological Assesssments for Resettlement of Rongelap in the Republic of the Marshall Islands, National Research Council, National Academy Press, Washington DC, 1994, $108 \mathrm{pp}$.

Seaborg, G. T., and W. D. Loveland (1990), The Elements Beyond Uranium, John Wiley \& Sons, Inc., New York, NY, pp. 359.

Sun, L. C., C. B. Meinhold, A. R. Moorthy, E. Kaplan, and J. W. Baum (1997a), "Assessment of Plutonium Exposure in the Enewetak Population by Urinalysis," Health Physics 73(1): 127-132.

Sun, L.C., J. H. Clinton, E. Kaplan, and C. B. Meinhold (1997b), ${ }^{\text {"137 }} \mathrm{Cs}$ Exposure in the Marshallese Populations: An Assessment Based on Whole-Body Counting Measurement (19891994)

U.S. Department of Energy (DOE) (1982) Enewetak Radiological Support Project, Final Report, (Friesen, B. Ed.) U.S. DOE, Nevada Operations Office, Las Vegas, NV, NVO-213, pp. 349. 


\section{GLOSSARY OF TERMS}

\section{Absorbed Dose}

The absorbed dose is the energy deposited in an organ or tissue per unit mass of irradiated material. The common unit for absorbed dose is the rad, which is equivalent to 100 egs per gram of material.

The international scientific community has adopted the use of a different term for rad called a gray (Gy). One Gy is the same as $100 \mathrm{rad}$.

\section{Activity}

The transition rate or number of radioactive decays per unit time of a given radioactive source expressed in units of Becquerel, curie or other acceptable units.

\section{Alpha Particles}

Alpha particles are one of the primary types of radiation associated with radioactivity. Alpha rays are heavy, slow moving, charged particles that travel only one or two inches in air and can be stopped by a piece of paper or the dead, outside layers of skin. Because of the very short range of the emitted alpha radiation, the main concern in radiation protection is from the potential health effects of internally deposited alpha-emitting radionuclides.

\section{Background Radiation}

The average person in the United States receives about 360 mrem of ionizing radiation every year. About 300 mrem per year comes from natural background radiation from outer space, soil and air that people breath, and about 60 mrem from manmade sources such as medical exposures to diagnostic rays and consumer products (e.g., from smoking tobacco). The general worldwide contribution from radioactive fallout contamination is $<0.3 \%$ of the average total dose. Exposures to natural background radiation vary depending on the geographic area, diet, and factors such as the composition of materials used in the construction of homes. The natural background radiation dose in the Marshall Islands is around 140 mrem per year and is significantly less than what most people receive around the world.

\section{Baseline}

We have all been exposed to some level of worldwide fallout contamination. In the United States, it is estimated that the population receives up to 1.5 millirem $(0.3 \%$ of the average total annual dose) from worldwide fallout and about 0.5 millirem (or $0.1 \%$ of the average total annual dose) from operations related to nuclear power generation. Similarly, people living in the Marshall Islands will have very small quantities of internally deposited plutonium and cesium- 137 in their bodies from worldwide environmental contamination of food, air, water and soil. The residual system burden acquired from previous exposures provides a baseline for assessing the significance of any intake associated with resettlement.

Our measurements show that the baseline urinary excretion of plutonium by resettlement workers on Rongelap and the resident population on Enewetak is at or below the sensitivity of our measurements by accelerator mass spectrometry.

Whole-body counting will also be used to establish the cesium-137 baseline for the Rongelap population as resettlement begins. The aim of the Marshall Islands radiation protection monitoring program is to monitor internally deposited radionuclide that fall above the existing baseline and may potentially be associated with resettlement.

For the purposes of this discussion, the urinary excretion of plutonium must increase by about $3 \mu \mathrm{Bq}$ per day to register a positive detection at a reasonable level of uncertainty. Therefore, the minimal detectable dose for the plutonium urinalysis program is around 0.02 mrem per year.

Similarly, the Minimum Detectable Amount (MDA) for the whole-body counting systems on Rongelap and Enewetak range from $\sim 0.04-0.2 \mathrm{kBq}$. This translates into a detectable annual effective dose of around 0.2 to $0.7 \mathrm{mrem}$.

\section{Becquerel (Bq)}

A Becquerel (abbreviated as $\mathbf{B q}$ ) is the International System (SI) unit for the activity of radioactive material. One Bq of radioactive material is that amount of material in which one atom is transformed or undergoes one disintegration every second. The common units used in this report for 
reporting whole-body counting and plutonium urinalysis data are the $\mathbf{k B q}(\mathrm{kiloBq})$ and $\mu \mathrm{Bq}$ (microBq).

\section{Biokinectic}

The word 'biokinectic' is used here to describe the adsorption (uptake), distribution and retention of elements in humans.

\section{Calibration}

The process of adjusting, determining the response, or reading an instrument to a standard.

\section{Committed Dose Equivalent}

The time integral of a dose-equivalent rate in an organ or tissue that will be received by an individual following an intake of radioactive material into the body. When the time integral is not specified, it will be taken as 50 years for adults and to age 70 years for intakes by children. Committed dose equivalent is normally expressed in units of rem.

The international scientific community has adopted the use of a different term for rem called a seivert (Sv). One Sv is the same as $100 \mathrm{rem}$.

\section{Committed Effective Dose Equivalent}

The committed dose equivalents to various tissues or organ in the body each multiplied by an appropriate tissue-weighing factor and then summed. Committed effective dose equivalence (CEDE) is normally expressed in units of rem.

The international scientific community has adopted the use of a different term for rem called a sievert (Sv). One $\mathrm{Sv}$ is the same as 100 rem.

\section{Critical Level}

The amount of a count $\left(\mathrm{L}_{c}\right)$ or final measurement of a quantity of an analyte at or above which a decision is made that the analyte is definitely present $\left(\mathrm{L}_{\mathrm{c}} \approx \mathbf{M D A} / 2\right)$

\section{Default Assumptions}

The largest contribution to the radiation dose attributable to residual nuclear fallout in the Marshall Islands results from either internal exposure from intake of radionuclides through ingestion, inhalation and/or absorption through the skin, and external exposure from radionuclides distributed in the soil. External exposure rates can be measured directly using instrument surveys of the radiation field. The assignment of dose to internally deposited radionuclides is much more complicated. Biokinectic and dosimetric models developed by the International Commission on Radiological Protection (ICRP) are used to convert whole-body burdens (from wholebody counting or from in vitro bioassay tests, such as urinalysis) into dose. In the case of a chronic exposure, organ and body burdens continue to build up over time until a steady state is reached where losses due to decay and excretion are balanced by intake and absorption. Cesium-137 has an effective half-life in an adult of about 110 days and, under chronic exposure conditions, reaches a maximal dose rate after about 2 years. By contrast, plutonium absorbed from the gastrointestinal or respiratory tract enters the blood stream and deposits in liver and bone with an effective half-life of $20-50$ years. Only a small fraction of plutonium entering the blood stream is excreted in urine with the long-term excretion rate approaching $2 \times 10^{-5}$ of the systemic body burden per day. Knowledge of excretion rates and time of exposure are important when interpreting urinalysis data.

\section{Direct bioassay}

The measurements of radioactive material in the human body, utilizing instrumentation that detects radiation emitted from radioactive material in the body (synonymous with in vivo measurements)

\section{Dose Assessment}

The scientific process used to determine radiation dose and uncertainty in the dose.

\section{Dose Equivalent}

The dose equivalent is the adsorbed dose multiplied by a biological effectiveness factor for the radiation to cause biological damage. Dose equivalents are typically expressed in rem. A dose of 100 rem to an adult normally produces some clinical signs of radiation sickness and requires hospitalization.

The international scientific community has adopted the use of a different term for rem called a sievert (Sv). One Sv is the same as 100 rem. 


\section{Effective Dose Equivalent}

The effective dose equivalent for the whole-body is the sum of dose-equivalents for various organs in the body weighted to account for different sensitivities of the organs to radiation. It includes the dose from radiation sources internal and/or external to the body. The effective dose equivalent is usually expressed in units of millirem (mrem).

The international scientific community has adopted the use of a different term for millirem called a millisievert ( $\mathrm{mSv}$ ). One $\mathrm{mSv}$ is the same as 100 mrem.

\section{External Dose or Exposure}

That portion of the dose equivalent received from radiation sources outside the human body.

\section{Fission Track Analysis}

During neutron irradiation, heavy nuclei, such as uranium and plutonium, undergo nuclear fission with release of large fission fragments. This property have led to the development of a number of measurement techniques such as delayed neutron activation analysis and fission track analysis. Fission track analysis is a measurement technique commonly employed in plutonium urinalysis (bioassay) monitoring programs. Urine samples are chemically treated to remove plutonium. The plutonium is then mounted in contact with a special plastic or quartz slide known as solid state nuclear track detector (SSNTD). The slide, along with the sample, is then irradiated in a reactor where neutroninduced fission of plutonium-239 (or uranium-235) causes emission of energetic fission fragments. Some of the fragments penetrate into the SSNTD damaging the integrity of the material before coming to rest. The SSNTD is separated from the sample and chemically etched to expose the damaged areas (known as fission tracks) on the detector surface. The fission tracks are then counted under an optical microscope. The amount of plutonium (and/or uranium) present in the sample is a function of the total number of tracks and the neutron flux.

\section{Gamma-rays}

Gamma-rays are electromagnetic waves produced by spontaneous decay of radioactive elements. Sunlight also consists of electromagnetic waves, but gamma-rays have a shorter wavelength and much higher energy. High energy gamma-rays, such as those produced by decay of cesium-137, may penetrate deeply into the body and affect cells. Gamma-rays from a cobalt-60 source are often used for cancer radiotherapy.

\section{High-End Health Risk}

Relates to the maximally exposed individuals in a population.

In Vitro

In vitro measurements are synonymous with indirect bioassay techniques, such an urinalysis.

\section{In Vivo}

In vivo measurements are synonymous with direct bioassay techniques, such whole-body counting.

\section{Indirect bioassay}

Measurements to determine the presence of or estimate the amount of a radioactive material in the excreta, urine, or in other biological materials removed from the body (synonymous with in vitro measurements)

\section{Individual}

$$
\text { Any human being. }
$$

\section{Internal Dose or Exposure}

That portion of the dose equivalent received from radiation sources inside the human body.

\section{Isotope}

Atoms with the same number of protons but different numbers of neutrons are called isotopes of a specific element. We identify different isotopes by appending the total number of nucleons (the total number of proton plus neutrons in the nucleus of an atom) to the name of the element, e.g., cesium-137. Isotopes are usually written in an abbreviated form using the chemical symbol of the element. Two examples include ${ }^{137} \mathrm{Cs}$ for cesium-137, ${ }^{239} \mathrm{Pu}$ for plutonium-239, and ${ }^{40} \mathrm{~K}$ for potassium -40 . 


\section{Minimum Detectable Amount (MDA)}

The smallest activity or mass of an analyte in a sample or person that can be detected with an acceptable level of uncertainty.

\section{Monitoring}

The measurement of radiation levels or individual doses and the use of the results to assess radiological hazards or potential and actual doses resulting from exposures to ionizing radiation.

\section{Quality Assurance}

All those planned and systematic actions necessary to provide adequate confidence that an analyses, measurement, or surveillance program will perform satisfactorily.

\section{Quality Control}

Those actions that control the attributes of analytical process, system or facility according to predetermined quality requirements.

\section{Radiation Dose (or mrem)}

A generic term to describe the amount of radiation a person receives. Dose is measured in units of thousands of a roentgen equivalent man (rem) (called the millirem). The millirem is normally abbreviated as mrem. Dose is a general term used to assist in the management of individual exposure to radiation.

The international scientific community has adopted the use of a different term for millirem called a millisievert (mSv). One $\mathrm{mSv}$ is the same as 100 mrem.

\section{Radioactivity}

A natural and spontaneous process by which unstable atoms of an element emit energy and/or particles from their nuclei and, thus, change (or decay) to atoms of a different element or a different state of the same element.

\section{Validation}

Defining the process of the method capability and determining whether it can be properly applied as intended.

\section{Whole-body}

For the purposes of external exposure includes the head, trunk, the arms above and including the elbow, and legs above and including the knee. 


\section{Appendix A: INDIVIDUAL MEASUREMENT DATA}

2001.

The following data tables provide full disclosure of all verified measurement data collected to 31 December

Table 1. Whole-body Count data for agricultural workers and Enewetak Island residents (May-Dec. 2001).

Table 2. Plutonium urinalysis data for agricultural workers and Enewetak Island residents (CAMS/LLNL, July 2001 collection) 
Table 1. Whole-body count data for agricultural workers and Enewetak Island residents (May-Dec 2001).

\begin{tabular}{|c|c|c|c|c|c|c|c|c|c|c|c|}
\hline \multirow[b]{2}{*}{ ID \# } & \multirow[b]{2}{*}{ Gender } & \multirow[b]{2}{*}{$\begin{array}{c}\text { Count } \\
\text { Date }\end{array}$} & \multicolumn{4}{|c|}{${ }^{40} \mathrm{~K}(\mathrm{kBq})$} & \multicolumn{4}{|c|}{${ }^{137} \mathrm{Cs}(\mathrm{kBq})$} & \multirow[b]{2}{*}{$\begin{array}{c}\text { Method } \\
\text { Code }\end{array}$} \\
\hline & & & Value & Upper & Lower & MDA & Value & Upper & Lower & $\overline{\text { MDA }}$ & \\
\hline EN00002 Adult & Male & $5 / 19 / 2001$ & 4.0 & 4.3 & 3.8 & 0.7 & 0.17 & 0.18 & 0.15 & 0.089 & NaI_WBC \\
\hline EN00002 Adult & Male & $8 / 8 / 2001$ & 4.2 & 4.4 & 3.9 & 0.8 & 0.24 & 0.25 & 0.22 & 0.10 & NaI_WBC \\
\hline EN00003 Adult & Male & $5 / 19 / 2001$ & 4.0 & 4.3 & 3.7 & 0.6 & 0.00 & 0.00 & 0.00 & 0.065 & NaI_WBC \\
\hline EN00003 Adult & Male & $8 / 8 / 2001$ & 4.3 & 4.5 & 4.0 & 0.8 & 0.14 & 0.15 & 0.12 & 0.098 & Nal WBC \\
\hline EN00004 Adult & Male & $5 / 21 / 2001$ & 3.3 & 3.5 & 3.1 & 0.7 & 0.00 & 0.00 & 0.00 & 0.065 & NaI_WBC \\
\hline EN00004 Adult & Male & $6 / 28 / 2001$ & 3.7 & 3.9 & 3.4 & 0.7 & 0.00 & 0.00 & 0.00 & 0.063 & NaI_WBC \\
\hline EN00004 Adult & Male & $12 / 6 / 2001$ & 3.0 & 3.2 & 2.8 & 0.7 & 0.034 & 0.043 & 0.024 & 0.095 & Nal_WBC \\
\hline EN00005 Adult & Male & $5 / 21 / 2001$ & 4.1 & 4.3 & 3.8 & 0.6 & 0.27 & 0.29 & 0.25 & 0.10 & NaI_WBC \\
\hline EN00005 Adult & Male & $7 / 11 / 2001$ & 4.5 & 4.8 & 4.2 & 0.8 & 0.18 & 0.20 & 0.16 & 0.097 & NaI_WBC \\
\hline EN00005 Adult & Male & $9 / 4 / 2001$ & 4.8 & 5.1 & 4.5 & 0.8 & 0.20 & 0.22 & 0.19 & 0.092 & Nal_WBC \\
\hline EN00005 Adult & Male & $10 / 3 / 2001$ & 4.9 & 5.2 & 4.6 & 0.7 & 0.16 & 0.17 & 0.14 & 0.089 & NaI_WBC \\
\hline EN00005 Adult & Male & $11 / 7 / 2001$ & 4.4 & 4.6 & 4.1 & 0.7 & 0.18 & 0.20 & 0.17 & 0.093 & NaI_WBC \\
\hline EN00005 Adult & Male & $12 / 5 / 2001$ & 4.2 & 4.4 & 3.9 & 0.8 & 0.18 & 0.19 & 0.16 & 0.097 & NaI_WBC \\
\hline EN00006 Adult & Male & $5 / 21 / 2001$ & 3.4 & 3.6 & 3.2 & 0.6 & 0.18 & 0.20 & 0.17 & 0.092 & Nal_WBC \\
\hline EN00006 Adult & Male & $6 / 28 / 2001$ & 4.5 & 4.8 & 4.2 & 0.8 & 0.17 & 0.18 & 0.16 & 0.096 & NaI WBC \\
\hline EN00006 Adult & Male & $9 / 4 / 2001$ & 4.3 & & 4.1 & & 0.19 & 0.21 & 0.17 & 0.10 & NaI_WBC \\
\hline EN00006 Adult & Male & $10 / 3 / 2001$ & 4.5 & 4.8 & 4.2 & 0.8 & 0.24 & 0.26 & 0.23 & 0.10 & Nal_WBC \\
\hline EN00006 Adult & Male & $11 / 5 / 2001$ & 3.7 & 3.9 & 3.4 & 0.8 & 0.17 & 0.18 & 0.15 & 0.091 & Nal_WBC \\
\hline EN00006 Adult & Male & $12 / 5 / 2001$ & 4.4 & 4.6 & 4.1 & 0.7 & 0.18 & 0.20 & 0.17 & 0.094 & Nal_WBC \\
\hline EN00007 Adult & Male & $5 / 21 / 2001$ & 3.5 & 3.7 & 3.2 & 0.6 & 0.23 & 0.25 & 0.21 & 0.097 & Nal_WBC \\
\hline EN00007 Adult & Male & $6 / 28 / 2001$ & 4.1 & 4.3 & 3.8 & 0.8 & 0.16 & 0.17 & 0.14 & 0.096 & Nal_WBC \\
\hline EN00007 Adult & Male & $9 / 4 / 2001$ & 4.4 & 4.6 & 4.1 & 0.7 & 0.24 & 0.25 & 0.22 & 0.10 & Nal_WBC \\
\hline EN00007 Adult & Male & $10 / 3 / 2001$ & 4.2 & 4.5 & 4.0 & 0.7 & 0.23 & 0.25 & 0.21 & 0.099 & NaI_WBC \\
\hline EN00007 Adult & Male & $11 / 5 / 2001$ & 3.7 & 3.9 & 3.5 & 0.7 & 0.18 & 0.19 & 0.16 & 0.094 & Nal_WBC \\
\hline EN00008 Adult & Male & $5 / 21 / 2001$ & 3.3 & 3.6 & 3.1 & 0.6 & 0.088 & 0.099 & 0.077 & 0.085 & NaI_WBC \\
\hline EN00008 Adult & Male & $9 / 4 / 2001$ & 4.0 & 4.3 & 3.8 & 0.8 & 0.21 & 0.23 & 0.19 & 0.077 & NaI_WBC \\
\hline EN00008 Adult & Male & $10 / 3 / 2001$ & 4.0 & 4.3 & 3.8 & 0.8 & 0.14 & 0.15 & 0.13 & 0.092 & NaI_WBC \\
\hline EN00008 Adult & Male & $11 / 5 / 2001$ & 3.7 & 4.0 & 3.5 & 0.8 & 0.12 & 0.13 & 0.11 & 0.093 & NaI_WBC \\
\hline EN00008 Adult & Male & $12 / 14 / 2001$ & 4.1 & 4.4 & 3.9 & 0.8 & 0.15 & 0.17 & 0.14 & 0.095 & NaI WBC \\
\hline EN00009 Adult & Male & $5 / 21 / 2001$ & 2.6 & 2.8 & 2.4 & 0.6 & 0.10 & 0.11 & 0.086 & 0.073 & NaI_WBC \\
\hline EN00009 Adult & Male & $6 / 28 / 2001$ & 3.4 & 3.7 & 3.2 & 0.8 & 0.083 & 0.095 & 0.071 & 0.084 & NaI_WBC \\
\hline EN00009 Adult & Male & $9 / 4 / 2001$ & 3.6 & 3.8 & 3.3 & 0.8 & 0.055 & 0.066 & 0.044 & 0.086 & NaI_WBC \\
\hline EN00009 Adult & Male & $10 / 3 / 2001$ & 3.6 & 3.9 & 3.4 & 0.8 & 0.050 & 0.060 & 0.040 & 0.082 & NaI_WBC \\
\hline EN00009 Adult & Male & $11 / 6 / 2001$ & 3.4 & 3.6 & 3.2 & 0.7 & 0.00 & 0.00 & 0.00 & 0.064 & NaI_WBC \\
\hline EN00009 Adult & Male & $12 / 5 / 2001$ & 3.2 & 3.4 & 3.0 & 0.7 & 0.098 & 0.11 & 0.087 & 0.074 & NaI_WBC \\
\hline EN00010 Adult & Male & $5 / 21 / 2001$ & 4.0 & 4.3 & 3.7 & 0.7 & 0.12 & 0.13 & 0.11 & 0.092 & NaI_WBC \\
\hline EN00010 Adult & Male & $6 / 28 / 2001$ & 4.7 & 5.0 & 4.4 & 0.8 & 0.095 & 0.11 & 0.084 & 0.087 & NaI_WBC \\
\hline EN00010 Adult & Male & $9 / 4 / 2001$ & 4.9 & 5.2 & 4.6 & 0.8 & 0.18 & 0.20 & 0.16 & 0.099 & NaI_WBC \\
\hline EN00010 Adult & Male & $10 / 3 / 2001$ & 5.3 & 5.6 & 5.0 & 0.8 & 0.20 & 0.22 & 0.18 & 0.10 & NaI_WBC \\
\hline EN00010 Adult & Male & $11 / 5 / 2001$ & 4.7 & 5.0 & 4.4 & 0.8 & 0.10 & 0.12 & 0.091 & 0.088 & NaI_WBC \\
\hline EN00010 Adult & Male & $12 / 5 / 2001$ & 4.7 & 5.0 & 4.5 & 0.8 & 0.097 & 0.11 & 0.084 & 0.087 & Nal_WBC \\
\hline EN00011 Adult & Male & $5 / 21 / 2001$ & 3.2 & 3.4 & 3.0 & 0.6 & 0.20 & 0.22 & 0.18 & 0.098 & NaI_WBC \\
\hline
\end{tabular}


Table 1. (Continued).

\begin{tabular}{|c|c|c|c|c|c|c|c|c|c|c|c|c|}
\hline \multirow[b]{2}{*}{ ID \# } & \multirow{2}{*}{$\begin{array}{c}\text { Age } \\
\text { Type } \\
\end{array}$} & \multirow[b]{2}{*}{ Gender } & \multirow{2}{*}{$\begin{array}{c}\text { Count } \\
\text { Date }\end{array}$} & \multicolumn{4}{|c|}{${ }^{40} \mathrm{~K}(\mathrm{kBq})$} & \multicolumn{4}{|c|}{${ }^{137} \mathrm{Cs}(\mathrm{kBq})$} & \multirow{2}{*}{$\begin{array}{c}\text { Method } \\
\text { Code }\end{array}$} \\
\hline & & & & Value & Upper & Lower & MDA & Value & Upper & Lower & MDA & \\
\hline EN00011 & Adult & Male & $6 / 28 / 2001$ & 4.5 & 4.8 & 4.2 & 0.8 & 0.20 & 0.22 & 0.19 & 0.10 & NaI_WBC \\
\hline EN00011 & Adult & Male & $9 / 5 / 2001$ & 4.5 & 4.8 & 4.2 & 0.8 & 0.20 & 0.22 & 0.18 & 0.095 & NaI_WBC \\
\hline EN00011 & Adult & Male & $10 / 3 / 2001$ & 4.3 & 4.6 & 4.1 & 0.7 & 0.15 & 0.16 & 0.14 & 0.099 & NaI_WBC \\
\hline EN00011 & Adult & Male & $11 / 6 / 2001$ & 3.9 & 4.2 & 3.7 & 0.8 & 0.16 & 0.18 & 0.15 & 0.091 & Nal_WBC \\
\hline EN0001 & Adult & Male & $12 / 6 / 2001$ & 3.5 & 3.7 & 3.3 & 0.8 & 0.19 & 0.21 & 0.18 & 0.075 & NaI_WBC \\
\hline EN00012 & Adult & Male & $5 / 21 / 2001$ & 3.1 & 3.3 & 2.9 & 0.7 & 0.063 & 0.073 & 0.053 & 0.081 & Nal_WBC \\
\hline EN00012 & Adult & Male & $6 / 28 / 2001$ & 4.2 & 4.5 & 3.9 & 0.8 & 0.062 & 0.072 & 0.052 & 0.098 & NaI_WBC \\
\hline EN00012 & Adult & Male & $10 / 5 / 2001$ & 4.8 & 5.1 & 4.5 & 0.7 & 0.12 & 0.13 & 0.11 & 0.077 & Nal_WBC \\
\hline EN00012 & Adult & Male & $11 / 5 / 2001$ & 3.6 & 3.8 & 3.3 & 0.8 & 0.00 & 0.00 & 0.00 & 0.063 & NaI_WBC \\
\hline EN00012 & Adult & Male & $12 / 5 / 2001$ & 3.8 & 4.0 & 3.5 & 0.7 & 0.00 & 0.00 & 0.00 & 0.061 & NaI_WBC \\
\hline EN00013 & Adult & Male & $5 / 21 / 2001$ & 3.8 & 4.1 & 3.6 & 0.6 & 0.00 & 0.00 & 0.00 & 0.062 & NaI_WBC \\
\hline EN00013 & Adult & Male & $6 / 28 / 2001$ & 4.8 & 5.1 & 4.5 & 0.8 & 0.00 & 0.00 & 0.00 & 0.064 & Nal_WBC \\
\hline EN00013 & Adult & Male & $9 / 5 / 2001$ & 4.7 & 4.9 & 4.4 & 0.8 & 0.00 & 0.00 & 0.00 & 0.060 & NaI_WBC \\
\hline EN00013 & Adult & Male & $10 / 4 / 2001$ & 4.6 & 4.9 & 4.4 & 0.7 & 0.00 & 0.00 & 0.00 & 0.060 & NaI_WBC \\
\hline EN00013 & Adult & Male & $11 / 6 / 2001$ & 4.1 & 4.4 & 3.8 & 0.8 & 0.00 & 0.00 & 0.00 & 0.061 & NaI_WBC \\
\hline EN00013 & Adult & Male & $12 / 14 / 2001$ & 4.3 & 4.5 & 4.0 & 0.7 & 0.00 & 0.00 & 0.00 & 0.060 & Nal_WBC \\
\hline EN00014 & Adult & Male & $5 / 21 / 2001$ & 3.5 & 3.7 & 3.2 & 0.7 & 0.00 & 0.00 & 0.00 & 0.065 & NaI_WBC \\
\hline EN00015 & Adult & Male & $5 / 21 / 2001$ & 3.0 & 3.3 & 2.8 & 0.7 & 0.091 & 0.10 & 0.079 & 0.084 & NaI_WBC \\
\hline EN00015 & Adult & Male & $9 / 4 / 2001$ & 3.7 & 4.0 & 3.5 & 0.8 & 0.13 & 0.14 & 0.11 & 0.076 & NaI_WBC \\
\hline EN00015 & Adult & Male & $10 / 4 / 2001$ & 4.3 & 4.5 & 4.0 & 0.8 & 0.095 & 0.11 & 0.083 & 0.087 & NaI_WBC \\
\hline EN00015 & Adult & Male & $11 / 5 / 2001$ & 3.4 & 3.6 & 3.2 & 0.8 & 0.11 & 0.12 & 0.097 & 0.074 & Nal_WBC \\
\hline EN00016 & Adult & Male & $5 / 21 / 2001$ & 3.9 & 4.2 & 3.7 & 0.7 & 0.11 & 0.12 & 0.093 & 0.088 & NaI_WBC \\
\hline EN00016 & Adult & Male & $8 / 8 / 2001$ & 4.2 & 4.4 & 3.9 & 0.7 & 0.089 & 0.10 & 0.077 & 0.074 & Nal_WBC \\
\hline EN00016 & Adult & Male & $12 / 19 / 2001$ & 4.7 & 5.0 & 4.4 & 0.8 & 0.12 & 0.13 & 0.11 & 0.076 & NaI_WBC \\
\hline EN00017 & Adult & Male & $5 / 21 / 2001$ & 4.4 & 4.7 & 4.1 & 0.7 & 0.00 & 0.00 & 0.00 & 0.060 & Nal_WBC \\
\hline EN00018 & Adult & Male & $7 / 10 / 2001$ & 4.9 & 5.2 & 4.6 & 0.7 & 0.13 & 0.14 & 0.12 & 0.085 & Nal_WBC \\
\hline EN00018 & Adult & Male & $9 / 5 / 2001$ & 4.9 & 5.2 & 4.6 & 0.7 & 0.21 & 0.22 & 0.19 & 0.095 & NaI_WBC \\
\hline EN00018 & Adult & Male & $10 / 3 / 2001$ & 4.5 & 4.7 & 4.2 & 0.8 & 0.19 & 0.21 & 0.17 & 0.098 & NaI_WBC \\
\hline EN00018 & Adult & Male & $11 / 6 / 2001$ & 4.6 & 4.9 & 4.3 & 0.7 & 0.14 & 0.16 & 0.13 & 0.086 & NaI_WBC \\
\hline EN00018 & Adult & Male & $12 / 6 / 2001$ & 4.0 & 4.3 & 3.8 & 0.8 & 0.13 & 0.15 & 0.12 & 0.086 & Nal_WBC \\
\hline EN00019 & Adult & Male & $5 / 22 / 2001$ & 3.5 & 3.8 & 3.3 & 0.7 & 0.12 & 0.13 & 0.11 & 0.086 & Nal_WBC \\
\hline EN00019 & Adult & Male & $6 / 28 / 2001$ & 4.8 & 5.1 & 4.5 & 0.8 & 0.17 & 0.19 & 0.16 & 0.089 & Nal_WBC \\
\hline EN00019 & Adult & Male & $9 / 4 / 2001$ & 3.9 & 4.2 & 3.7 & 0.8 & 0.18 & 0.20 & 0.17 & 0.087 & NaI_WBC \\
\hline EN00019 & Adult & Male & $10 / 3 / 2001$ & 4.3 & 4.6 & 4.0 & 0.8 & 0.25 & 0.27 & 0.23 & 0.10 & NaI_WBC \\
\hline EN00019 & Adult & Male & $11 / 5 / 2001$ & 4.0 & 4.3 & 3.8 & 0.7 & 0.18 & 0.19 & 0.16 & 0.090 & NaI_WBC \\
\hline EN00019 & Adult & Male & $12 / 5 / 2001$ & 3.7 & 3.9 & 3.4 & 0.7 & 0.11 & 0.12 & 0.094 & 0.086 & Nal_WBC \\
\hline EN00020 & Adult & Male & $5 / 22 / 2001$ & 3.6 & 3.8 & 3.3 & 0.7 & 0.14 & 0.15 & 0.12 & 0.088 & NaI_WBC \\
\hline EN00020 & Adult & Male & 9/5/200] & 4.5 & 4.8 & 4.3 & 0.8 & 0.18 & 0.19 & 0.16 & 0.089 & NaI_WBC \\
\hline EN00020 & Adult & Male & $10 / 3 / 2001$ & 4.5 & 4.7 & 4.2 & 0.7 & 0.21 & 0.22 & 0.19 & 0.10 & NaI_WBC \\
\hline EN00020 & Adult & Male & $11 / 5 / 2001$ & 4.2 & 4.4 & 3.9 & 0.8 & 0.22 & 0.23 & 0.20 & 0.10 & Nal_WBC \\
\hline EN00020 & Adult & Male & $12 / 6 / 2001$ & 4.0 & 4.2 & 3.7 & 0.8 & 0.22 & 0.24 & 0.20 & 0.10 & Nal_WBC \\
\hline EN00021 & Adult & Male & $5 / 22 / 2001$ & 4.4 & 4.7 & 4.1 & 0.7 & 0.21 & 0.23 & 0.20 & 0.093 & NaI_WBC \\
\hline
\end{tabular}


Table 1. (Continued).

\begin{tabular}{|c|c|c|c|c|c|c|c|c|c|c|c|c|}
\hline \multirow[b]{2}{*}{ ID \# } & \multirow{2}{*}{$\begin{array}{l}\text { Age } \\
\text { Type }\end{array}$} & \multirow[b]{2}{*}{ Gender } & \multirow{2}{*}{$\begin{array}{l}\text { Count } \\
\text { Date }\end{array}$} & \multicolumn{4}{|c|}{${ }^{40} \mathrm{~K}(\mathbf{k B q})$} & \multicolumn{4}{|c|}{${ }^{137} \mathrm{Cs}(\mathbf{k B q})$} & \multirow{2}{*}{$\begin{array}{c}\text { Method } \\
\text { Code }\end{array}$} \\
\hline & & & & Value & Upper & Lower & MDA & Value & Upper & Lower & MDA & \\
\hline \multicolumn{2}{|c|}{ EN00021 Adult } & Male & $9 / 5 / 2001$ & 4.9 & 5.1 & 4.6 & 0.8 & 0.15 & 0.17 & 0.14 & 0.093 & NaI_WBC \\
\hline \multicolumn{2}{|c|}{ EN00021 Adult } & Male & $10 / 3 / 2001$ & 4.9 & 5.2 & 4.6 & 0.8 & 0.17 & 0.19 & 0.16 & 0.10 & NaI_WBC \\
\hline \multicolumn{2}{|c|}{ EN00021 Adult } & Male & $11 / 5 / 2001$ & 4.2 & 4.4 & 3.9 & 0.8 & 0.092 & 0.10 & 0.081 & 0.086 & NaI_WBC \\
\hline \multicolumn{2}{|c|}{ EN00021 Adult } & Male & $12 / 5 / 2001$ & 4.5 & 4.7 & 4.2 & 0.7 & 0.11 & 0.13 & 0.10 & 0.087 & NaI_WBC \\
\hline \multicolumn{2}{|c|}{ EN00022 Adult } & Male & $5 / 22 / 2001$ & 3.9 & 4.1 & 3.6 & 0.6 & 0.15 & 0.17 & 0.14 & 0.089 & NaI_WBC \\
\hline \multicolumn{2}{|c|}{ EN00022 Adult } & Male & $6 / 29 / 2001$ & 4.2 & 4.5 & 4.0 & 0.8 & 0.14 & 0.15 & 0.12 & 0.083 & NaI_WBC \\
\hline \multicolumn{2}{|c|}{ EN00022 Adult } & Male & $9 / 5 / 2001$ & 4.5 & 4.8 & 4.3 & 0.8 & 0.18 & 0.20 & 0.17 & 0.10 & NaI_WBC \\
\hline \multicolumn{2}{|c|}{ EN00022 Adult } & Male & $10 / 3 / 2001$ & 4.8 & 5.1 & 4.5 & 0.8 & 0.13 & 0.15 & 0.12 & 0.091 & NaI_WBC \\
\hline \multicolumn{2}{|c|}{ EN00022 Adult } & Male & $11 / 7 / 2001$ & 4.4 & 4.6 & 4.1 & 0.8 & 0.12 & 0.14 & 0.11 & 0.086 & Nal_WBC \\
\hline \multicolumn{2}{|c|}{ EN00022 Adult } & Male & $12 / 12 / 2001$ & 4.6 & 4.9 & 4.3 & 0.8 & 0.11 & 0.12 & 0.098 & 0.087 & Nal_WBC \\
\hline \multicolumn{2}{|c|}{ EN00023 Teenager } & Male & $5 / 22 / 2001$ & 3.6 & 3.8 & 3.4 & 0.6 & 0.18 & 0.20 & 0.17 & 0.090 & Nal_WBC \\
\hline \multicolumn{2}{|c|}{ EN00023 Adult } & Male & $9 / 5 / 2001$ & 4.6 & 4.9 & 4.4 & 0.8 & 0.11 & 0.12 & 0.095 & 0.087 & Nal_WBC \\
\hline \multicolumn{2}{|c|}{ EN00023 Adult } & Male & $10 / 4 / 2001$ & 4.6 & 4.9 & 4.4 & 0.8 & 0.075 & 0.086 & 0.064 & 0.085 & Nal_WBC \\
\hline \multicolumn{2}{|c|}{ EN00023 Adult } & Male & $11 / 5 / 2001$ & 4.2 & 4.5 & 3.9 & 0.7 & 0.077 & 0.089 & 0.065 & 0.098 & Nal_WBC \\
\hline EN00023 & Adult & Male & $12 / 12 / 2001$ & 4.5 & 4.7 & 4.2 & 0.7 & 0.11 & 0.13 & 0.10 & 0.089 & Nal_WBC \\
\hline EN0002 & Adult & Male & $5 / 22 / 2001$ & 3.7 & 4.0 & 3.5 & 0.7 & 0.43 & 0.45 & 0.40 & 0.10 & Nal_WBC \\
\hline EN00024 & Adult & Male & $9 / 5 / 2001$ & 4.5 & 4.8 & 4.2 & 0.8 & 0.34 & 0.36 & 0.31 & 0.10 & NaI_WBC \\
\hline EN0002 & Adult & Male & $10 / 4 / 2001$ & 4.7 & 4.9 & 4.4 & 0.8 & 0.28 & 0.30 & 0.26 & 0.097 & NaI_WBC \\
\hline EN0002 & Adult & Male & $11 / 5 / 2001$ & 4.0 & 4.2 & 3.7 & 0.8 & 0.24 & 0.25 & 0.22 & 0.10 & NaI_WBC \\
\hline EN00025 & Adult & Male & $5 / 22 / 2001$ & 3.7 & 3.9 & 3.4 & 0.7 & 0.14 & 0.16 & 0.13 & 0.087 & Nal_WBC \\
\hline EN00025 & Adult & Male & $7 / 9 / 2001$ & 4.9 & 5.2 & 4.6 & 0.8 & 0.14 & 0.16 & 0.13 & 0.079 & NaI_WBC \\
\hline EN00025 & Adult & Male & $9 / 5 / 2001$ & 4.6 & 4.9 & 4.3 & 0.8 & 0.14 & 0.15 & 0.13 & 0.094 & NaI_WBC \\
\hline EN00025 & Adult & Male & $10 / 4 / 2001$ & 4.9 & 5.2 & 4.6 & 0.7 & 0.14 & 0.16 & 0.13 & 0.088 & NaI_WBC \\
\hline EN00025 & Adult & Male & $11 / 6 / 2001$ & 4.1 & 4.4 & 3.8 & 0.8 & 0.10 & 0.11 & 0.089 & 0.085 & Nal_WBC \\
\hline EN00026 & Adult & Male & $5 / 22 / 2001$ & 4.0 & 4.2 & 3.7 & 0.6 & 0.083 & 0.094 & 0.072 & 0.098 & Nal_WBC \\
\hline EN00026 & Adult & Male & $7 / 2 / 2001$ & 4.8 & 5.1 & 4.5 & 0.8 & 0.00 & 0.00 & 0.00 & 0.069 & Nal_WBC \\
\hline EN00027 & Adult & Male & $5 / 22 / 2001$ & 3.5 & 3.8 & 3.3 & 0.6 & 0.049 & 0.058 & 0.040 & 0.092 & Nal_WBC \\
\hline EN00027 & Adult & Male & $6 / 29 / 2001$ & 4.3 & 4.6 & 4.0 & 0.8 & 0.00 & 0.00 & 0.00 & 0.064 & NaI_WBC \\
\hline EN0002? & Adult & Male & $9 / 5 / 2001$ & 4.1 & 4.4 & 3.9 & 0.8 & 0.060 & 0.070 & 0.049 & 0.083 & NaI_WBC \\
\hline EN0002? & Adult & Male & $10 / 4 / 2001$ & 4.3 & 4.6 & 4.0 & 0.7 & 0.045 & 0.055 & 0.035 & 0.089 & NaI_WBC \\
\hline EN00027 & Adult & Male & $11 / 6 / 2001$ & 4.6 & 4.9 & 4.3 & 0.7 & 0.00 & 0.00 & 0.00 & 0.064 & NaI_WBC \\
\hline EN00028 & Adult & Male & $5 / 22 / 2001$ & 4.2 & 4.4 & 3.9 & 0.6 & 0.16 & 0.18 & 0.15 & 0.097 & NaI_WBC \\
\hline EN00028 & Adult & Male & $6 / 29 / 2001$ & 4.5 & 4.8 & 4.2 & 0.8 & 0.10 & 0.11 & 0.09 & 0.091 & Nal_WBC \\
\hline EN00028 & Adult & Male & $9 / 5 / 2001$ & 4.6 & 4.9 & 4.4 & 0.8 & 0.11 & 0.13 & 0.10 & 0.097 & NaI_WBC \\
\hline EN00028 & Adult & Male & $10 / 4 / 2001$ & 4.7 & 4.9 & 4.4 & 0.8 & 0.073 & 0.083 & 0.062 & 0.087 & NaI_WBC \\
\hline EN00028 & Adult & Male & $11 / 6 / 2001$ & 4.3 & 4.5 & 4.0 & 0.8 & 0.12 & 0.13 & 0.10 & 0.086 & NaI_WBC \\
\hline EN00029 & Adult & Male & $5 / 22 / 2001$ & 3.7 & 4.0 & 3.5 & 0.7 & 0.10 & 0.12 & 0.092 & 0.084 & NaI_WBC \\
\hline EN0002S & Adult & Male & $7 / 2 / 2001$ & 4.5 & 4.8 & 4.2 & 0.8 & 0.099 & 0.11 & 0.087 & 0.086 & Nal_WBC \\
\hline EN00029 & Adult & Male & $9 / 5 / 2001$ & 4.7 & 5.0 & 4.4 & 0.8 & 0.17 & 0.19 & 0.16 & 0.087 & NaI_WBC \\
\hline EN0002S & Adult & Male & $10 / 4 / 2001$ & 4.7 & 5.0 & 4.5 & 0.8 & 0.12 & 0.14 & 0.11 & 0.090 & NaI_WBC \\
\hline EN0002S & Adult & Male & $11 / 6 / 2001$ & 4.3 & 4.5 & 4.0 & 0.8 & 0.13 & 0.15 & 0.12 & 0.092 & NaI_WBC \\
\hline EN0002S & Adult & Male & $12 / 12 / 2001$ & 4.7 & 4.9 & 4.4 & 0.7 & 0.12 & 0.13 & 0.10 & 0.086 & NaI_WBC \\
\hline
\end{tabular}


Table 1. (Continued).

\begin{tabular}{|c|c|c|c|c|c|c|c|c|c|c|c|c|}
\hline \multirow[b]{2}{*}{ ID \# } & \multirow{2}{*}{$\begin{array}{l}\text { Age } \\
\text { Type }\end{array}$} & \multirow[b]{2}{*}{ Gender } & \multirow{2}{*}{$\begin{array}{l}\text { Count } \\
\text { Date }\end{array}$} & \multicolumn{4}{|c|}{${ }^{40} \mathrm{~K}(\mathrm{kBq})$} & \multicolumn{4}{|c|}{${ }^{137} \mathrm{Cs}(\mathrm{kBq})$} & \multirow{2}{*}{$\begin{array}{l}\text { Method } \\
\text { Code }\end{array}$} \\
\hline & & & & Value & Upper & Lower & MDA & Value & Upper & Lower & MDA & \\
\hline \multicolumn{2}{|c|}{ EN00030 Adult } & Male & $5 / 22 / 2001$ & 3.3 & 3.6 & 3.1 & 0.6 & 0.076 & 0.087 & 0.065 & 0.091 & Nal_WBC \\
\hline \multicolumn{2}{|c|}{ EN00031 Adult } & Male & $5 / 22 / 2001$ & 3.2 & 3.5 & 3.0 & 0.6 & 0.070 & 0.081 & 0.060 & 0.087 & Nal_WBC \\
\hline \multicolumn{2}{|c|}{ EN00032 Adult } & Male & $5 / 23 / 2001$ & 3.7 & 3.9 & 3.4 & 0.7 & 0.14 & 0.16 & 0.13 & 0.094 & Nal_WBC \\
\hline \multicolumn{2}{|c|}{ EN00032 Adult } & Male & $6 / 29 / 2001$ & 4.7 & 5.0 & 4.4 & 0.8 & 0.15 & 0.16 & 0.14 & 0.090 & NaI_WBC \\
\hline \multicolumn{2}{|c|}{ EN00032 Adult } & Male & $9 / 6 / 2001$ & 4.5 & 4.8 & 4.2 & 0.7 & 0.11 & 0.12 & 0.098 & 0.086 & Nal_WBC \\
\hline \multicolumn{2}{|c|}{ EN00032 Adult } & Male & $10 / 4 / 2001$ & 4.3 & 4.6 & 4.1 & 0.8 & 0.15 & 0.17 & 0.14 & 0.094 & Nal_WBC \\
\hline \multicolumn{2}{|c|}{ EN00032 Adult } & Male & $11 / 6 / 2001$ & 4.1 & 4.3 & 3.8 & 0.8 & 0.094 & 0.11 & 0.082 & 0.080 & NaI_WBC \\
\hline \multicolumn{2}{|c|}{ EN00032 Adult } & Male & $12 / 13 / 2001$ & 4.4 & 4.7 & 4.1 & 0.8 & 0.12 & 0.13 & 0.10 & 0.088 & NaI_WBC \\
\hline \multicolumn{2}{|c|}{ EN00033 Adult } & Male & $5 / 23 / 2001$ & 3.5 & 3.7 & 3.3 & 0.7 & 0.086 & 0.097 & 0.075 & 0.088 & NaI_WBC \\
\hline \multicolumn{2}{|c|}{ EN00033 Adult } & Male & $6 / 29 / 2001$ & 3.6 & 3.9 & 3.4 & 0.8 & 0.088 & 0.10 & 0.077 & 0.084 & NaI_WBC \\
\hline \multicolumn{2}{|c|}{ EN00033 Adult } & Male & $10 / 9 / 2001$ & 4.1 & 4.3 & 3.8 & 0.7 & 0.13 & 0.15 & 0.12 & 0.090 & NaI_WBC \\
\hline \multicolumn{2}{|c|}{ EN00033 Adult } & Male & $11 / 6 / 2001$ & 3.5 & 3.7 & 3.2 & 0.8 & 0.14 & 0.15 & 0.12 & 0.084 & NaI_WBC \\
\hline \multicolumn{2}{|c|}{ EN00034 Adult } & Male & $5 / 23 / 2001$ & 3.5 & 3.7 & 3.2 & 0.6 & 0.20 & 0.21 & 0.18 & 0.093 & NaI_WBC \\
\hline \multicolumn{2}{|c|}{ EN00034 Adult } & Male & $9 / 6 / 2001$ & 4.3 & 4.6 & 4.1 & 0.8 & 0.22 & 0.24 & 0.21 & 0.10 & NaI_WBC \\
\hline EN0003 & Adult & Male & $10 / 5 / 2001$ & 4.3 & 4.6 & 4.0 & 0.8 & 0.24 & 0.26 & 0.22 & 0.10 & NaI_WBC \\
\hline EN0003 & Adult & Male & $11 / 7 / 2001$ & 3.9 & 4.2 & 3.7 & 0.8 & 0.20 & 0.21 & 0.18 & 0.092 & NaI_WBC \\
\hline EN0003 & Adult & Male & $12 / 6 / 2001$ & 3.7 & 3.9 & 3.5 & 0.8 & 0.17 & 0.18 & 0.15 & 0.10 & NaI_WBC \\
\hline EN0003 & Adult & Male & $5 / 23 / 2001$ & 3.5 & 3.8 & 3.3 & 0.7 & 0.14 & 0.16 & 0.13 & 0.070 & NaI_WBC \\
\hline EN0003: & Adult & Male & $6 / 29 / 2001$ & 4.5 & 4.8 & 4.2 & 0.8 & 0.098 & 0.11 & 0.085 & 0.088 & NaI_WBC \\
\hline EN0003: & Adult & Male & $10 / 5 / 2001$ & 4.5 & 4.8 & 4.3 & 0.8 & 0.093 & 0.11 & 0.081 & 0.085 & Nal_WBC \\
\hline EN0003: & Adult & Male & $11 / 7 / 2001$ & 3.6 & 3.8 & 3.3 & 0.8 & 0.061 & 0.072 & 0.050 & 0.093 & NaI_WBC \\
\hline EN0003. & Adult & Male & $12 / 13 / 2001$ & 4.1 & 4.4 & 3.9 & 0.8 & 0.11 & 0.12 & 0.10 & 0.075 & Nal_WBC \\
\hline EN0003e & Adult & Male & $5 / 23 / 2001$ & 3.8 & 4.1 & 3.6 & 0.7 & 0.24 & 0.26 & 0.22 & 0.092 & NaI_WBC \\
\hline EN0003? & Adult & Male & $5 / 23 / 2001$ & 4.1 & 4.4 & 3.9 & 0.7 & 0.13 & 0.14 & 0.11 & 0.092 & Nal_WBC \\
\hline EN0003\& & Adult & Male & $5 / 24 / 2001$ & 4.1 & 4.3 & 3.8 & 0.8 & 0.25 & 0.27 & 0.23 & 0.11 & Nal_WBC \\
\hline EN00038 & Adult & Male & $6 / 29 / 2001$ & 4.2 & 4.5 & 4.0 & 0.8 & 0.27 & 0.29 & 0.25 & 0.096 & Nal_WBC \\
\hline EN0003 & Adult & Male & $9 / 6 / 2001$ & 4.6 & 4.8 & 4.3 & 0.8 & 0.28 & 0.30 & 0.26 & 0.10 & NaI_WBC \\
\hline EN00038 & Adult & Male & $10 / 5 / 2001$ & 4.7 & 5.0 & 4.4 & 0.8 & 0.22 & 0.23 & 0.20 & 0.094 & NaI_WBC \\
\hline EN00038 & Adult & Male & $11 / 6 / 2001$ & 4.2 & 4.5 & 3.9 & 0.8 & 0.14 & 0.15 & 0.12 & 0.087 & NaI_WBC \\
\hline EN0003 & Adult & Male & $12 / 14 / 2001$ & 5.1 & 5.4 & 4.8 & 0.7 & 0.17 & 0.19 & 0.16 & 0.093 & NaI_WBC \\
\hline EN0003 & Adult & Male & $5 / 24 / 2001$ & 4.4 & 4.7 & 4.1 & 0.8 & 0.31 & 0.33 & 0.29 & 0.079 & NaI_WBC \\
\hline EN0003 & Adult & Male & $7 / 10 / 2001$ & 4.5 & 4.8 & 4.2 & 0.8 & 0.20 & 0.22 & 0.19 & 0.10 & NaI_WBC \\
\hline EN0003 & Adult & Male & $9 / 6 / 2001$ & 4.2 & 4.5 & 4.0 & 0.8 & 0.27 & 0.29 & 0.25 & 0.10 & NaI_WBC \\
\hline EN0003 & Adult & Male & $10 / 5 / 2001$ & 4.8 & 5.1 & 4.5 & 0.8 & 0.29 & 0.31 & 0.27 & 0.10 & NaI_WBC \\
\hline EN0003 & Adult & Male & $11 / 6 / 2001$ & 4.1 & 4.4 & 3.9 & 0.8 & 0.23 & 0.25 & 0.21 & 0.10 & Nal_WBC \\
\hline EN0003S & Adult & Male & $12 / 5 / 2001$ & 4.3 & 4.5 & 4.0 & 0.8 & 0.23 & 0.25 & 0.21 & 0.095 & NaI_WBC \\
\hline EN0004C & Adult & Male & $5 / 24 / 2001$ & 4.4 & 4.7 & 4.1 & 0.8 & 0.032 & 0.042 & 0.023 & 0.086 & NaI_WBC \\
\hline EN0004 & Adult & Male & $5 / 24 / 2001$ & 4.3 & 4.6 & 4.1 & 0.8 & 0.094 & 0.11 & 0.082 & 0.088 & NaI_WBC \\
\hline EN00042 & Adult & Male & $5 / 24 / 2001$ & 4.6 & 4.9 & 4.3 & 0.8 & 0.19 & 0.21 & 0.18 & 0.098 & Nal_WBC \\
\hline EN00042 & Adult & Male & $9 / 6 / 2001$ & 5.1 & 5.4 & 4.8 & 0.8 & 0.12 & 0.14 & 0.11 & 0.095 & NaI_WBC \\
\hline EN00042 & Adult & Male & $10 / 5 / 2001$ & 5.3 & 5.6 & 5.0 & 0.8 & 0.11 & 0.12 & 0.098 & 0.088 & $\mathrm{NaI} \mathrm{WBC}$ \\
\hline EN00042 & Adult & Male & $11 / 7 / 2001$ & 4.7 & 5.0 & 4.4 & 0.8 & 0.20 & 0.22 & 0.19 & 0.077 & NaI_WBC \\
\hline
\end{tabular}


Table 1. (Continued).

\begin{tabular}{|c|c|c|c|c|c|c|c|c|c|c|c|}
\hline \multirow[b]{2}{*}{ ID \# } & \multirow[b]{2}{*}{ Gender } & \multirow{2}{*}{$\begin{array}{l}\text { Count } \\
\text { Date }\end{array}$} & \multicolumn{4}{|c|}{${ }^{40} \mathrm{~K}(\mathrm{kBq})$} & \multicolumn{4}{|c|}{${ }^{137} \mathrm{Cs}(\mathbf{k B q})$} & \multirow{2}{*}{$\begin{array}{l}\text { Method } \\
\text { Code }\end{array}$} \\
\hline & & & Value & Upper & Lower & MDA & Value & Upper & Lower & MDA & \\
\hline EN00042 Adult & Male & $12 / 13 / 2001$ & 5.3 & 5.6 & 4.9 & 0.8 & 0.16 & 0.18 & 0.15 & 0.090 & NaI_WBC \\
\hline EN00043 Adult & Male & $5 / 24 / 2001$ & 4.6 & 4.9 & 4.3 & 0.8 & 0.092 & 0.10 & 0.080 & 0.093 & NaI_WBC \\
\hline EN00043 Adult & Male & $7 / 11 / 2001$ & 4.8 & 5.1 & 4.5 & 0.8 & 0.050 & 0.061 & 0.040 & 0.088 & NaI_WBC \\
\hline EN00043 Adult & Male & $9 / 6 / 2001$ & 4.5 & 4.8 & 4.2 & 0.8 & 0.046 & 0.054 & 0.037 & 0.087 & NaI_WBC \\
\hline EN00043 Adult & Male & $10 / 12 / 2001$ & 4.3 & 4.5 & 4.0 & 0.7 & 0.077 & 0.088 & 0.066 & 0.082 & Nal_WBC \\
\hline EN00043 Adult & Male & $11 / 6 / 2001$ & 4.3 & 4.6 & 4.0 & 0.7 & 0.034 & 0.040 & 0.027 & 0.086 & NaI_WBC \\
\hline EN00043 Adult & Male & $12 / 6 / 2001$ & 4.3 & 4.6 & 4.0 & 0.8 & 0.077 & 0.089 & 0.066 & 0.085 & NaI_WBC \\
\hline EN00044 Adult & Male & $5 / 25 / 2001$ & 4.3 & 4.5 & 4.0 & 0.8 & 0.27 & 0.29 & 0.26 & 0.10 & NaI_WBC \\
\hline EN00045 Adult & Male & $5 / 25 / 2001$ & 4.1 & 4.4 & 3.8 & 1.1 & 0.34 & 0.36 & 0.31 & 0.15 & NaI_WBC \\
\hline EN00046 Adult & Male & $5 / 25 / 2001$ & 4.4 & 4.7 & 4.1 & 0.8 & 0.23 & 0.25 & 0.21 & 0.092 & NaI_WBC \\
\hline EN00047 Adult & Male & $5 / 25 / 2001$ & 4.3 & 4.6 & 4.0 & 0.8 & 0.17 & 0.18 & 0.15 & 0.096 & Nal_WBC \\
\hline EN00047 Adult & Male & $6 / 29 / 2001$ & 4.2 & 4.5 & 3.9 & 0.8 & 0.13 & 0.15 & 0.12 & 0.093 & NaI_WBC \\
\hline EN00047 Adult & Male & $9 / 6 / 2001$ & 4.1 & 4.3 & 3.8 & 0.7 & 0.17 & 0.18 & 0.15 & 0.088 & NaI_WBC \\
\hline EN00047 Adult & Male & $10 / 5 / 2001$ & 4.5 & 4.8 & 4.2 & 0.8 & 0.17 & 0.19 & 0.16 & 0.095 & NaI_WBC \\
\hline EN00047 Adult & Male & $11 / 7 / 2001$ & 3.6 & 3.9 & 3.4 & 0.8 & 0.14 & 0.15 & 0.12 & 0.089 & NaI_WBC \\
\hline EN00048 Adult & Male & $5 / 25 / 2001$ & 4.0 & 4.2 & 3.7 & 0.8 & 0.042 & 0.052 & 0.033 & 0.084 & NaI_WBC \\
\hline EN00049 Adult & Male & $5 / 25 / 2001$ & 4.0 & 4.2 & 3.7 & 0.8 & 0.00 & 0.00 & 0.00 & 0.062 & Nal_WBC \\
\hline EN00050 Adult & Male & $5 / 25 / 2001$ & 4.5 & 4.8 & 4.2 & 0.8 & 0.094 & 0.11 & 0.082 & 0.087 & NaI_WBC \\
\hline EN00051 Adult & Male & $5 / 25 / 2001$ & 3.6 & 3.8 & 3.3 & 0.8 & 0.16 & 0.17 & 0.14 & 0.076 & NaI_WBC \\
\hline EN00052 Teenager & Male & $5 / 25 / 2001$ & 3.9 & 4.2 & 3.7 & 0.8 & 0.040 & 0.054 & 0.025 & 0.10 & NaI_WBC \\
\hline EN00053 Adult & Male & $5 / 25 / 2001$ & 4.3 & 4.5 & 4.0 & 0.7 & 0.17 & 0.18 & 0.15 & 0.077 & NaI_WBC \\
\hline EN00054 Adult & Male & $5 / 25 / 2001$ & 4.4 & 4.7 & 4.1 & 0.9 & 0.19 & 0.21 & 0.17 & 0.12 & Nal_WBC \\
\hline EN00055 Adult & Male & $5 / 25 / 2001$ & 4.3 & 4.6 & 4.0 & 0.8 & 0.16 & 0.18 & 0.15 & 0.10 & Nal_WBC \\
\hline EN00056 Adult & Male & $5 / 28 / 2001$ & 2.6 & 2.8 & 2.4 & 0.8 & 0.00 & 0.00 & 0.00 & 0.064 & Nal_WBC \\
\hline EN00057 Adult & Male & $5 / 28 / 2001$ & 4.3 & 4.6 & 4.0 & 0.8 & 0.26 & 0.28 & 0.24 & 0.10 & NaI_WBC \\
\hline EN00058 Adult & Male & $5 / 28 / 2001$ & 4.4 & 4.7 & 4.1 & 0.8 & 0.076 & 0.087 & 0.065 & 0.087 & NaI_WBC \\
\hline EN00059 Adult & Male & $5 / 28 / 2001$ & 3.8 & 4.0 & 3.5 & 0.8 & 0.23 & 0.24 & 0.21 & 0.10 & NaI_WBC \\
\hline EN00060 Adult & Male & $5 / 28 / 2001$ & 4.1 & 4.4 & 3.8 & 0.8 & 0.12 & 0.13 & 0.10 & 0.093 & NaI_WBC \\
\hline EN00061 Adult & Female & $5 / 28 / 2001$ & 2.4 & 2.6 & 2.2 & 0.8 & 0.00 & 0.00 & 0.00 & 0.064 & NaI WBC \\
\hline EN00062 Adult & Female & $5 / 28 / 2001$ & 2.9 & 3.1 & 2.7 & 0.8 & 0.048 & 0.057 & 0.039 & 0.095 & NaI_WBC \\
\hline EN00063 Teenager & Female & $5 / 28 / 2001$ & 2.3 & 2.5 & 2.2 & 0.8 & 0.00 & 0.00 & 0.00 & 0.061 & NaI_WBC \\
\hline EN00064 Adult & Male & $5 / 28 / 2001$ & 3.5 & 3.8 & 3.3 & 0.8 & 0.15 & 0.16 & 0.13 & 0.074 & NaI_WBC \\
\hline EN00065 Teenager & Male & $5 / 28 / 2001$ & 3.1 & 3.3 & 2.8 & 0.8 & 0.12 & 0.14 & 0.11 & 0.088 & Nal_WBC \\
\hline EN00066 Adult & Female & $5 / 29 / 2001$ & 3.1 & 3.3 & 2.9 & 0.7 & 0.27 & 0.29 & 0.25 & 0.10 & Nal_WBC \\
\hline EN00067 Adult & Male & $5 / 29 / 2001$ & 2.4 & 2.6 & 2.2 & 0.8 & 0.10 & 0.11 & 0.088 & 0.097 & Nal_WBC \\
\hline EN00068 Adult & Male & $5 / 29 / 2001$ & 4.4 & 4.7 & 4.1 & 0.8 & 0.14 & 0.16 & 0.13 & 0.094 & Nal_WBC \\
\hline EN00069 Adult & Male & $5 / 30 / 2001$ & 4.0 & 4.2 & 3.7 & 0.8 & 0.21 & 0.23 & 0.19 & 0.096 & NaI_WBC \\
\hline EN00070Teenager & Male & $5 / 30 / 2001$ & 4.1 & 4.3 & 3.8 & 0.8 & 0.20 & 0.21 & 0.18 & 0.074 & NaI_WBC \\
\hline EN00071 Adult & Male & $5 / 30 / 2001$ & 4.9 & 5.2 & 4.6 & 0.8 & 0.19 & 0.20 & 0.17 & 0.078 & NaI_WBC \\
\hline EN00072 Adult & Female & $5 / 30 / 2001$ & 2.8 & 3.0 & 2.6 & 0.7 & 0.081 & 0.092 & 0.070 & 0.087 & NaI_WBC \\
\hline EN00073 Adult & Female & $5 / 30 / 2001$ & 2.5 & 2.7 & 2.3 & 0.8 & 0.086 & 0.097 & 0.076 & 0.072 & Nal_WBC \\
\hline EN00074 Adult & Female & $5 / 30 / 2001$ & 2.9 & 3.2 & 2.7 & 0.8 & 0.13 & 0.15 & 0.12 & 0.091 & NaI WBC \\
\hline
\end{tabular}


Table 1. (Continued).

\begin{tabular}{|c|c|c|c|c|c|c|c|c|c|c|c|}
\hline $\begin{array}{l}\text { Age } \\
\text { Type }\end{array}$ & \multirow[b]{2}{*}{ Gender } & \multirow{2}{*}{$\begin{array}{l}\text { Count } \\
\text { Date }\end{array}$} & \multicolumn{4}{|c|}{${ }^{4^{40}} \mathrm{~K}(\mathbf{k B q})$} & \multicolumn{3}{|c|}{${ }^{137} \mathrm{Cs}(\mathbf{k B q})$} & \multirow[b]{2}{*}{ MDA } & \multirow{2}{*}{$\begin{array}{c}\text { Method } \\
\text { Code }\end{array}$} \\
\hline ID \# & & & Value & Upper & Lower & MDA & Value & Upper & Lower & & \\
\hline EN00075 Teenager & Male & $5 / 30 / 2001$ & 3.3 & 3.5 & 3.1 & 0.8 & 0.063 & 0.074 & 0.052 & 0.091 & NaI_WBC \\
\hline EN00076 Teenager & Male & $5 / 30 / 2001$ & 2.7 & 3.0 & 2.5 & 0.8 & 0.077 & 0.088 & 0.067 & 0.079 & NaI_WBC \\
\hline EN00077 Adult & Female & $5 / 30 / 2001$ & 2.4 & 2.6 & 2.2 & 0.8 & 0.056 & 0.067 & 0.045 & 0.087 & NaI_WBC \\
\hline EN00078 Adult & Female & $5 / 30 / 2001$ & 3.8 & 4.0 & 3.5 & 0.8 & 0.11 & 0.12 & 0.095 & 0.093 & $\mathrm{NaI}$ WBC \\
\hline EN00079 Adult & Female & $5 / 30 / 2001$ & 2.8 & 3.0 & 2.6 & 0.8 & 0.00 & 0.00 & 0.00 & 0.062 & NaI_WBC \\
\hline EN00080 Adult & Male & $5 / 30 / 2001$ & 3.3 & 3.5 & 3.1 & 0.8 & 0.083 & 0.095 & 0.071 & 0.085 & NaI_WBC \\
\hline EN00081 Adult & Male & $5 / 30 / 2001$ & 3.4 & 3.6 & 3.1 & 0.8 & 0.19 & 0.21 & 0.18 & 0.086 & NaI_WBC \\
\hline EN00082 Teenager & Male & $5 / 30 / 2001$ & 3.8 & 4.0 & 3.5 & 0.8 & 0.11 & 0.12 & 0.096 & 0.084 & NaI_WBC \\
\hline EN00083 Teenager & Male & $5 / 30 / 2001$ & 3.9 & 4.1 & 3.6 & 0.7 & 0.11 & 0.12 & 0.098 & 0.10 & NaI_WBC \\
\hline EN00084 Adult & Male & $5 / 30 / 2001$ & 4.6 & 4.9 & 4.3 & 0.8 & 0.12 & 0.13 & 0.11 & 0.095 & NaI_WBC \\
\hline EN00084 Adult & Male & $6 / 29 / 2001$ & 4.5 & 4.8 & 4.2 & 0.8 & 0.13 & 0.15 & 0.12 & 0.089 & NaI_WBC \\
\hline EN00084 Adult & Male & $9 / 6 / 2001$ & 4.7 & 5.0 & 4.4 & 0.8 & & 0.12 & 0.091 & 0.090 & NaI_WBC \\
\hline EN00084 Adult & Male & $10 / 5 / 2001$ & 5.2 & 5.5 & 4.9 & 0.8 & 0.15 & 0.16 & 0.13 & 0.090 & NaI_WBC \\
\hline EN00084 Adult & Male & $11 / 7 / 2001$ & 4.7 & 4.9 & 4.4 & 0.8 & 0.18 & 0.20 & 0.17 & 0.10 & NaI_WBC \\
\hline EN00084 Adult & Male & $12 / 12 / 2001$ & 4.2 & 4.5 & 3.9 & 0.8 & 0.13 & 0.15 & 0.12 & 0.084 & Nal_WBC \\
\hline EN00085 Adult & Male & $5 / 30 / 2001$ & 4.3 & 4.6 & 4.1 & 0.8 & 0.19 & 0.20 & 0.17 & 0.10 & NaI_WBC \\
\hline EN00086 Adult & Male & $5 / 31 / 2001$ & 3.5 & 3.8 & 3.3 & 0.8 & 0.26 & 0.28 & 0.24 & 0.078 & NaI_WBC \\
\hline EN00087 Adult & Male & $5 / 31 / 2001$ & 4.2 & 4.4 & 3.9 & 0.8 & 0.00 & 0.00 & 0.00 & 0.063 & NaI_WBC \\
\hline EN00088 Adult & Male & $5 / 31 / 2001$ & 4.5 & 4.8 & 4.2 & 0.7 & 0.00 & 0.00 & 0.00 & 0.061 & Nal_WBC \\
\hline EN00089 Teenager & Male & $5 / 31 / 2001$ & 4.0 & 4.3 & 3.8 & 0.8 & 0.086 & 0.097 & 0.075 & 0.080 & NaI_WBC \\
\hline EN00090 Adult & Male & $5 / 31 / 2001$ & 3.8 & 4.1 & 3.6 & 0.8 & 0.00 & 0.00 & 0.00 & 0.062 & NaI_WBC \\
\hline EN00091 Adult & Male & $5 / 31 / 2001$ & 3.9 & 4.1 & 3.6 & 0.8 & 0.06 & 0.074 & 0.052 & 0.095 & NaI_WBC \\
\hline EN00092 Adult & Male & $6 / 2 / 2001$ & 4.5 & 4.8 & 4.3 & 0.7 & 0.069 & 0.081 & 0.058 & 0.10 & NaI_WBC \\
\hline EN00093 Adult & Male & $6 / 2 / 2001$ & 3.9 & 4.2 & 3.7 & 0.8 & 0.00 & 0.00 & 0.00 & 0.061 & NaI_WBC \\
\hline EN00094 Adult & Male & $6 / 2 / 2001$ & 4.6 & 4.9 & 4.3 & 0.7 & 0.30 & 0.32 & 0.28 & 0.106 & NaI_WBC \\
\hline EN00095 Adult & Male & $6 / 2 / 2001$ & 4.3 & 4.6 & 4.1 & 0.8 & 0.13 & 0.14 & 0.11 & 0.078 & NaI_WBC \\
\hline EN00096 Adult & Male & $6 / 2 / 2001$ & 4.0 & 4.2 & 3.7 & 0.7 & 0.053 & 0.064 & 0.042 & 0.086 & NaI_WBC \\
\hline EN00097 Adult & Male & $6 / 2 / 2001$ & 4.1 & 4.3 & 3.8 & 0.8 & 0.00 & 0.00 & 0.00 & 0.060 & NaI_WBC \\
\hline EN00098 Adult & Male & $6 / 2 / 2001$ & 4.7 & 4.9 & 4.4 & 0.8 & 0.19 & 0.20 & 0.17 & 0.078 & NaI_WBC \\
\hline EN00099 Adult & Male & $6 / 2 / 2001$ & 5.1 & 5.4 & 4.8 & 0.8 & 0.097 & 0.11 & 0.084 & 0.10 & NaI_WBC \\
\hline EN00100 Adult & Male & $6 / 4 / 2001$ & 3.6 & 3.9 & 3.4 & 0.8 & 0.21 & 0.22 & 0.19 & 0.098 & NaI_WBC \\
\hline EN00101 Adult & Male & $6 / 4 / 2001$ & 5.0 & 5.3 & 4.7 & 0.8 & 0.087 & 0.098 & 0.076 & 0.079 & Nal_WBC \\
\hline EN00102 Adult & Male & $6 / 4 / 2001$ & 4.2 & 4.5 & 3.9 & 0.8 & 0.075 & 0.084 & 0.065 & 0.068 & Nal_WBC \\
\hline EN00103 Adult & Male & $6 / 4 / 2001$ & 4.3 & 4.6 & 4.0 & 0.8 & 0.079 & 0.090 & 0.068 & 0.093 & NaI_WBC \\
\hline EN00104 Adult & Male & $6 / 4 / 2001$ & 4.6 & 4.9 & 4.3 & 0.8 & 0.19 & 0.21 & 0.17 & 0.10 & Nal_WBC \\
\hline EN00105 Adult & Male & $6 / 4 / 2001$ & 4.3 & 4.6 & 4.0 & 0.8 & 0.14 & 0.15 & 0.12 & 0.085 & NaI_WBC \\
\hline EN00106 Adult & Male & $6 / 4 / 2001$ & 3.6 & 3.8 & 3.4 & 0.7 & 0.11 & 0.12 & 0.098 & 0.082 & NaI_WBC \\
\hline EN00107 Adult & Male & $6 / 4 / 2001$ & 4.4 & 4.6 & 4.1 & 0.8 & 0.15 & 0.16 & 0.14 & 0.091 & NaI_WBC \\
\hline EN00108 Adult & Male & $6 / 4 / 2001$ & 4.0 & 4.3 & 3.7 & 0.8 & 0.33 & 0.35 & 0.30 & 0.10 & NaI_WBC \\
\hline EN00109 Adult & Male & $6 / 4 / 2001$ & 4.5 & 4.8 & 4.2 & 0.8 & 0.12 & 0.13 & 0.10 & 0.074 & NaI_WBC \\
\hline EN00110 Adult & Male & $6 / 4 / 2001$ & 3.7 & 3.9 & 3.5 & 0.8 & 0.15 & 0.17 & 0.14 & 0.076 & NaI_WBC \\
\hline EN00111 Adult & Male & $6 / 4 / 2001$ & 4.9 & 5.2 & 4.6 & 0.8 & 0.099 & 0.11 & 0.087 & 0.086 & NaI_WBC \\
\hline
\end{tabular}


Table 1. (Continued).

\begin{tabular}{|c|c|c|c|c|c|c|c|c|c|c|c|}
\hline & \multirow[b]{2}{*}{ Gender } & \multirow{2}{*}{$\begin{array}{l}\text { Count } \\
\text { Date }\end{array}$} & \multicolumn{4}{|c|}{${ }^{40} K(\mathbf{k B q})$} & \multicolumn{4}{|c|}{${ }^{137} \mathrm{Cs}(\mathbf{k B q})$} & \multirow{2}{*}{$\begin{array}{c}\text { Method } \\
\text { Code }\end{array}$} \\
\hline Type & & & Value & Upper & Lower & MDA & Value & Upper & Lower & MDA & \\
\hline EN00112 Teenager & Male & $6 / 6 / 2001$ & 2.7 & 2.9 & 2.5 & 0.8 & 0.00 & 0.00 & 0.00 & 0.061 & NaI WBC \\
\hline EN00113 Teenager & Male & $6 / 6 / 2001$ & 3.1 & 3.3 & 2.9 & 0.7 & 0.00 & 0.00 & 0.00 & 0.059 & NaI_WBC \\
\hline EN00114 Adult & Male & $6 / 6 / 2001$ & 4.1 & 4.3 & 3.8 & 0.8 & 0.46 & 0.49 & 0.44 & 0.10 & NaI_WBC \\
\hline EN00115 Adult & Male & $6 / 6 / 2001$ & 3.5 & 3.8 & 3.3 & 0.8 & 0.055 & 0.066 & 0.044 & 0.080 & NaI_WBC \\
\hline EN00116 Adult & Male & $6 / 6 / 2001$ & 4.2 & 4.4 & 3.9 & 0.8 & 0.75 & 0.79 & 0.71 & 0.11 & NaI_WBC \\
\hline EN00116 Adult & Male & $9 / 14 / 2001$ & 4.7 & 4.9 & 4.4 & 0.8 & 0.69 & 0.73 & 0.66 & 0.11 & NaI_WBC \\
\hline EN00116 Adult & Male & $10 / 5 / 2001$ & 4.9 & 5.2 & 4.6 & 0.7 & 0.65 & 0.69 & 0.61 & 0.11 & $\mathrm{NaI} \mathrm{WBC}$ \\
\hline EN00116 Adult & Male & $11 / 7 / 2001$ & 4.3 & 4.5 & 4.0 & 0.8 & 0.46 & 0.49 & 0.44 & 0.11 & NaI_WBC \\
\hline EN00116 Adult & Male & $12 / 14 / 2001$ & 4.7 & 4.9 & 4.4 & 0.8 & 0.47 & 0.50 & 0.44 & 0.11 & NaI_WBC \\
\hline EN00117 Adult & Male & $6 / 6 / 2001$ & 3.7 & 3.9 & 3.4 & 0.8 & 0.22 & 0.24 & 0.21 & 0.10 & NaI_WBC \\
\hline EN00118 Adult & Male & $6 / 6 / 2001$ & 4.5 & 4.7 & 4.2 & 0.8 & 0.056 & 0.066 & 0.046 & 0.075 & NaI_WBC \\
\hline EN00119 Teenager & Male & $6 / 6 / 2001$ & 3.4 & 3.6 & 3.1 & 0.8 & 0.095 & 0.11 & 0.083 & 0.091 & Nal WBC \\
\hline EN00120 Adult & Male & $6 / 6 / 2001$ & 4.2 & 4.4 & 3.9 & 0.8 & 0.00 & 0.00 & 0.00 & 0.064 & NaI_WBC \\
\hline EN00121 Teenager & Male & $6 / 6 / 2001$ & 3.9 & 4.1 & 3.6 & 0.7 & 0.15 & 0.16 & 0.13 & 0.077 & NaI_WBC \\
\hline EN00122 Adult & Male & $6 / 6 / 2001$ & 3.6 & 3.8 & 3.3 & 0.8 & 0.047 & 0.058 & 0.036 & 0.084 & NaI_WBC \\
\hline EN00123 Adult & Male & $6 / 6 / 2001$ & 4.0 & 4.2 & 3.7 & 0.8 & 0.11 & 0.12 & 0.10 & 0.090 & NaI_WBC \\
\hline EN00124 Adult & Male & $6 / 7 / 2001$ & 4.1 & 4.3 & 3.8 & 0.8 & 0.093 & 0.10 & 0.082 & 0.076 & NaI_WBC \\
\hline EN00125 Adult & Male & $6 / 7 / 2001$ & 3.7 & 4.0 & 3.5 & 0.8 & 0.078 & 0.089 & 0.066 & 0.083 & NaI_WBC \\
\hline EN00126 Adult & Male & $6 / 7 / 2001$ & 3.5 & 3.7 & 3.3 & 0.8 & 0.20 & 0.22 & 0.18 & 0.11 & NaI_WBC \\
\hline EN00127 Adult & Male & $6 / 7 / 2001$ & 4.5 & 4.8 & 4.2 & 0.8 & 0.29 & 0.31 & 0.27 & 0.10 & Nal_WBC \\
\hline EN00128 Adult & Male & $6 / 7 / 2001$ & 3.5 & 3.7 & 3.3 & 0.8 & 0.041 & 0.051 & 0.030 & 0.090 & NaI_WBC \\
\hline EN00129 Adult & Male & $6 / 7 / 2001$ & 3.8 & 4.1 & 3.6 & 0.8 & 0.15 & 0.16 & 0.13 & 0.080 & NaI_WBC \\
\hline EN00130 Adult & Male & $6 / 7 / 2001$ & 4.5 & 4.8 & 4.3 & 0.7 & 0.00 & 0.00 & 0.00 & 0.063 & NaI_WBC \\
\hline EN00131 Adult & Male & $6 / 7 / 2001$ & 4.5 & 4.8 & 4.2 & 0.8 & 0.17 & 0.19 & 0.16 & 0.078 & NaI_WBC \\
\hline EN00132 Adult & Male & $6 / 8 / 2001$ & 4.3 & 4.6 & 4.1 & 0.8 & 0.00 & 0.00 & 0.00 & 0.062 & NaI_WBC \\
\hline EN00133 Adult & Male & $6 / 8 / 2001$ & 4.7 & 5.0 & 4.4 & 0.8 & 0.13 & 0.14 & 0.12 & 0.093 & NaI_WBC \\
\hline EN00134 Adult & Male & $6 / 8 / 2001$ & 4.2 & 4.5 & 3.8 & 1.4 & 0.00 & 0.00 & 0.00 & 0.11 & NaI_WBC \\
\hline EN00135 Adult & Male & $6 / 8 / 2001$ & 3.4 & 3.6 & 3.1 & 0.8 & 0.00 & 0.00 & 0.00 & 0.061 & NaI_WBC \\
\hline EN00136 Teenager & Male & $6 / 8 / 2001$ & 3.3 & 3.6 & 3.1 & 0.8 & 0.00 & 0.00 & 0.00 & 0.059 & NaI_WBC \\
\hline EN00137 Adult & Male & $6 / 8 / 2001$ & 4.3 & 4.6 & 4.0 & 0.8 & 0.17 & 0.19 & 0.16 & 0.10 & NaI_WBC \\
\hline EN00138 Adult & Male & $6 / 8 / 2001$ & 4.8 & 5.1 & 4.5 & 0.8 & 0.13 & 0.14 & 0.12 & 0.091 & NaI_WBC \\
\hline EN00139 Teenager & Male & $6 / 8 / 2001$ & 3.6 & 3.8 & 3.4 & 0.8 & 0.00 & 0.00 & 0.00 & 0.060 & NaI_WBC \\
\hline EN00140 Teenager & Male & $6 / 8 / 2001$ & 4.1 & 4.3 & 3.8 & 0.8 & 0.040 & 0.053 & 0.028 & 0.10 & NaI_WBC \\
\hline EN00141 Adult & Male & $6 / 11 / 2001$ & 3.6 & 3.9 & 3.4 & 0.8 & 0.38 & 0.40 & 0.35 & 0.10 & NaI_WBC \\
\hline EN00142 Adult & Male & $6 / 11 / 2001$ & 4.1 & 4.4 & 3.9 & 0.8 & 0.33 & 0.35 & 0.30 & 0.10 & NaI_WBC \\
\hline EN00143 Adult & Male & $6 / 11 / 2001$ & 4.0 & 4.3 & 3.7 & 0.8 & 0.11 & 0.12 & 0.096 & 0.089 & NaI_WBC \\
\hline EN00144 Adult & Male & $6 / 11 / 2001$ & 4.6 & 4.9 & 4.3 & 0.8 & 0.16 & 0.18 & 0.15 & 0.095 & NaI_WBC \\
\hline EN00145 Adult & Male & $6 / 11 / 2001$ & 4.1 & 4.3 & 3.8 & 0.8 & 0.18 & 0.19 & 0.16 & 0.093 & NaI_WBC \\
\hline EN00146 Adult & Male & $6 / 11 / 2001$ & 2.9 & 3.1 & 2.7 & 0.8 & 0.18 & 0.20 & 0.17 & 0.087 & Nal_WBC \\
\hline EN00147 Adult & Male & $6 / 11 / 2001$ & 3.9 & 4.2 & 3.7 & 0.7 & 0.15 & 0.17 & 0.14 & 0.093 & NaI_WBC \\
\hline EN00148 Adult & Male & $6 / 11 / 2001$ & 3.6 & 3.9 & 3.4 & 0.8 & 0.22 & 0.23 & 0.20 & 0.097 & NaI_WBC \\
\hline EN00149 Adult & Male & $6 / 11 / 2001$ & 2.9 & 3.1 & 2.7 & 0.8 & 0.13 & 0.14 & 0.11 & 0.086 & NaI_WBC \\
\hline
\end{tabular}


Table 1. (Continued).

\begin{tabular}{|c|c|c|c|c|c|c|c|c|c|c|c|}
\hline \multirow[b]{2}{*}{ ID \# } & \multirow[b]{2}{*}{ Gender } & \multirow{2}{*}{$\begin{array}{l}\text { Count } \\
\text { Date }\end{array}$} & \multicolumn{4}{|c|}{${ }^{40} \mathrm{~K}(\mathbf{k B q})$} & \multicolumn{4}{|c|}{${ }^{137} \mathrm{Cs}(\mathbf{k B q})$} & \multirow{2}{*}{$\begin{array}{l}\text { Method } \\
\text { Code }\end{array}$} \\
\hline & & & Value & Upper & Lower & MDA & Value & Upper & Lower & MDA & \\
\hline EN00150 Adult & Male & $6 / 12 / 2001$ & 3.7 & 4.0 & 3.5 & 0.8 & 0.093 & 0.11 & 0.082 & 0.091 & NaI_WBC \\
\hline EN00151 Adult & Male & $6 / 12 / 2001$ & 3.9 & 4.1 & 3.6 & 0.8 & 0.70 & 0.74 & 0.66 & 0.11 & NaI_WBC \\
\hline EN00151 Adult & Male & $8 / 13 / 2001$ & 4.2 & 4.5 & 3.9 & 0.8 & 0.78 & 0.82 & 0.74 & 0.11 & $\mathrm{NaI}$ WBC \\
\hline EN00151 Adult & Male & $9 / 6 / 2001$ & 4.5 & 4.7 & 4.2 & 0.8 & 0.76 & 0.80 & 0.71 & 0.11 & NaI_WBC \\
\hline EN00151 Adult & Male & $10 / 5 / 2001$ & 4.5 & 4.7 & 4.2 & 0.8 & 0.74 & 0.78 & 0.70 & 0.11 & NaI_WBC \\
\hline EN00151 Adult & Male & $11 / 7 / 2001$ & 3.8 & 4.1 & 3.6 & 0.8 & 0.60 & 0.64 & 0.57 & 0.10 & NaI_WBC \\
\hline EN00151 Adult & Male & $12 / 13 / 2001$ & 4.3 & 4.6 & 4.1 & 0.8 & 0.52 & 0.55 & 0.49 & 0.11 & NaI_WBC \\
\hline EN00152 Adult & Male & $6 / 12 / 2001$ & 2.9 & 3.2 & 2.7 & 0.8 & 0.26 & 0.28 & 0.24 & 0.093 & NaI_WBC \\
\hline EN00153 Adult & Male & $6 / 12 / 2001$ & 3.4 & 3.6 & 3.2 & 0.8 & 0.17 & 0.18 & 0.15 & 0.092 & NaI_WBC \\
\hline EN00154 Adult & Male & $6 / 12 / 2001$ & 4.2 & 4.5 & 4.0 & 0.7 & 0.15 & 0.16 & 0.13 & 0.076 & NaI_WBC \\
\hline EN00155 Adult & Male & $6 / 12 / 2001$ & 3.5 & 3.8 & 3.3 & 0.8 & 0.11 & 0.12 & 0.097 & 0.086 & Nal_WBC \\
\hline EN00156 Teenager & Male & $6 / 12 / 2001$ & 4.0 & 4.2 & 3.7 & 0.8 & 0.00 & 0.00 & 0.00 & 0.061 & NaI_WBC \\
\hline EN00157 Teenager & Male & $6 / 12 / 2001$ & 4.8 & 5.1 & 4.5 & 0.7 & 0.00 & 0.00 & 0.00 & 0.063 & NaI_WBC \\
\hline EN00158 Teenager & Male & $6 / 13 / 2001$ & 2.8 & 3.0 & 2.6 & 0.8 & 0.061 & 0.072 & 0.051 & 0.097 & Nal_WBC \\
\hline EN00159 Adult & Male & $6 / 13 / 2001$ & 3.4 & 3.7 & 3.2 & 0.7 & 0.054 & 0.063 & 0.045 & 0.093 & NaI_WBC \\
\hline EN00160 Adult & Male & $6 / 14 / 2001$ & 4.3 & 4.6 & 4.0 & 0.7 & 0.33 & 0.35 & 0.30 & 0.11 & NaI_WBC \\
\hline EN00161 Teenager & Male & $6 / 14 / 2001$ & 3.7 & 4.0 & 3.5 & 0.8 & 0.00 & 0.00 & 0.00 & 0.059 & NaI_WBC \\
\hline EN00162 Adult & Male & $6 / 14 / 2001$ & 3.7 & 3.9 & 3.4 & 0.8 & 0.12 & 0.13 & 0.11 & 0.086 & NaI_WBC \\
\hline EN00163 Adult & Male & $6 / 14 / 2001$ & 4.2 & 4.5 & 4.0 & 0.8 & 0.15 & 0.16 & 0.13 & 0.074 & Nal_WBC \\
\hline EN00164 Adult & Male & $6 / 15 / 2001$ & 3.7 & 3.9 & 3.5 & 0.8 & 0.40 & 0.43 & 0.38 & 0.11 & Nal_WBC \\
\hline EN00165 Adult & Male & $6 / 15 / 2001$ & 4.3 & 4.5 & 4.0 & 0.8 & 0.14 & 0.15 & 0.12 & 0.089 & NaI_WBC \\
\hline EN00166 Teenager & Male & $6 / 15 / 2001$ & 3.2 & 3.4 & 3.0 & 0.7 & 0.19 & 0.21 & 0.18 & 0.098 & NaI_WBC \\
\hline EN00167 Adult & Male & $6 / 15 / 2001$ & 3.9 & 4.2 & 3.7 & 0.8 & 0.00 & 0.00 & 0.00 & 0.062 & NaI_WBC \\
\hline EN00168 Adult & Male & $6 / 15 / 2001$ & 4.8 & 5.1 & 4.5 & 0.8 & 0.00 & 0.00 & 0.00 & 0.065 & NaI_WBC \\
\hline EN00169 Adult & Male & $6 / 19 / 2001$ & 2.7 & 2.9 & 2.5 & 0.7 & 0.00 & 0.00 & 0.00 & 0.062 & NaI_WBC \\
\hline EN00170 Adult & Male & $6 / 19 / 2001$ & 4.4 & 4.7 & 4.1 & 0.8 & 0.17 & 0.19 & 0.16 & 0.096 & NaI_WBC \\
\hline EN00171 Adult & Male & $6 / 20 / 2001$ & 3.4 & 3.7 & 3.2 & 0.7 & 0.00 & 0.00 & 0.00 & 0.064 & NaI_WBC \\
\hline EN00172 Adult & Male & $6 / 20 / 2001$ & 4.6 & 4.9 & 4.3 & 0.8 & 0.13 & 0.14 & 0.11 & 0.095 & NaI_WBC \\
\hline EN00173 Adult & Male & $6 / 22 / 2001$ & 4.1 & 4.3 & 3.8 & 0.8 & 0.18 & 0.20 & 0.17 & 0.099 & NaI_WBC \\
\hline EN00174 Adult & Male & $6 / 22 / 2001$ & 4.9 & 5.2 & 4.6 & 0.8 & 0.00 & 0.00 & 0.00 & 0.066 & NaI_WBC \\
\hline EN00175 Adult & Male & $6 / 22 / 2001$ & 4.7 & 5.0 & 4.4 & 0.8 & 0.095 & 0.11 & 0.084 & 0.089 & NaI_WBC \\
\hline EN00176 Adult & Male & $6 / 25 / 2001$ & 4.3 & 4.6 & 4.0 & 0.7 & 0.39 & 0.41 & 0.37 & 0.10 & Nal_WBC \\
\hline EN00177 Adult & Male & $6 / 28 / 2001$ & 4.9 & 5.2 & 4.6 & 0.7 & 0.13 & 0.14 & 0.12 & 0.088 & Nal_WBC \\
\hline EN00178 Adult & Male & $7 / 2 / 2001$ & 4.4 & 4.7 & 4.1 & 0.8 & 0.00 & 0.00 & 0.00 & 0.060 & NaI_WBC \\
\hline EN00179 Adult & Female & $7 / 9 / 2001$ & 2.9 & 3.1 & 2.7 & 0.8 & 0.00 & 0.00 & 0.00 & 0.061 & Nal_WBC \\
\hline EN00180 Child & Male & $7 / 9 / 2001$ & 2.5 & 2.7 & 2.3 & 0.8 & 0.00 & 0.00 & 0.00 & 0.061 & NaI_WBC \\
\hline EN00181 Teenager & Male & $7 / 9 / 2001$ & 3.6 & 3.9 & 3.4 & 0.7 & 0.043 & 0.054 & 0.033 & 0.087 & NaI_WBC \\
\hline EN00182 Teenager & Male & $7 / 9 / 2001$ & 2.5 & 2.7 & 2.3 & 0.8 & 0.00 & 0.00 & 0.00 & 0.059 & Nal_WBC \\
\hline EN00183 Adult & Male & $7 / 10 / 2001$ & 4.3 & 4.5 & 4.0 & 0.8 & 0.21 & 0.23 & 0.19 & 0.10 & NaI_WBC \\
\hline EN00184 Adult & Male & $7 / 10 / 2001$ & 4.0 & 4.3 & 3.8 & 0.8 & 0.00 & 0.00 & 0.00 & 0.063 & NaI_WBC \\
\hline EN00185 Adult & Male & $7 / 10 / 2001$ & 4.6 & 4.8 & 4.3 & 0.8 & 0.29 & 0.31 & 0.27 & 0.11 & Nal_WBC \\
\hline EN00186 Adult & Male & $7 / 10 / 2001$ & 4.2 & 4.4 & 3.9 & 0.7 & 0.12 & 0.13 & 0.11 & 0.074 & Nal_WBC \\
\hline
\end{tabular}


Table 1. (Continued).

\begin{tabular}{|c|c|c|c|c|c|c|c|c|c|c|c|}
\hline \multirow[b]{2}{*}{ ID \# } & \multirow[b]{2}{*}{ Gender } & \multirow{2}{*}{$\begin{array}{l}\text { Count } \\
\text { Date }\end{array}$} & \multicolumn{4}{|c|}{${ }^{40} \mathrm{~K}(\mathrm{kBq})$} & \multicolumn{4}{|c|}{${ }^{137} \mathrm{Cs}(\mathbf{k B q})$} & \multirow{2}{*}{$\begin{array}{c}\text { Method } \\
\text { Code }\end{array}$} \\
\hline & & & Value & Upper & Lower & MDA & Value & Upper & Lower & MDA & \\
\hline EN00187 Adult & Male & $7 / 10 / 2001$ & 4.3 & 4.6 & 4.1 & 0.8 & 0.093 & 0.10 & 0.082 & 0.073 & NaI WBC \\
\hline EN00188 Adult & Male & $7 / 10 / 2001$ & 5.0 & 5.3 & 4.7 & 0.8 & 0.00 & 0.00 & 0.00 & 0.059 & NaI_WBC \\
\hline EN00189 Adult & Male & $7 / 10 / 2001$ & 3.9 & 4.1 & 3.6 & 0.8 & 0.081 & 0.092 & 0.070 & 0.10 & NaI_WBC \\
\hline EN00190 Adult & Male & $7 / 10 / 2001$ & 5.0 & 5.3 & 4.7 & 0.8 & 0.00 & 0.00 & 0.00 & 0.063 & NaI WBC \\
\hline EN00191 Adult & Male & $7 / 10 / 2001$ & 4.6 & 4.9 & 4.3 & 0.7 & 0.00 & 0.00 & 0.00 & 0.063 & NaI_WBC \\
\hline EN00192 Adult & Male & $7 / 10 / 2001$ & 3.6 & 3.9 & 3.4 & 0.8 & 0.00 & 0.00 & 0.00 & 0.059 & Nal_WBC \\
\hline EN00193 Adult & Female & $7 / 10 / 2001$ & 3.2 & 3.4 & 2.9 & 0.7 & 0.00 & 0.00 & 0.00 & 0.064 & NaI_WBC \\
\hline EN00194 Adult & Male & $7 / 11 / 2001$ & 5.4 & 5.7 & 5.1 & 0.8 & 0.00 & 0.00 & 0.00 & 0.063 & $\mathrm{NaI} W B C$ \\
\hline EN00195 Adult & Male & $7 / 11 / 2001$ & 3.8 & 4.1 & 3.6 & 0.8 & 0.052 & 0.061 & 0.043 & 0.089 & NaI_WBC \\
\hline EN00196 Adult & Female & $7 / 11 / 2001$ & 2.9 & 3.1 & 2.7 & 0.7 & 0.056 & 0.068 & 0.044 & 0.10 & NaI_WBC \\
\hline EN00197 Adult & Female & $7 / 11 / 2001$ & 2.7 & 2.9 & 2.5 & 0.7 & 0.00 & 0.00 & 0.00 & 0.060 & Nal_WBC \\
\hline EN00198 Teenager & Female & $7 / 11 / 2001$ & 2.8 & 3.0 & 2.6 & 0.7 & 0.00 & 0.00 & 0.00 & 0.061 & NaI_WBC \\
\hline EN00200 Adult & Male & $7 / 12 / 2001$ & 3.7 & 3.9 & 3.4 & 0.8 & 0.00 & 0.00 & 0.00 & 0.061 & Nal_WBC \\
\hline EN00201 Adult & Female & $7 / 12 / 2001$ & 2.3 & 2.5 & 2.1 & 0.8 & 0.22 & 0.24 & 0.21 & 0.099 & NaI_WBC \\
\hline EN00202 Adult & Female & $7 / 12 / 2001$ & 2.4 & 2.6 & 2.2 & 0.8 & 0.00 & 0.00 & 0.00 & 0.061 & NaI_WBC \\
\hline EN00203 Adult & Female & $7 / 12 / 2001$ & 3.2 & 3.4 & 2.9 & 0.7 & 0.13 & 0.14 & 0.11 & 0.086 & Nal_WBC \\
\hline EN00204 Adult & Female & $7 / 12 / 2001$ & 3.0 & 3.3 & 2.8 & 0.7 & 0.11 & 0.13 & 0.10 & 0.090 & NaI_WBC \\
\hline EN00205 Adult & Female & $7 / 12 / 2001$ & 3.1 & 3.3 & 2.9 & 0.7 & 0.20 & 0.22 & 0.18 & 0.097 & NaI_WBC \\
\hline EN00206 Adult & Male & $7 / 12 / 2001$ & 4.5 & 4.8 & 4.3 & 0.7 & 0.10 & 0.11 & 0.090 & 0.086 & NaI_WBC \\
\hline EN00207 Adult & Female & $7 / 13 / 2001$ & 2.8 & 3.0 & 2.6 & 0.7 & 0.062 & 0.072 & 0.051 & 0.093 & NaI_WBC \\
\hline EN00208 Adult & Female & $7 / 13 / 2001$ & 3.1 & 3.4 & 2.9 & 0.8 & 0.00 & 0.00 & 0.00 & 0.062 & NaI_WBC \\
\hline EN00209 Adult & Female & $7 / 13 / 2001$ & 3.1 & 3.3 & 2.8 & 0.7 & 0.11 & 0.12 & 0.096 & 0.072 & NaI_WBC \\
\hline EN00210 Adult & Female & $7 / 13 / 2001$ & 2.5 & 2.7 & 2.3 & 0.7 & 0.00 & 0.00 & 0.00 & 0.061 & NaI_WBC \\
\hline EN00211 Adult & Female & $7 / 13 / 2001$ & 3.1 & 3.3 & 2.9 & 0.7 & 0.22 & 0.24 & 0.20 & 0.10 & NaI_WBC \\
\hline EN00212 Adult & Female & $7 / 13 / 2001$ & 2.3 & 2.5 & 2.1 & 0.7 & 0.00 & 0.00 & 0.00 & 0.063 & NaI_WBC \\
\hline EN00213 Adult & Female & $7 / 13 / 2001$ & 3.6 & 3.8 & 3.3 & 0.7 & 0.18 & 0.20 & 0.17 & 0.10 & Nal_WBC \\
\hline EN00214 Adult & Female & $7 / 13 / 2001$ & 2.9 & 3.1 & 2.7 & 0.8 & 0.056 & 0.070 & 0.042 & 0.10 & NaI_WBC \\
\hline EN00215 Adult & Female & $7 / 13 / 2001$ & 3.3 & 3.5 & 3.1 & 0.7 & 0.074 & 0.085 & 0.064 & 0.072 & NaI_WBC \\
\hline EN00216 Teenager & Female & $7 / 13 / 2001$ & 2.5 & 2.7 & 2.3 & 0.7 & 0.00 & 0.00 & 0.00 & 0.062 & NaI_WBC \\
\hline EN00217 Child & Female & $7 / 13 / 2001$ & 2.4 & 2.6 & 2.2 & 0.8 & 0.00 & 0.00 & 0.00 & 0.058 & NaI_WBC \\
\hline EN00218 Adult & Female & $7 / 13 / 2001$ & 2.6 & 2.8 & 2.4 & 0.7 & 0.00 & 0.00 & 0.00 & 0.060 & NaI_WBC \\
\hline EN00219 Teenager & Female & $7 / 13 / 2001$ & 3.0 & 3.2 & 2.7 & 0.8 & 0.00 & 0.00 & 0.00 & 0.060 & Nal_WBC \\
\hline EN00220 Adult & Female & $7 / 13 / 2001$ & 2.8 & 3.0 & 2.6 & 0.7 & 0.11 & 0.12 & 0.095 & 0.082 & Nal_WBC \\
\hline EN00221 Adult & Female & $7 / 13 / 2001$ & 3.4 & 3.6 & 3.2 & 0.7 & 0.089 & 0.10 & 0.078 & 0.073 & Nal_WBC \\
\hline EN00222 Adult & Female & $7 / 13 / 2001$ & 2.8 & 3.0 & 2.6 & 0.8 & 0.00 & 0.00 & 0.00 & 0.060 & NaI_WBC \\
\hline EN00223 Teenager & Male & $7 / 24 / 2001$ & 2.7 & 2.9 & 2.5 & 0.8 & 0.084 & 0.095 & 0.073 & 0.087 & NaI_WBC \\
\hline EN00224 Teenager & Male & $7 / 24 / 2001$ & 3.9 & 4.1 & 3.6 & 0.8 & 0.067 & 0.077 & 0.058 & 0.070 & NaI_WBC \\
\hline EN00225 Teenager & Male & $7 / 24 / 2001$ & 2.2 & 2.4 & 2.0 & 0.8 & 0.067 & 0.077 & 0.057 & 0.088 & Nal_WBC \\
\hline EN00226 Teenager & Male & $7 / 24 / 2001$ & 4.4 & 4.6 & 4.1 & 0.8 & 0.00 & 0.00 & 0.00 & 0.060 & NaI_WBC \\
\hline EN00227 Adult & Male & $7 / 24 / 2001$ & 4.5 & 4.8 & 4.2 & 0.8 & 0.00 & 0.00 & 0.00 & 0.060 & NaI_WBC \\
\hline EN00228 Adult & Male & $7 / 24 / 2001$ & 4.1 & 4.4 & 3.9 & 0.8 & 0.068 & 0.078 & 0.057 & 0.086 & Nal_WBC \\
\hline EN00229 Teenager & Male & $7 / 26 / 2001$ & 3.7 & 4.0 & 3.5 & 0.8 & 0.035 & 0.045 & 0.025 & 0.085 & $\mathrm{NaI} \mathrm{WBC}$ \\
\hline
\end{tabular}


Table 1. (Continued).

\begin{tabular}{|c|c|c|c|c|c|c|c|c|c|c|c|}
\hline \multirow[b]{2}{*}{ ID \# } & \multirow[b]{2}{*}{ Gender } & \multirow{2}{*}{$\begin{array}{l}\text { Count } \\
\text { Date }\end{array}$} & \multicolumn{4}{|c|}{${ }^{40} \mathrm{~K}(\mathbf{k B q})$} & \multicolumn{4}{|c|}{${ }^{137} \mathrm{Cs}(\mathbf{k B q})$} & \multirow{2}{*}{$\begin{array}{l}\text { Method } \\
\text { Code }\end{array}$} \\
\hline & & & Value & Upper & Lower & MDA & Value & Upper & Lower & MDA & \\
\hline EN00230 Adult & Male & $7 / 31 / 2001$ & 3.4 & 3.7 & 3.2 & 0.8 & 0.00 & 0.00 & 0.00 & 0.063 & NaI_WBC \\
\hline EN00231 Child & Female & $8 / 9 / 2001$ & 2.1 & 2.3 & 1.9 & 0.7 & 0.00 & 0.00 & 0.00 & 0.056 & NaI_WBC \\
\hline EN00232 Child & Female & $8 / 9 / 2001$ & 2.4 & 2.6 & 2.2 & 0.7 & 0.00 & 0.00 & 0.00 & 0.059 & NaI_WBC \\
\hline EN00233 Child & Female & $8 / 9 / 2001$ & 2.6 & 2.7 & 2.4 & 0.7 & 0.00 & 0.00 & 0.00 & 0.058 & NaI_WBC \\
\hline EN00234 Child & Female & $8 / 9 / 2001$ & 2.2 & 2.3 & 2.0 & 0.8 & 0.00 & 0.00 & 0.00 & 0.058 & NaI_WBC \\
\hline EN00235 Adult & Male & $8 / 10 / 2001$ & 3.7 & 4.0 & 3.5 & 0.8 & 0.21 & 0.23 & 0.19 & 0.093 & NaI_WBC \\
\hline EN00236 Adult & Female & $8 / 10 / 2001$ & 2.8 & 3.0 & 2.6 & 0.7 & 0.046 & 0.056 & 0.036 & 0.085 & NaI_WBC \\
\hline EN00237 Adult & Female & $8 / 10 / 2001$ & 2.4 & 2.6 & 2.2 & 0.7 & 0.00 & 0.00 & 0.00 & 0.061 & Nal_WBC \\
\hline EN00238 Adult & Male & $8 / 10 / 2001$ & 3.9 & 4.2 & 3.7 & 0.8 & 0.00 & 0.00 & 0.00 & 0.065 & NaI_WBC \\
\hline EN00239 Adult & Female & $8 / 10 / 2001$ & 2.5 & 2.7 & 2.3 & 0.8 & 0.21 & 0.22 & 0.19 & 0.090 & NaI_WBC \\
\hline EN00240 Adult & Female & $8 / 10 / 2001$ & 2.6 & 2.8 & 2.5 & 0.8 & 0.042 & 0.051 & 0.033 & 0.084 & NaI_WBC \\
\hline EN00241 Adult & Female & $8 / 10 / 2001$ & 2.4 & 2.6 & 2.2 & 0.8 & 0.083 & 0.095 & 0.071 & 0.098 & NaI_WBC \\
\hline EN00242 Adult & Female & $8 / 13 / 2001$ & 2.7 & 2.9 & 2.5 & 0.7 & 0.066 & 0.076 & 0.057 & 0.072 & NaI_WBC \\
\hline EN00243 Adult & Male & $8 / 13 / 2001$ & 4.2 & 4.5 & 3.9 & 0.7 & 0.041 & 0.052 & 0.031 & 0.095 & NaI_WBC \\
\hline EN00244 Adult & Male & $8 / 13 / 2001$ & 4.6 & 4.9 & 4.3 & 0.8 & 0.29 & 0.31 & 0.27 & 0.11 & Nal_WBC \\
\hline EN00245 Adult & Female & $8 / 13 / 2001$ & 2.9 & 3.1 & 2.7 & 0.8 & 0.066 & 0.076 & 0.055 & 0.083 & NaI_WBC \\
\hline EN00246 Adult & Female & $8 / 13 / 2001$ & 2.7 & 2.9 & 2.5 & 0.7 & 0.00 & 0.00 & 0.00 & 0.061 & Nal_WBC \\
\hline EN00247 Adult & Female & $8 / 13 / 2001$ & 2.8 & 3.0 & 2.6 & 0.7 & 0.073 & 0.084 & 0.062 & 0.091 & Nal_WBC \\
\hline EN00248 Adult & Female & $8 / 13 / 2001$ & 3.3 & 3.6 & 3.1 & 0.7 & 0.036 & 0.044 & 0.028 & 0.082 & Nal_WBC \\
\hline EN00249 Adult & Female & $8 / 13 / 2001$ & 3.1 & 3.3 & 2.9 & 0.8 & 0.072 & 0.084 & 0.061 & 0.085 & NaI_WBC \\
\hline EN00250 Adult & Female & $8 / 14 / 2001$ & 3.1 & 3.3 & 2.9 & 0.7 & 0.00 & 0.00 & 0.00 & 0.058 & Nal_WBC \\
\hline EN00251 Adult & Female & $8 / 14 / 2001$ & 3.1 & 3.4 & 2.9 & 0.7 & 0.22 & 0.24 & 0.21 & 0.10 & NaI_WBC \\
\hline EN00252 Adult & Female & $8 / 14 / 2001$ & 2.8 & 3.0 & 2.6 & 0.7 & 0.34 & 0.36 & 0.31 & 0.099 & NaI_WBC \\
\hline EN00253 Adult & Female & $8 / 14 / 2001$ & 3.1 & 3.3 & 2.8 & 0.7 & 0.00 & 0.00 & 0.00 & 0.060 & Nal_WBC \\
\hline EN00254 Adult & Female & $8 / 14 / 2001$ & 2.9 & 3.1 & 2.7 & 0.8 & 0.082 & 0.093 & 0.070 & 0.088 & Nal_WBC \\
\hline EN00255 Adult & Male & $8 / 14 / 2001$ & 4.9 & 5.2 & 4.6 & 0.9 & 0.15 & 0.17 & 0.14 & 0.10 & NaI_WBC \\
\hline EN00256 Adult & Female & $8 / 14 / 2001$ & 3.0 & 3.2 & 2.8 & 0.7 & 0.00 & 0.00 & 0.00 & 0.062 & NaI_WBC \\
\hline EN00257 Adult & Female & $8 / 14 / 2001$ & 3.4 & 3.6 & 3.2 & 0.8 & 0.00 & 0.00 & 0.00 & 0.064 & NaI_WBC \\
\hline EN00258 Adult & Female & $8 / 14 / 2001$ & 3.1 & 3.3 & 2.9 & 0.8 & 0.034 & 0.042 & 0.026 & 0.088 & NaI_WBC \\
\hline EN00259 Adult & Female & $8 / 14 / 2001$ & 2.9 & 3.1 & 2.7 & 0.8 & 0.078 & 0.090 & 0.067 & 0.083 & NaI_WBC \\
\hline EN00260 Adult & Female & $8 / 14 / 2001$ & 3.3 & 3.5 & 3.0 & 0.7 & 0.00 & 0.00 & 0.00 & 0.061 & NaI_WBC \\
\hline EN00261 Adult & Female & $8 / 14 / 2001$ & 2.7 & 2.9 & 2.6 & 0.7 & 0.00 & 0.00 & 0.00 & 0.058 & NaI_WBC \\
\hline EN00262 Adult & Female & $8 / 15 / 2001$ & 3.4 & 3.6 & 3.2 & 0.8 & 0.19 & 0.21 & 0.18 & 0.094 & NaI_WBC \\
\hline EN00263 Adult & Female & $8 / 15 / 2001$ & 2.8 & 3.0 & 2.6 & 0.7 & 0.00 & 0.00 & 0.00 & 0.060 & NaI_WBC \\
\hline EN00264 Adult & Female & $8 / 15 / 2001$ & 3.0 & 3.2 & 2.8 & 0.7 & 0.11 & 0.12 & 0.099 & 0.088 & NaI_WBC \\
\hline EN00265 Adult & Female & $8 / 15 / 2001$ & 2.7 & 2.9 & 2.6 & 0.7 & 0.00 & 0.00 & 0.00 & 0.058 & NaI_WBC \\
\hline EN00266 Adult & Female & $8 / 15 / 2001$ & 3.4 & 3.6 & 3.2 & 0.8 & 0.14 & 0.16 & 0.13 & 0.076 & NaI_WBC \\
\hline EN00267 Adult & Female & $8 / 15 / 2001$ & 3.1 & 3.3 & 2.9 & 0.7 & 0.11 & 0.12 & 0.097 & 0.078 & NaI_WBC \\
\hline EN00268 Adult & Female & $8 / 15 / 2001$ & 2.6 & 2.8 & 2.4 & 0.7 & 0.052 & 0.063 & 0.041 & 0.093 & NaI_WBC \\
\hline EN00269 Adult & Female & $8 / 15 / 2001$ & 2.7 & 2.9 & 2.5 & 0.7 & 0.38 & 0.40 & 0.35 & 0.10 & NaI_WBC \\
\hline EN00270 Adult & Female & $8 / 15 / 2001$ & 2.9 & 3.1 & 2.7 & 0.7 & 0.20 & 0.21 & 0.18 & 0.092 & NaI_WBC \\
\hline EN00271 Adult & Female & $8 / 15 / 2001$ & 2.7 & 2.9 & 2.5 & 0.7 & 0.16 & 0.18 & 0.15 & 0.093 & NaI_WBC \\
\hline
\end{tabular}


Table 1. (Continued).

\begin{tabular}{|c|c|c|c|c|c|c|c|c|c|c|c|}
\hline \multirow[b]{2}{*}{ ID \# } & \multirow[b]{2}{*}{ Gender } & \multirow{2}{*}{$\begin{array}{l}\text { Count } \\
\text { Date }\end{array}$} & \multicolumn{4}{|c|}{${ }^{40} \mathrm{~K}(\mathrm{kBq})$} & \multicolumn{4}{|c|}{${ }^{137} \mathrm{Cs}(\mathrm{kBq})$} & \multirow{2}{*}{$\begin{array}{l}\text { Method } \\
\text { Code }\end{array}$} \\
\hline & & & Value & Upper & Lower & MDA & Value & Upper & Lower & MDA & \\
\hline EN00272 Teenager & Female & $8 / 15 / 2001$ & 2.8 & 3.0 & 2.6 & 0.8 & 0.00 & 0.00 & 0.00 & 0.063 & Nal_WBC \\
\hline EN00273 Adult & Female & $8 / 15 / 2001$ & 3.0 & 3.2 & 2.8 & 0.8 & 0.35 & 0.38 & 0.33 & 0.10 & NaI_WBC \\
\hline EN00274 Adult & Female & $8 / 16 / 2001$ & 3.0 & 3.2 & 2.8 & 0.7 & 0.29 & 0.31 & 0.27 & 0.098 & NaI_WBC \\
\hline EN00275 Adult & Female & $8 / 16 / 2001$ & 2.6 & 2.8 & 2.4 & 0.8 & 0.11 & 0.13 & 0.10 & 0.090 & NaI_WBC \\
\hline EN00276 Adult & Female & $8 / 16 / 2001$ & 3.4 & 3.6 & 3.2 & 0.8 & 0.11 & 0.13 & 0.10 & 0.086 & NaI_WBC \\
\hline EN00277 Adult & Female & $8 / 16 / 2001$ & 2.7 & 2.9 & 2.5 & 0.7 & 0.00 & 0.00 & 0.00 & 0.061 & NaI_WBC \\
\hline EN00278 Adult & Female & $8 / 16 / 2001$ & 2.8 & 3.0 & 2.6 & 0.8 & 0.18 & 0.19 & 0.16 & 0.086 & NaI_WBC \\
\hline EN00279 Adult & Female & $8 / 16 / 2001$ & 2.4 & 2.5 & 2.2 & 0.8 & 0.059 & 0.069 & 0.049 & 0.076 & NaI_WBC \\
\hline EN00280 Adult & Female & $8 / 16 / 2001$ & 2.6 & 2.7 & 2.4 & 0.8 & 0.10 & 0.11 & 0.090 & 0.073 & NaI_WBC \\
\hline EN00281 Adult & Female & $8 / 16 / 2001$ & 2.6 & 2.8 & 2.4 & 0.8 & 0.071 & 0.081 & 0.061 & 0.068 & NaI_WBC \\
\hline EN00282 Adult & Female & $8 / 16 / 2001$ & 3.1 & 3.3 & 2.9 & 0.8 & 0.10 & 0.11 & 0.088 & 0.089 & NaI_WBC \\
\hline EN00283 Adult & Female & $8 / 16 / 2001$ & 2.9 & 3.1 & 2.7 & 0.7 & 0.00 & 0.00 & 0.00 & 0.059 & NaI_WBC \\
\hline EN00284 Adult & Female & $8 / 16 / 2001$ & 2.8 & 3.0 & 2.6 & 0.8 & 0.12 & 0.14 & 0.11 & 0.076 & NaI_WBC \\
\hline EN00285 Adult & Female & $8 / 17 / 2001$ & 2.5 & 2.7 & 2.3 & 0.7 & 0.078 & 0.088 & 0.067 & 0.073 & NaI_WBC \\
\hline EN00286 Adult & Female & $8 / 17 / 2001$ & 2.7 & 2.9 & 2.5 & 0.8 & 0.19 & 0.20 & 0.17 & 0.10 & NaI_WBC \\
\hline EN00287 Adult & Female & $8 / 17 / 2001$ & 2.4 & 2.6 & 2.2 & 0.8 & 0.00 & 0.00 & 0.00 & 0.062 & NaI_WBC \\
\hline EN00288 Teenager & Female & $8 / 17 / 2001$ & 2.7 & 2.9 & 2.5 & 0.7 & 0.00 & 0.00 & 0.00 & 0.062 & NaI_WBC \\
\hline EN00289 Adult & Male & $8 / 17 / 2001$ & 3.0 & 3.2 & 2.8 & 0.7 & 0.00 & 0.00 & 0.00 & 0.057 & NaI_WBC \\
\hline EN00290 Adult & Female & $8 / 17 / 2001$ & 2.9 & 3.1 & 2.7 & 0.7 & 0.11 & 0.12 & 0.095 & 0.072 & NaI_WBC \\
\hline EN00291 Adult & Female & $8 / 17 / 2001$ & 2.7 & 2.9 & 2.6 & 0.7 & 0.20 & 0.22 & 0.18 & 0.078 & NaI_WBC \\
\hline EN00292 Adult & Female & $8 / 17 / 2001$ & 2.8 & 3.0 & 2.6 & 0.8 & 0.073 & 0.084 & 0.062 & 0.091 & NaI_WBC \\
\hline EN00293 Adult & Female & $8 / 17 / 2001$ & 2.6 & 2.8 & 2.4 & 0.7 & 0.052 & 0.061 & 0.043 & 0.097 & NaI_WBC \\
\hline EN00294 Adult & Female & $8 / 17 / 2001$ & 2.5 & 2.7 & 2.4 & 0.7 & 0.050 & 0.060 & 0.040 & 0.082 & NaI_WBC \\
\hline EN00295 Adult & Female & $8 / 17 / 2001$ & 3.0 & 3.2 & 2.8 & 0.8 & 0.036 & 0.046 & 0.026 & 0.084 & NaI_WBC \\
\hline EN00295 Adult & Female & $8 / 17 / 2001$ & 2.8 & 3.3 & 2.3 & 2.4 & 0.00 & 0.00 & 0.00 & 0.22 & NaI_WBC \\
\hline EN00295 Adult & Female & $9 / 28 / 2001$ & 2.8 & 3.0 & 2.6 & 0.7 & 0.028 & 0.037 & 0.019 & 0.075 & NaI_WBC \\
\hline EN00296 Adult & Female & $8 / 20 / 2001$ & 3.1 & 3.4 & 2.9 & 0.8 & 0.26 & 0.28 & 0.24 & 0.10 & NaI_WBC \\
\hline EN00297 Adult & Female & $8 / 20 / 2001$ & 2.9 & 3.1 & 2.7 & 0.7 & 0.00 & 0.00 & 0.00 & 0.061 & NaI_WBC \\
\hline EN00298 Adult & Female & $8 / 20 / 2001$ & 2.4 & 2.6 & 2.3 & 0.8 & 0.093 & 0.10 & 0.082 & 0.085 & NaI_WBC \\
\hline EN00299 Teenager & Female & $8 / 20 / 2001$ & 3.0 & 3.2 & 2.8 & 0.7 & 0.00 & 0.00 & 0.00 & 0.060 & NaI_WBC \\
\hline EN00300 Adult & Female & $8 / 20 / 2001$ & 2.6 & 2.8 & 2.4 & 0.7 & 0.00 & 0.00 & 0.00 & 0.058 & NaI_WBC \\
\hline EN00301 Teenager & Female & $8 / 20 / 2001$ & 2.7 & 2.9 & 2.5 & 0.7 & 0.00 & 0.00 & 0.00 & 0.058 & NaI_WBC \\
\hline EN00302 Adult & Female & $8 / 20 / 2001$ & 2.5 & 2.7 & 2.3 & 0.8 & 0.00 & 0.00 & 0.00 & 0.063 & NaI_WBC \\
\hline EN00303 Adult & Female & $8 / 20 / 2001$ & 2.2 & 2.4 & 2.0 & 0.8 & 0.00 & 0.00 & 0.00 & 0.060 & NaI_WBC \\
\hline EN00304 Teenager & Female & $8 / 20 / 2001$ & 3.1 & 3.3 & 2.9 & 0.8 & 0.11 & 0.12 & 0.097 & 0.075 & NaI_WBC \\
\hline EN00305 Adult & Female & $8 / 21 / 2001$ & 3.5 & 3.7 & 3.2 & 0.7 & 0.069 & 0.081 & 0.058 & 0.086 & NaI_WBC \\
\hline EN00306 Adult & Female & $8 / 21 / 2001$ & 3.1 & 3.3 & 2.9 & 0.7 & 0.053 & 0.062 & 0.045 & 0.10 & NaI_WBC \\
\hline EN00307 Adult & Female & $8 / 21 / 2001$ & 2.8 & 3.0 & 2.6 & 0.7 & 0.00 & 0.00 & 0.00 & 0.058 & NaI_WBC \\
\hline EN00308 Adult & Female & $8 / 21 / 2001$ & 3.2 & 3.4 & 3.0 & 0.8 & 0.00 & 0.00 & 0.00 & 0.058 & NaI_WBC \\
\hline EN00309 Teenager & Female & $8 / 21 / 2001$ & 3.1 & 3.3 & 2.9 & 0.7 & 0.00 & 0.00 & 0.00 & 0.061 & NaI_WBC \\
\hline EN00310 Adult & Male & $8 / 27 / 2001$ & 4.6 & 4.9 & 4.3 & 0.8 & 0.00 & 0.00 & 0.00 & 0.062 & NaI_WBC \\
\hline EN00311 Adult & Female & $8 / 27 / 2001$ & 2.2 & 2.4 & 2.0 & 0.8 & 0.00 & 0.00 & 0.00 & 0.058 & NaI WBC \\
\hline
\end{tabular}


Table 1. (Continued).

\begin{tabular}{|c|c|c|c|c|c|c|c|c|c|c|c|}
\hline \multirow[b]{2}{*}{ ID \# } & \multirow[b]{2}{*}{ Gender } & \multirow{2}{*}{$\begin{array}{l}\text { Count } \\
\text { Date }\end{array}$} & \multicolumn{4}{|c|}{${ }^{40} \mathrm{~K}(\mathbf{k B q})$} & \multicolumn{4}{|c|}{${ }^{137} \mathrm{Cs}(\mathbf{k B q})$} & \multirow{2}{*}{$\begin{array}{l}\text { Method } \\
\text { Code }\end{array}$} \\
\hline & & & Value & Upper & Lower & MDA & Value & Upper & Lower & MDA & \\
\hline EN00312 Teenager & Female & $8 / 27 / 2001$ & 2.7 & 2.9 & 2.5 & 0.8 & 0.00 & 0.00 & 0.00 & 0.059 & NaI_WBC \\
\hline EN00313 Teenager & Female & $8 / 27 / 2001$ & 2.6 & 2.8 & 2.4 & 0.7 & 0.00 & 0.00 & 0.00 & 0.061 & NaI_WBC \\
\hline EN00314 Adult & Female & $8 / 27 / 2001$ & 3.0 & 3.2 & 2.8 & 0.8 & 0.00 & 0.00 & 0.00 & 0.063 & NaI_WBC \\
\hline EN00315 Adult & Female & $8 / 27 / 2001$ & 2.7 & 2.9 & 2.5 & 0.8 & 0.00 & 0.00 & 0.00 & 0.057 & NaI_WBC \\
\hline EN00316 Adult & Female & $8 / 27 / 2001$ & 2.6 & 2.7 & 2.4 & 0.7 & 0.00 & 0.00 & 0.00 & 0.060 & NaI_WBC \\
\hline EN00317 Adult & Female & $8 / 27 / 2001$ & 2.5 & 2.7 & 2.3 & 0.8 & 0.00 & 0.00 & 0.00 & 0.062 & NaI_WBC \\
\hline EN00318 Adult & Female & $8 / 28 / 2001$ & 2.6 & 2.8 & 2.5 & 0.8 & 0.043 & 0.054 & 0.033 & 0.091 & NaI_WBC \\
\hline EN00319 Adult & Female & $8 / 28 / 2001$ & 2.9 & 3.1 & 2.7 & 0.8 & 0.11 & 0.13 & 0.10 & 0.077 & Nal_WBC \\
\hline EN00320 Adult & Female & $8 / 28 / 2001$ & 2.9 & 3.2 & 2.7 & 0.8 & 0.00 & 0.00 & 0.00 & 0.057 & NaI_WBC \\
\hline EN00321 Adult & Male & $8 / 28 / 2001$ & 4.3 & 4.6 & 4.0 & 0.8 & 0.00 & 0.00 & 0.00 & 0.062 & NaI_WBC \\
\hline EN00322 Adult & Female & $8 / 28 / 2001$ & 3.1 & 3.3 & 2.9 & 0.7 & 0.089 & 0.10 & 0.078 & 0.074 & Nal_WBC \\
\hline EN00323 Adult & Female & $8 / 28 / 2001$ & 2.5 & 2.7 & 2.3 & 0.8 & 0.073 & 0.085 & 0.060 & 0.10 & NaI_WBC \\
\hline EN00324 Adult & Female & $9 / 3 / 2001$ & 2.6 & 2.8 & 2.5 & 0.8 & 0.076 & 0.087 & 0.065 & 0.082 & Nal_WBC \\
\hline EN00325 Adult & Female & $9 / 3 / 2001$ & 2.8 & 3.0 & 2.6 & 0.7 & 0.078 & 0.090 & 0.067 & 0.10 & Nal_WBC \\
\hline EN00326 Adult & Female & $9 / 3 / 2001$ & 3.0 & 3.2 & 2.8 & 0.7 & 0.00 & 0.00 & 0.00 & 0.058 & NaI_WBC \\
\hline EN00327 Adult & Male & $9 / 5 / 2001$ & 5.0 & 5.3 & 4.8 & 0.8 & 0.049 & 0.059 & 0.038 & 0.085 & Nal_WBC \\
\hline EN00328 Adult & Male & $9 / 10 / 2001$ & 4.6 & 4.9 & 4.3 & 0.8 & 0.00 & 0.00 & 0.00 & 0.062 & NaI_WBC \\
\hline EN00329 Adult & Female & $9 / 11 / 2001$ & 3.5 & 3.8 & 3.3 & 0.7 & 0.00 & 0.00 & 0.00 & 0.061 & NaI_WBC \\
\hline EN00330 Adult & Female & $9 / 11 / 2001$ & 3.2 & 3.4 & 2.9 & 0.7 & 0.11 & 0.12 & 0.093 & 0.079 & Nal_WBC \\
\hline EN00331 Adult & Female & $9 / 11 / 2001$ & 3.0 & 3.2 & 2.8 & 0.7 & 0.18 & 0.20 & 0.17 & 0.076 & NaI_WBC \\
\hline EN00332 Adult & Female & $9 / 11 / 2001$ & 3.2 & 3.5 & 3.0 & 0.8 & 0.098 & 0.11 & 0.086 & 0.087 & Nal_WBC \\
\hline EN00333 Adult & Female & $9 / 11 / 2001$ & 3.0 & 3.2 & 2.8 & 0.7 & 0.00 & 0.00 & 0.00 & 0.059 & NaI_WBC \\
\hline EN00334 Adult & Female & $9 / 11 / 2001$ & 3.1 & 3.4 & 2.9 & 0.8 & 0.11 & 0.12 & 0.096 & 0.091 & NaI_WBC \\
\hline EN00335 Adult & Female & $9 / 13 / 2001$ & 3.6 & 3.8 & 3.4 & 0.7 & 0.00 & 0.00 & 0.00 & 0.063 & NaI_WBC \\
\hline EN00336 Adult & Female & $9 / 13 / 2001$ & 3.4 & 3.6 & 3.2 & 0.7 & 0.092 & 0.10 & 0.080 & 0.083 & NaI_WBC \\
\hline EN00337 Adult & Female & $9 / 13 / 2001$ & 2.9 & 3.1 & 2.7 & 0.8 & 0.00 & 0.00 & 0.00 & 0.061 & NaI_WBC \\
\hline EN00338 Adult & Female & $9 / 13 / 2001$ & 3.2 & 3.4 & 3.0 & 0.8 & 0.086 & 0.097 & 0.075 & 0.075 & NaI_WBC \\
\hline EN00339 Adult & Female & $9 / 13 / 2001$ & 3.3 & 3.6 & 3.1 & 0.8 & 0.10 & 0.12 & 0.090 & 0.10 & NaI_WBC \\
\hline EN00340 Adult & Female & $9 / 13 / 2001$ & 3.3 & 3.5 & 3.1 & 0.8 & 0.077 & 0.088 & 0.067 & 0.074 & NaI_WBC \\
\hline EN00341 Adult & Male & $9 / 19 / 2001$ & 4.5 & 4.8 & 4.2 & 0.7 & 0.069 & 0.080 & 0.059 & 0.090 & NaI_WBC \\
\hline EN00342 Adult & Male & $9 / 19 / 2001$ & 4.8 & 5.1 & 4.5 & 0.8 & 0.00 & 0.00 & 0.00 & 0.058 & NaI_WBC \\
\hline EN00343 Adult & Female & $9 / 21 / 2001$ & 2.6 & 2.7 & 2.4 & 0.7 & 0.00 & 0.00 & 0.00 & 0.056 & NaI_WBC \\
\hline EN00344 Adult & Male & $9 / 21 / 2001$ & 5.0 & 5.3 & 4.7 & 0.8 & 0.00 & 0.00 & 0.00 & 0.065 & NaI_WBC \\
\hline EN00345 Adult & Female & $9 / 21 / 2001$ & 2.7 & 2.9 & 2.5 & 0.7 & 0.050 & 0.060 & 0.040 & 0.10 & Nal_WBC \\
\hline EN00346 Adult & Female & $9 / 21 / 2001$ & 3.2 & 3.5 & 3.0 & 0.8 & 0.10 & 0.12 & 0.092 & 0.083 & Nal_WBC \\
\hline EN00347 Teenager & Female & $9 / 21 / 2001$ & 3.6 & 3.8 & 3.4 & 0.7 & 0.00 & 0.00 & 0.00 & 0.062 & NaI_WBC \\
\hline EN00348 Adult & Female & $9 / 21 / 2001$ & 3.3 & 3.5 & 3.0 & 1.0 & 0.00 & 0.00 & 0.00 & 0.091 & NaI_WBC \\
\hline EN00348 Adult & Female & $9 / 21 / 2001$ & 3.5 & 3.7 & 3.2 & 0.8 & 0.078 & 0.090 & 0.067 & 0.085 & NaI_WBC \\
\hline EN00349 Adult & Female & $9 / 27 / 2001$ & 3.2 & 3.4 & 3.0 & 0.7 & 0.00 & 0.00 & 0.00 & 0.062 & NaI_WBC \\
\hline EN00350 Adult & Female & $9 / 27 / 2001$ & 3.0 & 3.2 & 2.8 & 0.8 & 0.041 & 0.050 & 0.032 & 0.081 & NaI_WBC \\
\hline EN00351 Adult & Male & $9 / 27 / 2001$ & 4.4 & 4.7 & 4.2 & 0.7 & 0.00 & 0.00 & 0.00 & 0.061 & NaI_WBC \\
\hline EN00352 Teenager & Female & $9 / 28 / 2001$ & 3.1 & 3.3 & 2.9 & 0.7 & 0.00 & 0.00 & 0.00 & 0.059 & NaI_WBC \\
\hline
\end{tabular}


Table 1. (Continued).

\begin{tabular}{|c|c|c|c|c|c|c|c|c|c|c|c|}
\hline & \multirow[b]{2}{*}{ Gender } & \multirow{2}{*}{$\begin{array}{l}\text { Count } \\
\text { Date }\end{array}$} & \multicolumn{4}{|c|}{${ }^{40} \mathrm{~K}(\mathrm{kBq})$} & \multicolumn{4}{|c|}{${ }^{137} \mathrm{Cs}(\mathbf{k B q})$} & \multirow{2}{*}{$\begin{array}{c}\text { Method } \\
\text { Code }\end{array}$} \\
\hline Type & & & Value & Upper & Lower & MDA & Value & Upper & Lower & MDA & \\
\hline EN00353 Adult & Male & $9 / 28 / 2001$ & 4.2 & 4.4 & 3.9 & 0.7 & 0.00 & 0.00 & 0.00 & 0.058 & NaI_WBC \\
\hline EN00354 Adult & Male & $10 / 8 / 2001$ & 4.2 & 4.5 & 3.9 & 0.7 & 0.00 & 0.00 & 0.00 & 0.058 & NaI_WBC \\
\hline EN00355 Adult & Male & $10 / 8 / 2001$ & 4.1 & 4.4 & 3.9 & 0.8 & 0.00 & 0.00 & 0.00 & 0.058 & NaI_WBC \\
\hline EN00356 Adult & Male & $10 / 8 / 2001$ & 3.1 & 3.3 & 2.9 & 0.7 & 0.00 & 0.00 & 0.00 & 0.058 & Nal_WBC \\
\hline EN00357 Adult & Male & $10 / 9 / 2001$ & 2.5 & 2.7 & 2.3 & 0.7 & 0.00 & 0.00 & 0.00 & 0.057 & NaI_WBC \\
\hline EN00358 Adult & Female & $10 / 9 / 2001$ & 2.3 & 2.5 & 2.2 & 0.7 & 0.00 & 0.00 & 0.00 & 0.058 & NaI_WBC \\
\hline EN00359 Adult & Male & $10 / 9 / 2001$ & 3.7 & 3.9 & 3.5 & 0.7 & 0.00 & 0.00 & 0.00 & 0.057 & NaI_WBC \\
\hline EN00360 Adult & Female & $10 / 9 / 2001$ & 2.8 & 3.0 & 2.6 & 0.9 & 0.00 & 0.00 & 0.00 & 0.078 & NaI_WBC \\
\hline EN00361 Adult & Male & $10 / 10 / 2001$ & 4.3 & 4.6 & 4.0 & 0.7 & 0.11 & 0.12 & 0.095 & 0.088 & NaI_WBC \\
\hline EN00362 Adult & Female & $10 / 10 / 2001$ & 2.5 & 2.7 & 2.3 & 0.7 & 0.046 & 0.054 & 0.037 & 0.083 & NaI_WBC \\
\hline EN00363 Adult & Female & $10 / 10 / 2001$ & 2.8 & 3.0 & 2.6 & 0.8 & 0.00 & 0.00 & 0.00 & 0.060 & NaI_WBC \\
\hline EN00364 Adult & Male & $10 / 11 / 2001$ & 4.2 & 4.4 & 3.9 & 0.8 & 0.21 & 0.22 & 0.19 & 0.098 & NaI_WBC \\
\hline EN00365 Adult & Female & $10 / 12 / 2001$ & 2.3 & 2.5 & 2.1 & 0.7 & 0.00 & 0.00 & 0.00 & 0.058 & NaI_WBC \\
\hline EN00366 Adult & Male & $10 / 12 / 2001$ & 2.9 & 3.1 & 2.7 & 0.8 & 0.051 & 0.060 & 0.042 & 0.095 & NaI_WBC \\
\hline EN00367 Adult & Female & $10 / 12 / 2001$ & 2.2 & 2.4 & 2.0 & 0.8 & 0.050 & 0.060 & 0.040 & 0.083 & NaI_WBC \\
\hline EN00368 Adult & Female & $10 / 12 / 2001$ & 2.8 & 3.0 & 2.6 & 0.8 & 0.14 & 0.15 & 0.12 & 0.099 & NaI_WBC \\
\hline EN00369 Adult & Female & $10 / 12 / 2001$ & 2.3 & 2.5 & 2.1 & 0.7 & 0.00 & 0.00 & 0.00 & 0.058 & NaI_WBC \\
\hline EN00370 Adult & Male & $10 / 12 / 2001$ & 3.6 & 3.8 & 3.3 & 0.8 & 0.00 & 0.00 & 0.00 & 0.058 & NaI_WBC \\
\hline EN00371 Adult & Male & $10 / 17 / 2001$ & 4.2 & 4.5 & 4.0 & 0.8 & 0.049 & 0.060 & 0.039 & 0.079 & Nal_WBC \\
\hline EN00372 Adult & Female & $10 / 18 / 2001$ & 2.8 & 3.0 & 2.6 & 0.8 & 0.00 & 0.00 & 0.00 & 0.061 & NaI_WBC \\
\hline EN00373 Adult & Female & $10 / 19 / 2001$ & 2.9 & 3.1 & 2.7 & 0.8 & 0.00 & 0.00 & 0.00 & 0.061 & NaI WBC \\
\hline EN00374 Adult & Female & $10 / 19 / 2001$ & 2.5 & 2.7 & 2.3 & 0.8 & 0.00 & 0.00 & 0.00 & 0.063 & NaI_WBC \\
\hline EN00375 Adult & Male & $10 / 19 / 2001$ & 4.2 & 4.4 & 3.9 & 0.8 & 0.00 & 0.00 & 0.00 & 0.063 & NaI_WBC \\
\hline EN00376 Teenager & Male & $10 / 19 / 2001$ & 3.0 & 3.2 & 2.8 & 0.7 & 0.00 & 0.00 & 0.00 & 0.059 & NaI_WBC \\
\hline EN00377 Adult & Female & $10 / 19 / 2001$ & 2.6 & 2.8 & 2.5 & 0.7 & 0.00 & 0.00 & 0.00 & 0.056 & NaI_WBC \\
\hline EN00377 Adult & Female & $10 / 25 / 2001$ & 2.7 & 2.9 & 2.5 & 0.8 & 0.00 & 0.00 & 0.00 & 0.057 & Nal_WBC \\
\hline EN00378 Adult & Male & $10 / 19 / 2001$ & 4.3 & 4.6 & 4.0 & 0.8 & 0.00 & 0.00 & 0.00 & 0.060 & NaI_WBC \\
\hline EN00378 Adult & Male & $10 / 25 / 2001$ & 4.1 & 4.4 & 3.9 & 0.7 & 0.00 & 0.00 & 0.00 & 0.061 & NaI_WBC \\
\hline EN00379 Adult & Male & $10 / 19 / 2001$ & 3.6 & 3.8 & 3.3 & 0.8 & 0.064 & 0.075 & 0.053 & 0.087 & NaI_WBC \\
\hline EN00379 Adult & Male & $10 / 19 / 2001$ & 3.5 & 3.8 & 3.3 & 0.7 & 0.078 & 0.089 & 0.067 & 0.10 & NaI_WBC \\
\hline EN00379 Adult & Male & $10 / 19 / 2001$ & 4.0 & 4.3 & 3.6 & 1.5 & 0.00 & 0.00 & 0.00 & 0.13 & NaI_WBC \\
\hline EN00379 Adult & Male & $10 / 19 / 2001$ & 3.6 & 3.8 & 3.4 & 0.8 & 0.14 & 0.15 & 0.13 & 0.072 & NaI_WBC \\
\hline EN00379 Adult & Male & $10 / 25 / 2001$ & 3.3 & 3.5 & 3.1 & 0.8 & 0.050 & 0.06 & 0.04 & 0.089 & NaI_WBC \\
\hline EN00380 Teenager & Male & $10 / 25 / 2001$ & 3.9 & 4.1 & 3.6 & 0.7 & 0.00 & 0.00 & 0.00 & 0.061 & Nal_WBC \\
\hline EN00381 Adult & Male & $10 / 26 / 2001$ & 4.2 & 4.5 & 4.0 & 0.8 & 0.00 & 0.00 & 0.00 & 0.060 & NaI_WBC \\
\hline EN00382 Adult & Male & $10 / 29 / 2001$ & 3.7 & 3.9 & 3.4 & 0.7 & 0.00 & 0.00 & 0.00 & 0.061 & NaI_WBC \\
\hline EN00383 Adult & Male & $10 / 29 / 2001$ & 3.0 & 3.2 & 2.8 & 0.8 & 0.00 & 0.00 & 0.00 & 0.057 & NaI_WBC \\
\hline EN00384 Adult & Male & $10 / 29 / 2001$ & 4.4 & 4.7 & 4.1 & 0.7 & 0.00 & 0.00 & 0.00 & 0.060 & NaI_WBC \\
\hline EN00385 Adult & Female & $10 / 29 / 2001$ & 2.7 & 2.9 & 2.5 & 0.7 & 0.072 & 0.082 & 0.062 & 0.071 & Nal_WBC \\
\hline EN00386 Adult & Female & $10 / 29 / 2001$ & 2.8 & 3.0 & 2.6 & 0.7 & 0.00 & 0.00 & 0.00 & 0.060 & NaI_WBC \\
\hline EN00387 Adult & Female & $10 / 30 / 2001$ & 2.6 & 2.8 & 2.4 & 0.8 & 0.25 & 0.27 & 0.24 & 0.10 & NaI_WBC \\
\hline EN00388 Teenager & Male & $10 / 30 / 2001$ & 2.9 & 3.1 & 2.7 & 0.8 & 0.00 & 0.00 & 0.00 & 0.059 & $\mathrm{NaI} W B$ \\
\hline
\end{tabular}


Table 1. (Continued).

\begin{tabular}{|c|c|c|c|c|c|c|c|c|c|c|c|c|}
\hline \multirow[b]{2}{*}{ ID \# } & \multirow{2}{*}{$\begin{array}{c}\text { Age } \\
\text { Type }\end{array}$} & \multirow[b]{2}{*}{ Gender } & \multirow{2}{*}{$\begin{array}{l}\text { Count } \\
\text { Date }\end{array}$} & \multicolumn{4}{|c|}{${ }^{40} \mathrm{~K}(\mathrm{kBq})$} & \multicolumn{4}{|c|}{${ }^{137} \mathrm{Cs}(\mathrm{kBq})$} & \multirow{2}{*}{$\begin{array}{l}\text { Method } \\
\text { Code }\end{array}$} \\
\hline & & & & Value & Upper & Lower & MDA & Value & Upper & Lower & MDA & \\
\hline \multicolumn{2}{|c|}{ EN00389 Adult } & Male & $11 / 2 / 2001$ & 4.2 & 4.4 & 3.9 & 0.8 & 0.00 & 0.00 & 0.00 & 0.063 & NaI_WBC \\
\hline \multicolumn{2}{|c|}{ EN00390 Adult } & Female & $11 / 2 / 2001$ & 2.6 & 2.7 & 2.4 & 0.7 & 0.00 & 0.00 & 0.00 & 0.062 & NaI_WBC \\
\hline \multicolumn{2}{|c|}{ EN00391 Adult } & Male & $11 / 2 / 2001$ & 4.0 & 4.2 & 3.7 & 0.7 & 0.16 & 0.18 & 0.15 & 0.096 & NaI_WBC \\
\hline \multicolumn{2}{|c|}{ EN00392 Adult } & Female & $11 / 2 / 2001$ & 2.7 & 2.9 & 2.5 & 0.8 & 0.089 & 0.10 & 0.077 & 0.084 & NaI_WBC \\
\hline \multicolumn{2}{|c|}{ EN00393 Adult } & Male & $11 / 2 / 2001$ & 4.6 & 4.9 & 4.4 & 0.8 & 0.12 & 0.14 & 0.11 & 0.088 & NaI_WBC \\
\hline \multicolumn{2}{|c|}{ EN00394 Teenager } & Male & $11 / 8 / 2001$ & 4.2 & 4.5 & 4.0 & 0.8 & 0.070 & 0.080 & 0.060 & 0.073 & NaI_WBC \\
\hline \multicolumn{2}{|c|}{ EN00395 Adult } & Male & $11 / 9 / 2001$ & 3.3 & 3.5 & 3.1 & 0.8 & 0.15 & 0.16 & 0.13 & 0.093 & NaI_WBC \\
\hline \multicolumn{2}{|c|}{ EN00396 Adult } & Female & $11 / 9 / 2001$ & 2.8 & 3.0 & 2.6 & 0.8 & 0.11 & 0.13 & 0.10 & 0.087 & NaI_WBC \\
\hline \multicolumn{2}{|c|}{ EN00397 Adult } & Female & $11 / 9 / 2001$ & 3.0 & 3.3 & 2.8 & 0.7 & 0.084 & 0.096 & 0.073 & 0.081 & NaI_WBC \\
\hline \multicolumn{2}{|c|}{ EN00398 Adult } & Male & $11 / 9 / 2001$ & 3.5 & 3.7 & 3.3 & 0.8 & 0.13 & 0.14 & 0.12 & 0.072 & NaI_WBC \\
\hline \multicolumn{2}{|c|}{ EN00399 Adult } & Female & $11 / 9 / 2001$ & 2.3 & 2.5 & 2.1 & 0.7 & 0.059 & 0.069 & 0.048 & 0.082 & Nal_WBC \\
\hline \multicolumn{2}{|c|}{ EN00400 Adult } & Female & $11 / 9 / 2001$ & 2.5 & 2.7 & 2.3 & 0.7 & 0.00 & 0.00 & 0.00 & 0.061 & NaI_WBC \\
\hline \multicolumn{2}{|c|}{ EN00401 Adult } & Fernale & $11 / 13 / 2001$ & 3.0 & 3.2 & 2.8 & 0.7 & 0.00 & 0.00 & 0.00 & 0.059 & NaI_WBC \\
\hline \multicolumn{2}{|c|}{ EN00402 Adult } & Male & $11 / 13 / 2001$ & 2.7 & 2.9 & 2.5 & 0.8 & 0.00 & 0.00 & 0.00 & 0.060 & NaI_WBC \\
\hline \multicolumn{2}{|c|}{ EN00403 Adult } & Male & $11 / 14 / 2001$ & 4.1 & 4.4 & 3.9 & 0.8 & 0.17 & 0.18 & 0.15 & 0.094 & NaI_WBC \\
\hline \multicolumn{2}{|c|}{ EN00404 Adult } & Fermale & $11 / 14 / 2001$ & 2.7 & 2.9 & 2.5 & 0.7 & 0.040 & 0.050 & 0.031 & 0.084 & Nal_WBC \\
\hline \multicolumn{2}{|c|}{ EN00405 Teenager } & Female & $11 / 14 / 2001$ & 2.5 & 2.7 & 2.3 & 0.7 & 0.16 & 0.17 & 0.14 & 0.076 & Nal_WBC \\
\hline \multicolumn{2}{|c|}{ EN00405 Teenager } & Female & $11 / 14 / 2001$ & 2.7 & 2.9 & 2.5 & 0.7 & 0.16 & 0.17 & 0.14 & 0.076 & NaI_WBC \\
\hline \multicolumn{2}{|c|}{ EN00407 Adult } & Female & $11 / 19 / 2001$ & 2.6 & 2.7 & 2.4 & 0.8 & 0.15 & 0.16 & 0.13 & 0.075 & NaI_WBC \\
\hline EN00408 & Adult & Female & $11 / 19 / 2001$ & 2.7 & 2.9 & 2.5 & 0.8 & 0.00 & 0.00 & 0.00 & 0.060 & NaI_WBC \\
\hline EN0040 & Adult & Female & $11 / 20 / 2001$ & 2.3 & 2.5 & 2.1 & 0.8 & 0.063 & 0.073 & 0.053 & 0.093 & NaI_WBC \\
\hline EN0041 & Adult & Female & $11 / 20 / 2001$ & 2.6 & 2.8 & 2.4 & 0.7 & 0.00 & 0.00 & 0.00 & 0.057 & Nal_WBC \\
\hline EN0041 & Adult & Male & $11 / 21 / 2001$ & 4.3 & 4.6 & 4.0 & 0.8 & 0.00 & 0.00 & 0.00 & 0.062 & NaI_WBC \\
\hline EN00412 & Teenager & Male & $11 / 23 / 2001$ & 3.4 & 3.6 & 3.2 & 0.8 & 0.063 & 0.073 & 0.053 & 0.085 & NaI_WBC \\
\hline EN0041: & Adult & Male & $11 / 26 / 2001$ & 3.4 & 3.6 & 3.2 & 0.8 & 0.00 & 0.00 & 0.00 & 0.061 & NaI_WBC \\
\hline EN0041 & Teenager & Male & $11 / 28 / 2001$ & 2.8 & 3.0 & 2.6 & 0.7 & 0.062 & 0.072 & 0.053 & 0.071 & Nal_WBC \\
\hline EN0041: & Teenager & Male & $11 / 28 / 2001$ & 3.1 & 3.4 & 2.9 & 0.8 & 0.080 & 0.092 & 0.068 & 0.087 & NaI_WBC \\
\hline EN0041 & Teenager & Male & $11 / 28 / 2001$ & 2.9 & 3.1 & 2.7 & 0.7 & 0.00 & 0.00 & 0.00 & 0.057 & NaI_WBC \\
\hline EN0041 & Teenager & Male & $11 / 28 / 2001$ & 3.3 & 3.5 & 3.1 & 0.7 & 0.12 & 0.13 & 0.11 & 0.076 & NaI_WBC \\
\hline EN0041 & Teenager & Male & $11 / 28 / 2001$ & 2.7 & 2.9 & 2.5 & 0.8 & 0.056 & 0.066 & 0.046 & 0.083 & Nal_WBC \\
\hline EN0042 & Adult & Male & $12 / 12 / 2001$ & 4.0 & 4.3 & 3.8 & 0.8 & 0.083 & 0.094 & 0.072 & 0.082 & NaI_WBC \\
\hline
\end{tabular}


Table 2. Plutonium urinalysis data for agricultural workers and Enewetak Island residents (CAMS/LLNL, July 2001 collection)."

${ }^{239} \mathrm{Pu}(\boldsymbol{\mu B q})$

ID\#

\begin{tabular}{|c|c|c|c|c|c|c|c|c|c|c|c|}
\hline EN00005 & Adult & Male & $7 / 30 / 2001$ & -0.2 & 0.4 & -0.8 & 1.5 & 0.0 & 0.6 & -0.7 & 4.3 \\
\hline EN00006 & Adult & Male & $7 / 30 / 2001$ & 0.2 & 0.8 & -0.4 & 1.5 & 0.0 & 0.7 & -0.7 & 4.3 \\
\hline EN00007 & Adult & Male & $8 / 1 / 2001$ & 0.1 & 0.7 & -0.4 & 1.5 & 0.0 & 0.6 & -0.7 & 4.3 \\
\hline EN00008 & Adult & Male & $7 / 26 / 2001$ & -0.2 & 0.6 & -0.9 & 1.5 & 0.0 & 0.8 & -0.8 & 4.3 \\
\hline EN00010 & Adult & Male & $8 / 1 / 2001$ & 0.5 & 1.1 & -0.2 & 1.5 & 0.0 & 0.6 & -0.7 & 4.3 \\
\hline EN00010 & Adult & Male & $8 / 6 / 2001$ & -0.2 & 0.4 & -0.8 & 1.5 & 0.0 & 0.6 & -0.7 & 4.3 \\
\hline EN00011 & Adult & Male & $8 / 1 / 2001$ & -0.2 & 0.4 & -0.7 & 1.5 & 0.0 & 0.6 & -0.7 & 4.3 \\
\hline EN00015 & Adult & Male & $7 / 30 / 2001$ & -0.2 & 0.5 & -0.8 & 1.5 & 0.0 & 0.7 & -0.8 & 4.3 \\
\hline EN00018 & Adult & Male & $7 / 31 / 2001$ & -0.2 & 0.5 & -0.9 & 1.5 & 0.0 & 0.8 & -0.8 & 4.3 \\
\hline EN00020 & Adult & Male & $7 / 30 / 2001$ & 0.1 & 0.6 & -0.5 & 1.5 & 0.0 & 0.6 & -0.6 & 4.3 \\
\hline EN00022 & Adult & Male & $7 / 30 / 2001$ & -0.2 & 0.4 & -0.7 & 1.5 & 0.0 & 0.6 & -0.7 & 4.3 \\
\hline EN00023 & Teenager & Male & $7 / 26 / 2001$ & 1.6 & 2.7 & 0.6 & 1.5 & 0.0 & 0.7 & -0.8 & 4.3 \\
\hline EN00025 & Adult & Male & $7 / 30 / 2001$ & 1.4 & 2.3 & 0.5 & 1.5 & 0.0 & 0.7 & -0.7 & 4.3 \\
\hline EN00029 & Adult & Male & $8 / 2 / 2001$ & 0.5 & 1.2 & -0.2 & 1.5 & 0.0 & 0.6 & -0.7 & 4.3 \\
\hline EN00029 & Adult & Male & $8 / 6 / 2001$ & 0.2 & 0.5 & 0.0 & 0.6 & 0.6 & 1.5 & -0.3 & 2.4 \\
\hline EN00034 & Adult & Male & $8 / 2 / 2001$ & 0.3 & 0.8 & -0.3 & 1.5 & 0.0 & 0.5 & -0.6 & 4.3 \\
\hline EN00035 & Adult & Male & $8 / 3 / 2001$ & 0.1 & 0.6 & -0.5 & 1.5 & 0.0 & 0.6 & -0.6 & 4.3 \\
\hline EN00038 & Adult & Male & $7 / 30 / 2001$ & 2.2 & 3.4 & 1.0 & 1.5 & 0.0 & 0.8 & -0.8 & 4.3 \\
\hline EN00041 & Adult & Male & $8 / 2 / 2001$ & 0.5 & 1.2 & -0.1 & 1.5 & 0.0 & 0.6 & -0.7 & 4.3 \\
\hline EN00043 & Adult & Male & $8 / 1 / 2001$ & -0.2 & 0.4 & -0.7 & 1.5 & 0.0 & 0.6 & -0.7 & 4.3 \\
\hline EN00047 & Adult & Male & $8 / 1 / 2001$ & -0.2 & 0.4 & -0.8 & 1.5 & 0.0 & 0.7 & -0.7 & 4.3 \\
\hline EN00053 & Adult & Male & $7 / 27 / 2001$ & 0.5 & 1.2 & -0.2 & 1.5 & 0.0 & 0.6 & -0.7 & 4.3 \\
\hline EN00053 & Adult & Male & $8 / 6 / 2001$ & 0.9 & 1.7 & 0.1 & 1.5 & 0.0 & 0.7 & -0.7 & 4.3 \\
\hline EN00065 & Teenager & Male & $7 / 25 / 2001$ & -0.2 & 0.5 & -0.8 & 1.5 & 0.0 & 0.8 & -0.8 & 4.3 \\
\hline EN00080 & Adult & Male & $7 / 26 / 2001$ & 0.5 & 1.2 & -0.2 & 1.5 & 0.0 & 0.6 & -0.7 & 4.3 \\
\hline EN00082 & Teenager & Male & $7 / 26 / 2001$ & -0.2 & 0.5 & -0.8 & 1.5 & 0.0 & 0.7 & -0.8 & 4.3 \\
\hline EN00084 & Adult & Male & $8 / 1 / 2001$ & 0.4 & 1.0 & -0.2 & 1.5 & 1.0 & 1.7 & 0.3 & 4.3 \\
\hline EN00088 & Adult & Male & $8 / 2 / 2001$ & -0.2 & 0.6 & -0.9 & 1.5 & 0.0 & 0.8 & -0.9 & 4.3 \\
\hline EN00093 & Adult & Male & $7 / 26 / 2001$ & 0.7 & 1.5 & -0.1 & 1.5 & 0.0 & 0.7 & -0.8 & 4.3 \\
\hline EN00094 & Adult & Male & $7 / 31 / 2001$ & 0.3 & 0.9 & -0.4 & 1.5 & 1.6 & 2.6 & 0.6 & 4.3 \\
\hline EN00103 & Adult & Male & $8 / 1 / 2001$ & 0.1 & 0.7 & -0.4 & 1.5 & 0.0 & 0.6 & -0.7 & 4.3 \\
\hline EN00114 & Adult & Male & $7 / 31 / 2001$ & 0.1 & 0.3 & -0.1 & 0.6 & 0 & 0.8 & -0.8 & 2.4 \\
\hline EN00114 & Adult & Male & $8 / 6 / 2001$ & 0.05 & 0.2 & -0.1 & 0.6 & 0 & 0.5 & -0.5 & 2.4 \\
\hline EN00119 & Teenager & Male & $7 / 25 / 2001$ & -0.2 & 0.4 & -0.7 & 1.5 & 0.0 & 0.6 & -0.7 & 4.3 \\
\hline EN00125 & Adult & Male & $7 / 27 / 2001$ & 0.6 & 1.3 & -0.1 & 1.5 & 1.2 & 2.0 & 0.5 & 4.3 \\
\hline EN00125 & Adult & Male & $8 / 6 / 2001$ & 0.3 & 0.5 & 0.0 & 0.6 & 0 & 0.6 & -0.6 & 2.4 \\
\hline EN00126 & Adult & Male & $7 / 31 / 2001$ & 0.2 & 0.8 & -0.4 & 1.5 & 0.0 & 0.7 & -0.7 & 4.3 \\
\hline EN00135 & Adult & Male & $7 / 26 / 2001$ & 0.0 & 0.5 & -0.5 & 1.5 & 0.0 & 0.6 & -0.6 & 4.3 \\
\hline EN00141 & Adult & Male & $7 / 27 / 2001$ & 0.3 & 0.4 & 0.1 & 0.6 & 0.3 & 0.6 & 0.0 & 2.4 \\
\hline EN00142 & Adult & Male & $7 / 27 / 2001$ & -0.2 & 1.8 & -2.2 & 1.5 & 0.0 & 2.0 & -2.1 & 4.3 \\
\hline EN00148 & Adult & Male & $8 / 6 / 2001$ & 0.5 & 0.8 & 0.2 & 0.6 & 0 & 0.5 & -0.5 & 2.4 \\
\hline EN00149 & Adult & Male & $8 / 2 / 2001$ & 0.7 & 1.4 & 0.0 & 1.5 & 0.0 & 0.6 & -0.7 & 4.3 \\
\hline EN00153 & Adult & Male & $7 / 27 / 2001$ & 6.5 & 11.2 & 1.8 & 0.6 & 0 & 12.0 & -12.0 & 2.4 \\
\hline EN00161 & Adult & Male & $7 / 26 / 2001$ & 1.3 & 1.9 & 0.7 & 0.6 & 0 & 1.0 & -1.0 & 2.4 \\
\hline
\end{tabular}

${ }^{240} \mathrm{Pu}(\boldsymbol{\mu B q})$

Upper Lower

$\begin{array}{cccllr}\text { Age } & \text { Collection } & \text { Upper } & \text { Lower } & & \begin{array}{r}\text { Upper Lower } \\ \text { Type Gender Date }\end{array} \text { Value Level Level MDA Value Level Level }\end{array}$

MDA Notes 
Table 2. Continued.

\begin{tabular}{|c|c|c|c|c|c|c|c|c|c|c|c|c|}
\hline \multirow[b]{2}{*}{ ID\# } & \multirow[b]{2}{*}{$\begin{array}{r}\text { Age } \\
\text { Type }\end{array}$} & \multirow[b]{2}{*}{ Gender } & \multirow[b]{2}{*}{$\begin{array}{c}\text { Collection } \\
\text { Date }\end{array}$} & \multicolumn{4}{|c|}{${ }^{239} \mathrm{Pu}(\mu \mathrm{Bq})$} & \multicolumn{4}{|c|}{${ }^{240} \mathrm{Pu}(\mu \mathrm{Bq})$} & \multirow[b]{2}{*}{ Notes } \\
\hline & & & & Value & $\begin{array}{l}\text { Upper } \\
\text { Level }\end{array}$ & $\begin{array}{l}\text { Lower } \\
\text { Level }\end{array}$ & MDA & Value & $\begin{array}{l}\text { Upper } \\
\text { Level }\end{array}$ & $\begin{array}{r}\text { Lower } \\
\text { Level }\end{array}$ & MDA & \\
\hline EN00162 & Adult & Male & $7 / 27 / 2001$ & 0.4 & 0.8 & 0.1 & 0.6 & 1.1 & 2.5 & -0.4 & 2.4 & \\
\hline EN00165 & Adult & Male & $7 / 31 / 2001$ & 0.2 & 0.9 & -0.4 & 1.5 & 3.0 & 4.5 & 1.4 & 4.3 & \\
\hline EN00171 & Adult & Male & $7 / 31 / 2001$ & 1.2 & 2.3 & 0.1 & 1.5 & 0.0 & 0.9 & -0.9 & 4.3 & \\
\hline EN00176 & Adult & Male & $8 / 3 / 2001$ & -0.2 & 0.4 & -0.7 & 1.5 & 0.0 & 0.6 & -0.7 & 4.3 & \\
\hline EN00183 & Adult & Male & $7 / 27 / 2001$ & 0.6 & 1.3 & -0.1 & 1.5 & 0.0 & 0.7 & -0.7 & 4.3 & \\
\hline EN00223 & Teenager & Male & $7 / 25 / 2001$ & 0.2 & 0.7 & -0.4 & 1.5 & 0.0 & 0.6 & -0.6 & 4.3 & \\
\hline EN00224 & Teenager & Male & $7 / 25 / 2001$ & 0.1 & 0.7 & -0.4 & 1.5 & 0.0 & 0.6 & -0.7 & 4.3 & \\
\hline EN00225 & Teenager & Male & $7 / 25 / 2001$ & 0.5 & 1.1 & -0.2 & 1.5 & 0.0 & 0.6 & -0.7 & 4.3 & \\
\hline EN00226 & Teenager & Male & $7 / 25 / 2001$ & 0.4 & 1.1 & -0.4 & 1.5 & 0.0 & 0.8 & -0.9 & 4.3 & \\
\hline EN00227 & Adult & Male & $8 / 3 / 2001$ & 1.0 & 1.7 & 0.3 & 1.5 & 1.7 & 2.4 & 1.0 & 4.3 & \\
\hline EN00228 & Adult & Male & $8 / 3 / 2001$ & 0.8 & 1.1 & 0.4 & 0.6 & 0.5 & 1.1 & -0.1 & 2.4 & \\
\hline EN00229 & Teenager & Male & $8 / 2 / 2001$ & 0.5 & 1.2 & -0.2 & 1.5 & 0.0 & 0.6 & -0.7 & 4.3 & \\
\hline EN00230 & Adult & Male & $8 / 3 / 2001$ & -0.1 & 0.1 & -0.3 & 0.6 & 0 & 0.7 & -0.7 & 2.4 & \\
\hline Control & Adult & Male & $8 / 3 / 2001$ & 2.1 & 3.2 & 0.9 & 1.5 & 0.0 & 0.7 & -0.7 & 4.3 & \\
\hline Field Blank 1 & & & $7 / 25 / 2001$ & 0.3 & 0.9 & -0.4 & 1.5 & 0.0 & 0.7 & -0.8 & 4.3 & \\
\hline Field Blank 2 & & & $7 / 26 / 2001$ & -0.2 & 0.4 & -0.7 & 1.5 & 0.0 & 0.6 & -0.7 & 4.3 & \\
\hline Field Blank 3 & & & $7 / 27 / 2001$ & 0.3 & 1.0 & -0.4 & 1.5 & 0.0 & 0.7 & -0.8 & 4.3 & \\
\hline Field Blank 4 & & & $7 / 30 / 2001$ & 0.2 & 0.9 & -0.4 & 1.5 & 0.0 & 0.7 & -0.8 & 4.3 & \\
\hline Field Blank 5 & & & $7 / 31 / 2001$ & 0.8 & 1.7 & 0.0 & 1.5 & 0.0 & 0.8 & -0.8 & 4.3 & \\
\hline Field Blank 6 & & & $8 / 1 / 2001$ & 0.6 & 1.3 & -0.1 & 1.5 & 0.0 & 0.7 & -0.7 & 4.3 & \\
\hline Field Blank 7 & & & $8 / 2 / 2001$ & -0.2 & 0.4 & -0.7 & 1.5 & 0.0 & 0.6 & -0.7 & 4.3 & \\
\hline Field Blank 8 & & & $8 / 3 / 2001$ & -0.2 & 0.3 & -0.7 & 1.5 & 0.0 & 0.5 & -0.6 & 4.3 & \\
\hline Field Blank 9 & & & $8 / 6 / 2001$ & -0.2 & 0.3 & -0.7 & 1.5 & 0.0 & 0.6 & -0.6 & 4.3 & \\
\hline
\end{tabular}

a Verified urinalysis data as of $12 / 31 / 2001$.

Note A: Low recovery; failed Q.C. criteria for dose reporting. 